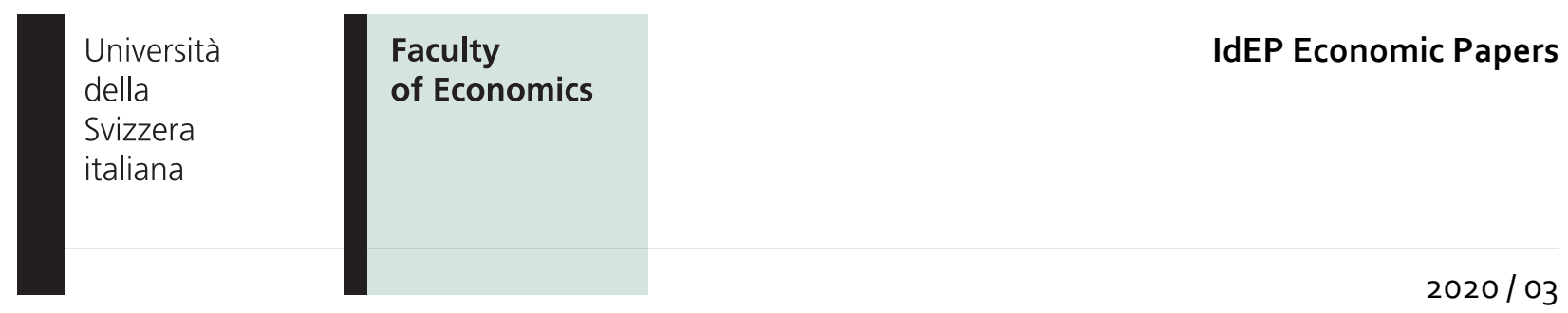

B. Lerch

Robots and nonparticipation in the US: where have all the workers gone? 


\title{
Robots and Non-participation in the US: Where Have All the Workers Gone?*
}

\author{
Benjamin Lerch \\ Università della Svizzera italiana
}

July 2021

\begin{abstract}
This paper analyzes the impact of one of the leading automation technologies of the last decades, industrial robots, on the declining labor force participation in the US. Exploiting exogenous variation in the adoption of robots across local labor markets and over time, I find that, on average, one additional robot drives two workers out of the labor force. Despite the adverse impact of robots, there is no evidence that displaced workers are migrating away from exposed labor markets or that labor force dropouts have been compensated by the labor force participation of a family member. Instead, I find that robot adoption leads to rising enrollment in post-secondary education institutions among young individuals, early retirement of older workers and a considerable fraction of middle-aged workers enrolling in disability insurance.
\end{abstract}

Keywords: industrial robots, labor force participation, education, disability, early retirement.

JEL Codes: I12, I26, J21, J26.

*I am extremely grateful to Giovanni Pica for his guidance in this project. I thank Daron Acemoglu, David Autor, Giuseppe Di Giacomo, David Dorn, Marius Faber, Lorenz Kueng, Fabrizio Mazzonna, Pascual Restrepo and the participants of the USI Brown Bag Seminars, the 2021 Young Swiss Economists Meeting and the 3rd QMUL Economics and Finance Workshop for valuable feedback. Additionally, I want to thank Pascual Restrepo for sharing their data. All remaining errors are my own.

Email: benjamin.lerch@usi.ch 


\section{$1 \quad$ Introduction}

Advances in labor-replacing technologies are poised to shape the future of labor markets, fueling the concerns that the automation of labor through robots and artificial intelligence is going to displace millions of workers in the years to come (Brynjolfsson and McAfee, 2014, Frey and Osborne, 2017). ${ }^{1}$ This is an issue with profound implications, since information technologies are disrupting labor markets at an unprecedented speed, forcing displaced individuals to leave the labor force and to seek alternative income sources (Ford, 2015). This paper analyzes the effect of one of the leading automation technologies of the last decades - industrial robots - on US labor force participation between the early 1990s and 2014, and investigates the margins of adjustment of displaced workers, including migration, intra-household labor supply, the accumulation of additional human capital, enrollment in disability insurance and early retirement.

Using individual-level data from the Census and the American Community Survey matched with industry-level data about the adoption of industrial robots from the International Federation of Robotics, I examine the effect of robots on labor force participation using a local labor market analysis. I focus on the labor supply decision of white working-age men, the demographic group that has experienced the largest decline in labor force participation over the last decades. Following Acemoglu and Restrepo (2020), I build a measure of robot exposure using a shift-share approach constructed from the interaction of baseline industry employment shares within local labor markets, proxied by Commuting Zones (CZs, Tolbert and Sizer, 1996), with the adoption of industrial robots in the US. Identification builds on the assumption that advances in robotics vary by industry and expose CZs differently depending on their industrial composition of employment. Firms' adoption of robots, however, is likely to be correlated with local labor market conditions that influence also the demand for labor and, therefore, participation rates. I account for endogeneity and identify the causal effect of robots on labor force participation using an instrumental variable strategy. I instrument the shift component using the contemporaneous adoption of industrial robots in Europe and instrument the share component with plausibly exogenous industry employment shares that precede the introduction of industrial robots.

\footnotetext{
${ }^{1}$ Frey and Osborne (2017) project that 47 percent of total US employment is at high risk of automation in the next two decades, unleashing worldwide worries about the future of work.
} 
The adoption of robots has already been shown to have adverse effects on the US labor market, reducing aggregate employment and displacing more than half a million workers between 1993 and 2014 (Acemoglu and Restrepo, 2020). ${ }^{2}$ Building on this result, I find that for every ten workers that have been displaced, six individuals are leaving the labor force, suggesting that the introduction of industrial robots in these years has displaced from the labor market roughly 375'000 workers, a number that is equivalent to 15 percent of the secular decline in labor force participation. On average, every additional robot has driven two workers out of the labor force. This result includes the direct effect of robots on manufacturing employment and spillover effects to other industries, resulting from the decline in local demand, but does not account for aggregate effects of robot adoption associated with cross-CZ spillovers that might affect labor market outcomes in other areas. $^{3}$

The purpose of this paper is, in first instance, to investigate the margins of adjustment of workers that left the labor force because of the local adoption of robots. There is no evidence of workers migrating away from exposed CZs to less affected areas, and most labor force dropouts have not been compensated by the labor force participation of a family member. These results raise questions about where displaced workers are going to and how they can afford not to work. To understand the underlying causes that drive individuals out of the labor force, it is important to consider that robots are affecting individuals' labor supply decisions differently depending on their age and education. The adverse effects of robots are strongest among less educated workers, since they are employed more often in blue-collar jobs of the manufacturing sector (Lerch, 2021), and increase with workers' age, as the ability to keep up with technological change declines and retirement age approaches.

I find that only one in ten non-participants is younger than 34 years. Two thirds of these individuals are not in the labor force because they are enrolled in a post-secondary education institution to acquire additional human capital in order to increase their competitiveness in the labor market,

\footnotetext{
${ }^{2}$ Displaced workers are individuals who do not find a job or who lost their job directly or indirectly due to the adoption of robots. The repeated cross-sectional nature of the data does not allow me to disentangle direct from indirect displacement effects of robots, since I am tracing local labor markets rather than the career progression of individual workers. Industrial robots are known to replace blue-collar manufacturing workers by taking over tasks previously performed by labor. As a response, these workers may leave the labor force or move to other nonautomated jobs (e.g. low-skill services) and displace workers that are not directly competing with robots. Moreover, reduced employment in the manufacturing sector could contract aggregate demand in the local economy, decreasing also the demand for labor in industries that are not directly affected by the shock.

${ }^{3}$ When considering general equilibrium effects, the labor market impact of robots on employment halves in size due to productivity benefits that are shared with the rest of the US economy (Acemoglu and Restrepo, 2020).
} 
while the remaining non-participants, mostly less educated ones, are idle. They are not engaging in any activity outside of the labor market and do not receive any publicly funded income. These individuals can afford not to work because they are usually living with their parents and are not financially independent.

Three out of ten individuals that leave the labor force because of automation are aged between 35 and 54 years. More than half of these workers enrolls in Social Security Disability Insurance (SSDI) or starts to withdraw pension plan income, while the remaining non-participants are idle and rely on their partner's income. When exposed to robots, prime-age workers report to suffer from worse physical and mental health, which could make them medically eligible for SSDI. This result may follow from the fact that for many US workers, the job loss is associated with losing health insurance. The inability to be treated by a doctor in case of need may substantially worsen the course of a disease which, if neglected for too long, may become severe and require surgery, and eventually lead to a disability. As a matter of fact, I find that robots increase hospitalization rates of patients with acute health issues, in particular those diagnosed with mental disorders. These health conditions, however, are often hard to verify and leave some margin of error in the evaluation process of the SSDI, which could also be misused by displaced workers whose real health condition does not prevent them from engaging in substantial gainful activity, but who do not find a job in more automated labor markets. Hence, I cannot exclude that non-participants are using SSDI as a sort of permanent unemployment insurance. ${ }^{4}$

The likelihood to leave the labor force because of automation is highest among older workers. Half of the overall increase in non-participation consists of workers above 55 years who retire prematurely by claiming Social Security retirement benefits early or by withdrawing pension plan income. This effect is already visible in their fifties for less educated workers, when most penalties on early withdrawals of pension plan income are waived for non-employed individuals, and from 62 years for college-educated workers, when they qualify for Social Security early retirement benefits.

The advances in automation technologies are changing the nature of work, making an increasing number of workers obsolete, who, as a consequence, are leaving the labor force, unless they are en-

\footnotetext{
${ }^{4}$ This suspicion is in line with the finding of Deshpande and Lockwood (2020) who show that individuals with less severe health conditions enroll in disability insurance in response to non-health related shocks and as an insurance against future non-health risks.
} 
dowed with easily redeployable general human capital. This paper offers policymakers first evidence about the margins of adjustment of displaced workers to understand where individuals end up after having been replaced by robots. This is a crucial issue, since this trend is likely to intensify in the years to come.

The paper is structured as follows. Section 2 gives an overview of the related literature. Section 3 describes the data. Section 4 presents the empirical strategy and challenges to identification. Section 5 reports the results about the effect of robots on non-participation and Section 6 investigates the margins of adjustment of displaced workers. Section 7 performs a set of robustness checks. Section 8 concludes.

\section{$2 \quad$ Literature}

This paper contributes to different strands of the literature. There is a growing number of studies on the disruptive labor market impacts of automation which shows that the use of new technologies is mostly affecting workers employed in middle-skill jobs with a high workload of routine tasks, causing a reallocation of labor towards high-skill and low-skill occupations that are difficult to automate (Goos et al., 2009, Acemoglu and Autor, 2011, Autor and Dorn, 2013). This phenomenon is often referred to as job polarization. Moreover, there is evidence which suggests that automation is also creating millions of new occupations (Autor, 2019). It is important to acknowledge, however, that these jobs often require the interplay of humans with machines and algorithms, and may not be performed by the workers that have been displaced by automation due to a skill mismatch (Grigoli et al., 2020, Jaimovich et al., 2020). ${ }^{5}$ These workers are likely to become unemployed or to leave the labor force altogether, unless they are endowed with easily redeployable general human capital. As shown in Acemoglu and Restrepo (2020), the introduction of industrial robots has reduced aggregate employment and wages in the United States, displacing thousands of workers since the 1990s. I build on this result to show that the adoption of robots has not only reduced employment,

\footnotetext{
${ }^{5}$ The World Economic Forum estimates that in the next years automation could create up to 133 million new roles that are expected to offset the number of jobs which disappear (WEF, 2018, p.viii). However, these occupations are emerging in different professional areas. On one hand, automation is decreasing the demand for routine taskintensive occupations, such as office clerks and machine operators. On the other hand, there is increasing demand for occupations that complement the new technologies, such as data analysts and scientists and machine learning specialists (WEF, 2018, pp.8-9). It is rather unlikely that a displaced secretary is going to become a software developer in the near future.
} 
but it has also contributed to the decline in US labor force participation of the last decades. ${ }^{6}$ The effects of robots on aggregate employment are less visible among European countries, where the displacement of low-skilled manufacturing workers is almost fully compensated by the employment growth in other sectors (Graetz and Michaels, 2018, Dauth et al., 2019). Nevertheless, the newly created jobs can often not be performed by the workers that have been displaced by automation due to a skill mismatch, leaving open the question of where these workers are ending up. I link these findings to three streams of the literature that analyze the margins of adjustment of individuals that are not participating in the labor force because of adverse shocks (for a review, see Abraham and Kearney, 2020).

First, recent studies find that adverse labor market shocks, including trade competition, immigration and automation, are raising high school graduation rates and college enrollment rates in the US (Hickman and Olney, 2011, Greenland and Lopresti, 2016, Di Giacomo and Lerch, 2021). ${ }^{7}$ The increase in college enrollment of the last decades is often considered to be a major determinant of the decline in labor force participation among the young (Juhn and Potter, 2006, Krueger, 2017). Based on this finding, I show that the increasing enrollment in post-secondary education institutions associated with robot exposure has indeed contributed to the decline in labor force participation of young workers. This result is in line with the empirical work which finds that displaced low-skilled workers enroll in community colleges to increase their competitiveness in the labor market (Foote and Grosz, 2020) and that college graduates adjust the timing of their labor market entry according to labor market conditions (Card and Lemieux, 2001, Kahn, 2010, Oreopoulos et al., 2012, Altonji et al., 2016).

Second, this paper relates to the literature that studies the impact of labor demand shocks and poor labor market conditions on disability take-up (e.g. Black et al., 2002, Autor et al., 2013, Maestas et al., 2015). In the last decades, an increasing fraction of disability claims is related to hard-to-verify impairments (Autor and Duggan, 2003, Liebman, 2015), suggesting that SSDI could be misused

\footnotetext{
${ }^{6}$ Anelli et al. (2019) complement these results by investigating the short-term impact of automation on labor force participation of men, finding no effects.

${ }^{7}$ Moreover, Dauth et al. (2019) observe a significant increase in the share of young workers with a college or university degree due to the adoption of robots in Germany, at the expense of the share of workers who completed an apprenticeship. Even though these results provide important evidence that automation increases the level of education among young workers, the consequences that educational choices have for the decision to participate in the labor force are still unclear.
} 
as a sort of permanent unemployment insurance against adverse shocks (Ford, 2015, p.43). Other empirical work argues that poor labor market conditions could also have a direct impact on workers' health (Hollingsworth et al., 2017) and that poor health is one of the main reasons for individuals not to join the labor force (Parsons, 1980a,b, Krueger, 2017). Since the early 2000s, the high job insecurity during periods of poor labor market conditions and the exposure to trade and automation shocks led to a substantial increase in mental health problems among working-age Americans (Pierce and Schott, 2018, Lang et al., 2019, Adda and Fawaz, 2020, Gihleb et al., 2020), with the strongest deterioration in health conditions among white males (Case and Deaton, 2015, 2017). ${ }^{8,9}$ This, in turn, may partially justify the increase in disability rolls observed during difficult economic times. I contribute to this literature by examining the impact of robots on individuals' health conditions and the enrollment in disability insurance related to the decline in labor force participation.

Third, I complement the stream of the literature that analyzes the impact of technological change on early retirement. Previous studies show that unobserved technological progress - measured as total factor productivity - increases the share of premature labor force exits of the older population (Bartel and Sicherman, 1993, Peracchi and Welch, 1994, Burlon and Vilalta-Bufí, 2016), with a considerable share of displaced workers filing for disability insurance (Ahituv and Zeira, 2011). ${ }^{10}$ This result follows from the fact that training programs for workers close to retirement are often costly and yield little gains, as the career horizon in which they can make use of the acquired skills is relatively short and their cognitive ability to keep up with technological progress declines with age (Mazzonna and Peracchi, 2012). In case they have been displaced, most of these workers opt for early retirement and leave the labor force permanently. In line with this literature, I show that the adoption of robots has a strong impact on the early retirement decision of older workers.

\footnotetext{
${ }^{8}$ These papers mostly use data from 1990 onward and find that poor labor market conditions and the job loss have a negative impact on people's mental health conditions (Eliason and Storrie, 2009, Sullivan and Von Wachter, 2009, Browning and Heinesen, 2012). In contrast, using US health data from the 1970s to the 1990s, scholars argue that the relationship between health problems and recessions is mostly countercyclical (Ruhm, 2000, 2003, Miller et al., 2009). These findings are expected to result from rising opportunity cost of time and less leisure time during economic upturns.

${ }^{9}$ Gihleb et al. (2020) find also that robot adoption reduces work-related injuries in the manufacturing sector, suggesting that automation has a beneficial effect on the physical health condition of workers that have not been displaced.

10 This result reflects the strategy of early retirees to maximize their lifetime retirement income. In fact, disability benefits are equal to full retirement benefits, independently of the age at application and conditionally on the disability having started before retirement. When the full retirement age is reached, disability benefits are converted into full retirement benefits, which are larger than early retirement benefits.
} 


\section{$3 \quad$ Data}

This section describes the main data sources along with a set of descriptive statistics.

\subsection{Industrial robots}

I obtain data on the adoption of robots from the International Federation of Robotics (IFR). The IFR is a survey that collects data about shipments and operational stocks of industrial robots by country, industry and year ranging back to 1993 for 50 countries. The IFR defines an industrial robot as an 'automatically controlled, reprogrammable, multipurpose manipulator, programmable in three or more axes, which can be either fixed in place or mobile for use in industrial automation applications' (IFR, 2018, p.29). That is, industrial robots are machines that can be programmed to autonomously perform several manual tasks (e.g. assembly, material handling, packing and welding) without the intervention of a human worker. They are often designed as robotic arms and do not include conveyor belts, cranes or elevators, since these machines do not meet the above requirements. The IFR breaks down the stock of operational robots according to the International Standard Industrial Classification (ISIC), Fourth Revision, and provides consistent data for six broad industries outside of the manufacturing sector and 13 industries within the manufacturing sector. $^{11}$

These data are praised for their reliability, but they include also some limitations that I briefly address in the following. First, a fraction of the stock of industrial robots is not attributed to any industry and is referred to as 'unclassified'. Following Graetz and Michaels (2018), I attribute unclassified robots proportionally to each industry's share of total classified robots for each year. Second, up to 2011, the IFR provides data on the operational stock of robots only for North America as a whole, which includes the United States, Canada and Mexico. This aggregation introduces noise, but is not a major concern for the identification of US robot adoption, since the Unites States account for more than 90 percent of the North American market and the instrumental variable (IV)

\footnotetext{
${ }^{11}$ Broad sectors include agriculture, forestry and fishing; construction; education, research and development; manufacturing; mining; utilities; and other non-manufacturing branches (e.g. services). Within the manufacturing sector, the IFR provides information about the stock of robots in the following industries: automotive; basic metals; electronics; food and beverages; industrial machinery; metal products; minerals; paper and printing; plastics and chemicals; textiles; wood and furniture; other transport equipment (e.g. airplanes, locomotives and ships); and other manufacturing branches.
} 
strategy presented in Section 4 purges this type of measurement error (Acemoglu and Restrepo, 2020). Third, the stock of robots by industry going back to the 1990s is only available for a subset of countries: Denmark, Finland, France, Germany, Italy, Norway, Spain, Sweden, and the United Kingdom. The IFR provides data on the total stock of robots in North America from 1993, but it does not provide industry breakdowns until 2004. For these years, I attribute the aggregate number of robots to industries proportionally to their shares of the total stock in $2004 .^{12}$

\subsection{Labor force}

To measure long-term changes in local labor market outcomes contemporaneous to the introduction of industrial robots, I obtain data from the Integrated Public Use Microdata Series (IPUMS) of the decennial Census for 1970, 1980, 1990 and 2000, and the American Community Survey (ACS) for 2007 and 2014 (Ruggles et al., 2019). ${ }^{13}$ These datasets are repeated cross-sectional surveys that include between 1 and 5 percent of the US population and provide a comprehensive set of information at the individual level, including labor force participation, demographic characteristics, school enrollment, income sources, and the place of residence of households and their members. ${ }^{14}$ An individual is considered to be out of the labor force if he or she is not employed and is not looking for work at the time the survey is conducted. I focus on the labor supply of working-age individuals between 25 and 64 years of age, since these workers are above the usual full-time school age and below the full retirement age. ${ }^{15}$ Furthermore, I restrict my sample to non-institutionalized nonHispanic white men. These individuals experienced the largest decline in labor force participation over the last decades (see Table A1) and their labor supply decision is least sensitive to external factors such as childbearing or discrimination. ${ }^{16}$

\footnotetext{
${ }^{12}$ I use the same procedure to impute the stock of robots for Denmark, a country included in the instrument (see Equation 4 in Section 4), for which the industry breakdown starts in 1996.

${ }^{13}$ I follow the literature and increase the sample size of the ACS 2007 and 2014 samples using data from the 3-year sample of 2006-2008 and the 5-year sample of 2012-2016.

${ }^{14}$ Income sources include wages; Social Security income; business and farm income; welfare income (public assistance); or interest, dividend and rental income. Appendix A1 briefly presents the institutional background of the US Social Security and pension plan system and discusses some shortcomings in the data from the Census and ACS.

${ }^{15}$ In the US, the usual high school age goes from 14 to 18 years, while undergraduate college starts at 19 years until 22 to 23 years. The full retirement age starts at 66 or 67 years, depending on the year of birth.

16 Table A1 shows that the non-participation rate decreased for women and increased only by 12.8 percent for non-white working-age men (including Hispanics), compared to a 47 percent increase for white men. Of course, robots may affect also the labor supply of other demographic groups, especially for workers employed in blue-collar occupations of the manufacturing sector. The impact of robots on labor market outcomes by gender, race and ethnicity is outside of the scope of this paper and is analyzed in a companion paper (Lerch, 2021).
} 
I aggregate individual-level data at the labor market level using 722 Commuting Zones (CZs) that cover the entire US mainland and act as proxies of local labor markers (Tolbert and Sizer, 1996). ${ }^{17}$ This aggregation allows me to build a measure of the labor force non-participation rate at the local labor market level:

$$
\mathrm{NP}_{c, t}=\frac{L_{c, t}}{N_{c, t}}
$$

where $L_{c, t}$ is the number of non-participants and $N_{c, t}$ is the working-age population in CZ $c$ in year $t$.

I supplement labor market data with health data from the Behavioral Risk Factor Surveillance System (BRFSS) of the Centers for Disease Control and Prevention (CDC) and the National Inpatient Sample (NIS) of the Healthcare Cost and Utilization Project (HCUP) for 1993, 2000, 2007 and 2011. ${ }^{18}$ The BRFSS is a telephone survey that provides data on health-related risk behaviors, chronic health conditions, and the use of preventive services. The NIS collects information on hospital stays each year using a 20-percent stratified sample of discharges from US community hospitals. For each discharge, I observe information on up to 15 diagnoses using classification codes from the International Classification of Diseases, Ninth Revision (ICD-9). I follow the Centers for Disease Control and Prevention (2009) and group ICD-9 codes into the most common causes of disability (arthritis and rheumatism; back and spine problems; circulatory system diseases; respiratory system diseases; mental disorders; and diabetes) and into other conditions that are not directly related to a disability. A more detailed description of the data is provided in Appendix A2.

\subsection{Descriptive statistics}

Figure 1 shows that since the 1990s the United States have experienced a massive rise in labor force non-participation of white working-age men, increasing from 10.20 percentage points in 1990

\footnotetext{
${ }^{17} \mathrm{CZs}$ represent economically relevant regions for labor markets and are formed by clusters of counties with strong commuting ties within CZs and weak commuting ties across CZs. The IPUMS provide county groups or Public Use Microdata Areas as lowest geographic units. Following Autor and Dorn (2013), I aggregate data at the CZ level using a crosswalk that provides a probabilistic matching of sub-state geographic units in US Census Public Use Files to CZs from David Dorn.

${ }^{18}$ After 2011, the BRFSS and NIS datasets do not provide geographic indicators that allow me to identify observations at the CZ level.
} 
to 15.02 percentage points in 2014 (almost a 50 percent increase, see Table 1). ${ }^{19}$ During the same period of time, the stock of robots has increased by about 1.5 robots per thousand workers (a fivefold or roughly 180'000 units compared to its 1993 level) and, according to the International Federation of Robotics, it is expected to grow even more in the future (IFR, 2018, pp.535-540). Figure 2 shows that robots are mainly employed in a subset of manufacturing industries (e.g. automotive, electronic, plastic and chemical, and metal production, see Table A3), suggesting that the shock is mostly concentrated in the Midwest of the US, especially in labor markets of the Rust Belt (Indiana, Michigan and Ohio, see Figure 3), as they are more specialized in these industries.

Furthermore, Table 1 provides an overview of the data that I use in the empirical analysis. Column 1 provides national means across all $722 \mathrm{CZs}$ included in my sample, while Columns 2 to 5 split the sample into four quartiles based on a CZ's exposure to robots and provide means for the respective quartile. Panel A shows that the decline in labor force participation between the 1990s and 2014 is largest in CZs with a heavy utilization of industrial robots (5.4 percentage points). Interestingly, labor force participation in these CZs is on a declining trend since the 1970s and, as illustrated in Panel B, these CZs are also highly exposed to import competition from China, after its admission to the World Trade Organization in 2001. These observations highlight the potentially confounding impact of these factors on the estimated labor market effect of robots, especially in CZs that are intensive in manufacturing employment (see Panel C). In the next section, I expound the identification strategy used to infer the causal effect of robot exposure on labor force participation.

\section{$4 \quad$ Empirical strategy}

This section presents the empirical strategy and potential threats to identification.

\footnotetext{
19 The declining trend in male labor force participation is already visible from the 1950s and has been compensated by a rise in female labor force participation for many years. However, since the mid 1990s, the labor force participation rate of women stagnated and did not compensate for the persistent decline in labor force participation of men. Tables A1 and A2 in the Appendix show that this increase is driven by a decline in labor force participation of prime-age individuals without a college degree and by a rise in the share of the population aged more than 50 years. The latter result follows from the fact that the 'baby boom' generation is moving from 26-44 years of age in 1990 to 50-68 years in 2014 and that older workers have lower labor force participation rates than prime-age workers.
} 


\subsection{Identification}

My analysis relies on a task-based framework in which robots compete with human labor in the execution of different tasks. Robots may increase or reduce employment, and accordingly may have an ambiguous impact on unemployment and labor force participation. The overall effect mainly depends on the relative size of three countervailing effects that influence the equilibrium impact of robots on the demand for labor (Acemoglu and Restrepo, 2018, 2019, 2020). First, robots generate a displacement effect, as they take over tasks otherwise performed by workers. This effect reduces the share of labor in the industry that is undergoing automation and may also reduce its overall labor demand. Second, robots increase the marginal productivity of labor and contribute to the creation of non-automated tasks, raising the demand for labor within the same industry (composition effect) and across industries (productivity effect). The effect of robots on the aggregate labor demand depends on the relative size of these effects.

I estimate the effect of robots on labor force non-participation as a share of the working-age population using a stacked first-difference specification with 722 CZs and three time periods (1993-2000, 2000-07, 2007-14). ${ }^{20}$ The key estimating equation is given by:

$$
\Delta \mathrm{NP}_{c,\left(t_{0}, t_{1}\right)}=\beta \mathrm{US} \text { robot exposure } c_{c,\left(t_{0}, t_{1}\right)}+\mathbf{X}_{c,\left(t_{0}, t_{1}\right)}^{\prime} \boldsymbol{\Gamma}+\varepsilon_{c,\left(t_{0}, t_{1}\right)}
$$

where $\Delta \mathrm{NP}_{c,\left(t_{0}, t_{1}\right)}$ is the change in the labor force non-participation rate among working-age individuals in CZ $c$ between year $t_{0}$ and $t_{1}$. Following Acemoglu and Restrepo (2020), I measure a local labor market's exposure to industrial robots using a shift-share approach:

$$
\text { US robot exposure } c_{c,\left(t_{0}, t_{1}\right)}=\sum_{j \in J} \ell_{c, j}^{1990}\left[\frac{R_{j, t_{1}}^{U S}-R_{j, t_{0}}^{U S}}{L_{j, 1990}^{U S}}-g_{j,\left(t_{0}, t_{1}\right)}^{U S} \frac{R_{j, t_{0}}^{U S}}{L_{j, 1990}^{U S}}\right]
$$

The term in brackets is a measure of industrial robot density, computed as the change in the stock of robots in industry $j \in J, \Delta R_{j,\left(t_{0}, t_{1}\right)}^{U S}$, relative to its workforce in $1990, L_{j, 1990}^{U S}$, adjusted for the

\footnotetext{
${ }^{20}$ Since I use data on labor market outcomes from the 1990 Census and health outcomes from the BRFSS and NIS that range only up to 2011, I rescale the 1990-2000 and 2007-11 periods to 7-year equivalent changes to achieve comparability across periods.
} 
adoption of robots that is driven by overall industry output growth, $g_{j,\left(t_{0}, t_{1}\right)}^{U S}=\Delta \ln \left(Y_{j, t}^{U S}\right) .{ }^{21}$ The industry-level shock is apportioned across local labor markets using CZs' industry employment shares, $\ell_{c, j}^{1990}=\frac{L_{c, j}^{199}}{L_{c}^{1990}}$. The baseline employment shares are kept constant to avoid endogeneity and serial correlation concerns across periods of my stacked first-difference specification.

Identification builds on the assumption that advances in robotics vary by industry and expose local labor markets differently depending on the industrial composition of employment. The adoption of robots, however, is likely to be correlated with the local labor market conditions. For instance, positive demand shocks might induce US firms to raise both capital and employment, biasing the estimates of the effect of robots upwards. To address the endogeneity concern and identify robot adoption that is driven by the supply channel, I instrument the shift-component of Equation 3 using contemporaneous changes in the stock of robots in seven European countries with a comparable adoption of robots as the US:

$$
\text { EU7 robot exposure } c_{c,\left(t_{0}, t_{1}\right)}=\sum_{j \in J} \frac{1}{7} \sum_{i \in E U 7} \ell_{c, j}^{1970}\left[\frac{R_{j, t_{1}}^{i}-R_{j, t_{0}}^{i}}{L_{j, 1990}^{i}}-g_{j,\left(t_{0}, t_{1}\right)}^{i} \frac{R_{j, t_{0}}^{i}}{L_{j, 1990}^{i}}\right]
$$

where $R_{j, t}^{i}$ is the stock of robots in country $i \in E U 7$ at time $t$ in industry $j$. EU7 countries include Denmark, Finland, France, Italy, Spain, Sweden and the United Kingdom. ${ }^{22}$ On average, these countries had a similar development in the adoption of robots as the US. Furthermore, I instrument the share component with plausibly exogenous employment shares (Goldsmith-Pinkham et al., 2020). I use shares from 1970 to focus on the industrial composition of employment that precedes the introduction of industrial robots, which started in the 1980s (Acemoglu and Restrepo, 2020).

As outlined in the previous section, there are several factors that might confound the estimates of the labor market effect of robots. Equation 2 controls for observable confounders by including a vector of regional characteristics and economic variables, $\mathbf{X}^{\prime}$. They include pre-existing trends in US labor force participation and employment in the manufacturing sector, a shift-share measure of

${ }^{21}$ The IFR estimates the operational stock of robots using the sum of robot installations in the previous 12 years. I stress this assumption in Appendix A3 and construct measures of the stock of robots based on yearly shipments using the perpetual inventory method at different depreciation rates.

${ }^{22}$ The IFR provides data on the stock of robots by industry from the early 1990s also for Norway. However, I have to omit this country because the necessary data to construct Equation 4 are not available in the EU KLEMS database, since Norway is not a member of the European Union. 
import competition from China (Autor et al., 2013), demographic characteristics of labor markets, the industrial and occupational composition of employment, and time-varying census-division fixed effects to control for division-specific business cycles. ${ }^{23}$ I keep CZ characteristics constant at their 1990 levels to avoid contamination by endogenous adjustments in the structure of labor markets in response to robot adoption. Further details about the construction of these variables are provided in Appendix A2.

\subsection{Threats to identification}

The IV strategy aims at identifying the labor market effects of exogenous improvements in robotics available to US firms. The strategy relies on the assumptions that the adoption of robots in European countries is positively related to the adoption of robots in the US, but it is unrelated to domestic labor market conditions. The first condition can be easily verified (see first-stage results in Table 2 and industry correlations in Figure 2). However, the exclusion restriction may not be necessarily fulfilled, since the rapid adoption of robots in Europe could have made European firms more competitive than their US peers, unveiling a possible causal link with US labor market conditions via international product market competition. Although I cannot fully rule out this possibility, I address this potential threat to identification through the construction of the instrument and a set of robustness checks.

First, the instrument purposely does not include the countries with the world's heaviest adoption of industrial robots, namely South Korea, Germany, and Japan. These countries are also among the main trading partners of the US and could directly affect US labor market conditions through their national adoption of robots. Second, I use alternative constructions of the instrument which include only countries $i \in E U 7$ that are least engaged in trade with the US (Denmark, Finland and Sweden) and whose adoption of robots is unlikely to affect US labor markets. Third, I control for international competition in the product market between the US and Europe by including a shiftshare measure à la Autor et al. (2013) of US import exposure from the European countries included in the instrument. Furthermore, I sequentially exclude each industry $j \in J$ from the shift-share measures to control for the existence of confounding industry-specific shocks that could influence

\footnotetext{
${ }^{23}$ Census divisions are administrative divisions of the US territory into nine groups of states: New England, Middle Atlantic, South Atlantic, East North Central, East South Central, West North Central, West South Central, Mountain and Pacific.
} 
labor market conditions and the adoption of industrial robots both in the US and in Europe. Section 7 shows that my results are unlikely to be driven by the increasing competition from Europe and common industry shocks.

\section{$5 \quad$ Results}

This section presents the results of the empirical analysis on the effect of robot exposure on US labor force participation.

\subsection{Robots and non-participation}

I start by estimating Equation 2 using the change in the share of employment, manufacturing employment and non-participation as outcomes. The IV estimates of the effect of robots are reported in Table 2. ${ }^{24}$ The coefficients are standardized and represent the estimated effect of a one standard deviation increase in robot exposure on the respective labor market outcome. All outcomes are expressed in percentage points of the working-age population. Panel A presents the estimates of the effect of robots on employment, Panel B on manufacturing employment and Panel $\mathrm{C}$ on nonparticipation. Finally, Panel D displays first-stage results which show that the adoption of robots in European countries is strongly correlated with the adoption of robots in the US throughout all specifications.

Column 1 presents the baseline estimates of the effect of robots on labor market outcomes controlling only for division-specific business cycles. Regressions are weighted by the $1990 \mathrm{CZ}$ population and standard errors allow for arbitrary clustering at the state level. In line with Acemoglu and Restrepo (2020), the estimates indicate that the introduction of robots has a negative employment effect that is driven by a reduction in manufacturing employment, i.e. the local displacement effect outweighs the productivity and the composition effect. Furthermore, my results show that for every 10 workers that have been displaced by automation, 6 individuals are leaving the labor force $(0.256 / 0.439)$. The estimates of this parsimonious specification have to be interpreted carefully, however, since omitted variables could confound the labor market effects of robots. To account for potential confounders,

\footnotetext{
${ }^{24}$ OLS and reduced form estimates of the effect of robot adoption on non-participation are presented in Table A4. IV estimates are larger in absolute magnitude than OLS estimates since US robot adoption is likely to be correlated with omitted demand shocks that bias the estimates towards zero.
} 
the following columns include a set of covariates about regional and economic characteristics of CZs.

Column 2 controls for the change in the local labor force participation rate and the decline in manufacturing employment between 1970 and 1990 to account for potential pre-trends that might have influenced subsequent labor market outcomes and the adoption of robots. The inclusion of these controls does not alter my estimates of the effect of robots, which are quantitatively and qualitatively similar to the estimates in Column $1 .^{25}$ Column 3 further includes a measure of import competition from China. Interestingly, the inclusion of the trade shock does not affect the magnitude and significance of my results. This finding shows that, in spite of both shocks being concentrated in the manufacturing sector, the labor market effects of robots and imports are mostly unrelated to each other, with the size of the estimated effect of imports on non-participation being smaller but not statistically different from the effect of robots $(0.20$ vs. 0.28 percentage points, see Table A6). ${ }^{26}$ Column 4 adds also a set of demographic, industry and occupation controls to account for systematic differences across local labor markets. Again, almost all estimates have a similar magnitude as in the previous specifications and are statistically significant at the 1 percent level. The only exception is an absolute decrease in the estimated effect of robots on employment in the manufacturing sector from -0.439 to -0.255 , which is in line with the inclusion of covariates that control for the secular decline in manufacturing employment. The significantly larger effect on overall employment suggests that the impact of robots is not limited to the manufacturing sector, but spills over also to other industries in the local economy. Similarly to the specification in Column 1, I find that for every 10 workers that have been displaced by robots, the labor force decreases by almost 6 individuals. This effect is driven by labor markets that are intensive in manufacturing employment (see Figure A1) and is visible already before the start of the Great Recession, which boosted labor force non-participation from the end of 2007, possibly confounding the effect of robots

\footnotetext{
${ }^{25} \mathrm{I}$ test for the existence of pre-trends that could bias my results also from a different perspective. I perform a 'placebo test' and estimate a two-period model in which I regress the change in the local non-participation rate for the 1970-80 and 1980-90 periods on the exposure to robots during the first two periods of my sample (1990-2000 and 2000-07). Table A5 summarizes the results. I do not find any significant relationship between the introduction of robots and trends in non-participation before the 1990s.

${ }^{26}$ Faber et al. (2019) compare the impact of robots and imports on local employment and find that the shocks are similar in their geographic distribution, but that there are substantial differences with respect to the spillover effects they exert to industries outside of the manufacturing sector, and hence on overall employment. Note that in the specification in Column 4 of Table A6, the estimate of the effect of import exposure decreases to 0.15 and becomes statistically different from the effect of robot exposure at the 5 percent level.
} 
(see Table A7). ${ }^{27}$ Finally, Column 5 displays unweighted regression estimates of the effect of robots on labor market outcomes. The estimates are less precise and are larger in magnitude than in the previous specifications, but they are proportionally comparable to weighted regression estimates: for every 10 workers that have been displaced by robots, about 5 individuals are leaving the labor force.

I use the specification of Column 4 as my preferred specification throughout the subsequent analysis, since it includes the full battery of controls and uses population weights to account for the relative contribution of labor markets to aggregate labor force participation. ${ }^{28,29}$ I find that, on average, a one standard deviation increase in robot exposure decreases labor force participation of white working-age men by 0.257 percentage points, which translates into a decrease in the local labor force of about two workers for each additional robot. ${ }^{30}$ This result is in line with the finding of Acemoglu and Restrepo (2020), who estimate a reduction in local employment of 6 workers per additional robot, including women and racial and ethnic minorities. According to Figure 1, the introduction of industrial robots between 1993 and 2014 has displaced roughly 375’000 workers from the labor force, which is equivalent to about 15 percent of the decline in US labor force participation in these years. This result includes only local effects of robot adoption and does not account for aggregate effects resulting from cross-CZ spillovers that could influence labor market conditions in other areas. When considering general equilibrium effects, the labor market impact of robots on employment halves in size due to productivity gains and reduced prices of tradable goods produced by robots

${ }^{27}$ A concern that I need to address is whether poor labor market conditions trigger workers' labor supply responses against the automation shock differently than during ordinary times. I account for this concern in two ways. First, I estimate Equation 2 by excluding the 2007-14 period to verify whether the effect of robot adoption on labor force participation is already visible before the Great Recession. Second, I interact robot exposure with a dummy for the 2007-14 period to test whether the effect of robots is statistically and economically different during the Great Recession. From the results emerges that there are no significant differences across periods.

28 Table A8 supports my preferred specification by showing that unobserved heterogeneity across CZs does not bias my estimates and that cross-sectional variation in robot exposure is an important source of its overall variation. The results are discussed in more detail in Appendix A3.

${ }^{29}$ As outlined in Cadena and Kovak (2016), when examining outcomes across labor markets of different sizes, efficient weights must account for individuals' sampling weights to account for inherent heteroskedasticity. They show that optimal weights are strongly correlated with initial population sizes and therefore are well approximated by the initial population of a local labor market.

${ }^{30}$ I first de-standardize the effect of robot exposure on the change in the non-participation rate by dividing the coefficient of my preferred specification in Table 2 by the standard deviation of the variable expressed in robots per thousand workers from Table A8 to obtain the estimated effect in terms of robots per thousand workers $(0.257 / 0.491=0.52$ percentage points $)$. I then use statistics about the US population from the IPUMS and about robot adoption from the IFR to estimate the average effect of one additional robot on the size of the labor force. 
that are shared with the rest of the US economy (Acemoglu and Restrepo, 2020). ${ }^{31}$ The purpose of this paper is, however, to investigate the margins of adjustment of workers that drop out of the labor force because of the local adoption of robots.

\subsection{Effects by age and education}

To understand the underlying causes that drive individuals out of the labor force, it is important to consider that robots might influence individuals' labor supply decisions differently depending on their demographic characteristics. For this purpose, I break down the working-age population in four 10-year age groups (25-34, 35-44, 45-54 and 55-64 years) and in two education levels, distinguishing between individuals that have achieved at least an undergraduate college degree and individuals without a college degree (college-educated and less educated). ${ }^{32}$ Table 3 illustrates the relative contribution of these groups to the aggregate effect of robots on non-participation.

Unsurprisingly, most of the decline in labor force participation is caused by individuals without a college degree (about 85 percent). These workers are often employed in occupations with a high workload of manual tasks (e.g. blue-collar jobs) and are more likely to be exposed to the adoption of robots (Lerch, 2021). Moreover, one in two workers that leave the labor force has more than 55 years, a result that is likely to follow from their proximity to the retirement age, while only about one in ten workers is younger than 34 years. Although to a smaller extent, robots influence negatively also the labor supply of individuals with a college degree. The size of the effect is smaller because of two reasons. First, college-educated workers are often employed in occupations that require the use of communication and interpersonal skills that are more difficult to automate (Acemoglu and Autor, 2011). Second, the share of college-educated individuals in the population is small, less than 25 percent (see Table 1).

To overcome the latter (mechanical) effect, Figure 4 illustrates the impact of robots on labor force

\footnotetext{
${ }^{31}$ Acemoglu and Restrepo (2020) present a parametric model to quantify aggregate employment effects of robots in the US and estimate that, when considering general equilibrium effects, the labor market impact of robots decreases from an employment reduction of 6 workers to about 3.3 workers. A full blown model that accounts for the general equilibrium effects of robots on labor force non-participation and displaced individuals' margins of adjustment is outside of the scope of this paper.

32 The less educated group includes high school and undergraduate college dropouts, individuals who have achieved at most a high school diploma, and students that are enrolled in college, but who have not achieved an undergraduate degree.
} 
non-participation within each demographic group $g$ :

$$
\mathrm{NP}_{c, t}^{g}=\frac{L_{c, t}^{g}}{N_{c, t}^{g}}
$$

where $L_{c, t}^{g}$ is the number of non-participants and $N_{c, t}^{g}$ is the working-age population of group $g$ in CZ $c$ in year $t$. In line with the previous result, I find that robots are mainly decreasing employment among less educated workers and that about one third of the displaced prime-age workers are leaving the labor force. This number increases up to 80 percent among older workers. Interestingly, when accounting for the relative size of population groups, I find that robots decrease labor force participation significantly also among college-educated young individuals (25 to 34 years) and older workers (55 to 64 years), while workers between 35 and 54 years are the least affected by the shock.

\section{$6 \quad$ Where have all the workers gone?}

The previous results show that the adoption of robots has adverse effects on US labor markets. However, I find no evidence of an increase of the migration flows from heavily exposed CZs to less affected areas, as illustrated in Table 4, suggesting that workers are not reacting to a displacement by moving their place of residence to another labor market. ${ }^{33}$ Moreover, I find only limited support for the hypothesis that the lower labor force participation of men is compensated by the labor force participation of a family member (Lundberg, 1985). Figure 5 shows that more than half of the individuals who do not participate in the labor force because of automation do not have a partner or a family member that is employed. ${ }^{34}$ These results raise the question of where individuals are going to, when they drop out of the labor force, and how they can afford not to work.

\footnotetext{
33 This result is in line with Faber et al. (2019), who show that the automation shock is not increasing out-migration from affected areas. In addition, Table A9 illustrates the effect of robot exposure on migration flows using data from the Internal Revenue Service (IRS) provided by Howard (2020). Interestingly, the effect of robots on outmigration remains economically and statistically insignificant, while, in my preferred specification, also the effect on in-migration loses significance relative to the estimates in Panel B of Table 4.

${ }^{34}$ Among independent family units (i.e. household head or spouse), two thirds of the individuals that left the labor force do not have a partner who could compensate their labor force dropout. This result is likely to be fueled also by adverse employment effects of robot exposure among women, as illustrated in Table A10, and is in line with Juhn and Potter (2006), who argue that the employment status of the partner is not a key determinant for the labor supply decision of men.
} 


\subsection{Post-secondary school enrollment}

This section investigates whether the decline in labor force participation among the young is fueled by individuals who leave the labor force temporarily or who delay their labor market entry to enroll in post-secondary education institutions. For this purpose, I split the increase in non-participation of Figure 4 between individuals who are enrolled in school and those who are not. ${ }^{35}$ Figure 6 illustrates the results.

I find that one quarter of the less educated young individuals, who do not participate in the labor force because of robots, is enrolled in school. This effect is driven by high school graduates who enroll in college (see Figure A2). The remaining non-participants are idle (see Figure A3), with most of them still having earned some income in the previous twelve months (see Figure A4) and not being financially independent (half of these individuals are either living with their parents or have a partner that is employed, see Figures A5 and A6). These individuals are likely to leave the labor force in the short-term because they are discouraged from worse job prospects, which makes them qualitatively more similar to unemployed individuals than to permanent labor force non-participants (Jones et al., 2002). ${ }^{36}$

Among college-educated individuals, almost two thirds of the non-participants are enrolled in graduate or in professional schools. These students have been employed (at least some time) in the previous five years, either by working part-time during their undergraduate studies and having delayed their labor market entry, or by working full-time and then leaving the labor force again (see Figure A7). ${ }^{37}$ The decision not to participate in the labor force is likely to be voluntarily and allows them to invest in additional human capital to increase their competitiveness in the labor

\footnotetext{
${ }^{35}$ I define school enrollment as schooling which leads to a high school diploma, a college degree or a graduate degree. School attendance identifies whether an individual is completing a schooling degree or, after completing it, continues with a higher degree. It does not include enrollment in a trade or business school, company training, or tutoring unless the course would be accepted for credit at a regular college.

${ }^{36}$ In line with these results, Aguiar et al. (2017) show that young individuals that are not financially independent supply less labor because of the rising value of leisure in the last decades.

${ }^{37}$ Column 1 of Figure A7 shows whether students have worked in the previous five years and Column 2 shows whether they have worked in a full-time or in a part-time job in the previous twelve months. Working hours are only available for the twelve months prior to the interview. I consider workers with an average working week of less than 30 hours (or less than 1560 hours a year) as part-time workers. It is important to note that an individual may be classified as non-participant, even if he or she worked in the previous twelve months, but he or she is not actively seeking a job at the time the survey is conducted.
} 
market. ${ }^{38}$ Also in this case, individuals can afford not to work because they are often not financially independent.

Even though I do not find evidence of migration flows from exposed CZs in response to the automation shock, I need to consider for the fact that students are substantially more mobile than the rest of the population and that they may migrate across CZs to enroll in college. For migrants, the decision to accumulate additional human capital is unlikely to be driven by the shock in the CZ in which the college is located, but rather by the shock in their CZ of origin. Following Di Giacomo and Lerch (2021), I address this concern by using a weighted shift-share measure that accounts also for the exposure to robots in the CZs from which students are migrating from. ${ }^{39}$ Reassuringly, the results are not significantly different from my preferred specification (see Table A11). Moreover, the results are robust to the inclusion of controls that account for the local supply of educational institutions (e.g. public, non-profit and community colleges), which could confound the decision of individuals to leave the labor force to enroll in college in response to the automation shock (see Table A12).

Figure 6 further shows that there is no evidence that the decrease in labor force participation caused by robot adoption is associated with an increase in post-secondary school enrollment after the age of 35 years. This finding suggests that this effect is limited to individuals in their early prime age, since they have the most to gain from additional human capital, given their long career horizon and many of them not being financially independent. In contrast, older workers are leaving the labor force for reasons that are discussed in the next sections.

\subsection{Disability insurance and health}

The US have experienced a tremendous increase in disability claims over the last decades. Evidence suggests that this trend has been fueled by a deterioration in the health conditions of the

\footnotetext{
${ }^{38}$ This suspicion follows from the fact that I do not observe any significant increase in the unemployment share of college-educated individuals because of the adoption of robots. On the contrary, Figure 4 illustrates that robot exposure has significantly increased unemployment among less educated young individuals, suggesting that most of these workers did not quit their job voluntarily, but that they have been (directly or indirectly) displaced by robots.

${ }^{39}$ Di Giacomo and Lerch (2021) reconstruct the shock for the CZ in which students are enrolled in college, $c_{d}$ (previously denoted with $c$ ), as a weighted average of the shocks in students' CZs of origin, $c_{o}$. The shocks are weighted by the share of students living in $c_{d}$ who come from $c_{o}$. Note that for non-migrants, the CZ of origin and the $\mathrm{CZ}$ in which the college is located are the same. Further details are provided in Appendix A2.
} 
working-age population and poor labor market conditions (see literature review in Section 2). This section investigates whether the adverse labor market impact of robots has contributed to the rise in disability take-up and whether it is associated with a direct effect of robots on workers' health conditions.

I start by breaking down the decrease in labor force participation illustrated in Figure 4 between nonparticipants who receive Social Security income (disability or retirement benefits), non-participants who exclusively withdraw income from their pension plans, and non-participants without any Social Security or pension plan income. This distinction allows me to identify the share of non-participants that responds to the automation shock by enrolling in disability insurance. Before 62 years of age, non-participants may claim Social Security income in form of disability benefits from the Social Security Disability Insurance (SSDI) program. ${ }^{40}$ After 62 years, they become eligible also for Social Security early retirement benefits. Figure 7 illustrates point estimates of the effect of robots on the change in non-participation by income source, age and education level. Panel A reports the results for college-educated individuals and Panel B for less educated individuals.

From the results emerges that almost all college-educated non-participants and one third of the less educated non-participants aged between 35 and 44 years are enrolled in disability insurance. These individuals are likely to leave the labor force permanently, since only a small fraction of disability beneficiaries exits the program again (Liebman, 2015, Raut, 2017). However, only few of them claim also Supplemental Security Income (SSI), suggesting that even if they are not working anymore, based on their income and resources, they do not qualify for additional financial support from the Social Security Administration (see Figure A8). The remaining non-participants with less than a college degree are mostly idle and are often not financially independent (three quarters of them are either living with their parents or have a partner that is employed, see Figures A5 and A6) or have earned some income in the previous twelve months (e.g. business and farm income; welfare income (public assistance); or interest, dividend and rental income, see Figure A4).

\footnotetext{
${ }^{40}$ To be precise, from the age of 60 years, widows or widowers may also claim Social Security survivor benefits. The adoption of robots could influence the number of survivor benefit recipients, if it affects the mortality rate of spouses of male non-participants. However, since I find only a limited impact of robots on employment and an insignificant impact on labor force participation of women (see Table A10), I feel comfortable in excluding this potential causal link. Therefore, I assume that the change in Social Security beneficiaries before the age of 62 years reflects the change in disability benefit recipients. Appendix A1 provides further details on the Social Security system in the US.
} 
From the age of 45 years, less educated non-participants start to withdraw also their pension plan income. The increase in disability take-up is quantitatively similar to the increase in the 35 to 44 group (but is estimated less precisely). From the age of 55 years, the increase in non-participants with Social Security or pension plan income increases sharply. This increase reflects the fact that Social Security income includes early retirement benefits for individuals aged more than 62 years and penalties on early withdrawals of pension plan income are often waived from the age of 55 . I discuss these results in the next section. Finally, I find that young non-participants do not enroll in disability insurance. This result is mainly driven by the fact that these workers have not paid enough Social Security taxes to be eligible for disability benefits.

The response of displaced workers to enroll in disability insurance may be driven by two factors. First, SSDI acts as a sort of permanent unemployment insurance against the risks of automation and worse future job prospects. Second, robots affect the health condition of workers who, as a consequence, become eligible for disability benefits. While I cannot exclude that non-participants are misusing SSDI as an insurance against adverse labor market shocks, I show that the increase in disability take-up comes along with an increase in disability-related physical and mental impairments. Additionally, I provide some insights about the impacts of robots on access to adequate healthcare services, smoking habits, and physical inactivity, which are common problems among disabled individuals.

Table 5 reports estimates of the labor market effect of robot exposure on self-reported health conditions, smoking and drinking habits, physical shape and access to healthcare services among employed and non-employed individuals using data from the BRFSS. ${ }^{41}$ I find that robots increase the share of individuals who drink regularly and decrease the share of smokers among the employed. ${ }^{42}$ The adoption of robots has also a negative effect on the share of people who do physical activities outside of their work environment, raising the share of non-employed individuals who suffer from obesity. Moreover, I find evidence that robots are influencing negatively individuals' self-perceived health. Specifically, the adoption of robots increases the share of non-employed individuals who report a fair or bad health condition and those who report persistent physical or mental health problems,

\footnotetext{
${ }^{41}$ The BRFSS does not explicitly distinguish between unemployed and non-participating individuals. Non-employed individuals include individuals who report to be out of work, unable to work, homemakers, students and retirees. ${ }^{42}$ I consider regular drinkers as people who drink alcohol in at least five days per week.
} 
with the latter being imprecisely estimated and not being statistically significant at conventional levels. ${ }^{43}$ These effects are driven by non-employed individuals aged between 35 and 44 years for whom also the effect on mental problems becomes statistically significant (see Figure A9). Additionally, I observe an increase in mental problems among non-employed individuals between 45 and 54 years and an increase in physical health problems among non-employed individuals between 55 and 64 years.

These results suggest that robots have indeed a negative impact on the average health condition of non-employed individuals, which could justify the increase in disability take-up of these individuals. According to Table 6, almost 8 in 10 workers that have been displaced by robots suffer from persistent physical health problems and 4 in 10 displaced workers suffer from persistent mental health problems. $^{44}$

The adoption of robots might affect workers' health conditions in two (not mutually exclusive) ways. First, workers who already suffer from health problems are less productive and are therefore more likely to be displaced by robots. These workers mechanically increase the share of non-employed individuals that suffers from health problems (Frank et al., 2019). ${ }^{45}$ Second, the health condition of displaced workers deteriorates after a job loss (Sullivan and Von Wachter, 2009). This mechanism is likely to be reinforced by the fact that for many US workers, losing their job is associated with losing health insurance (Schaller and Stevens, 2015). As a matter of fact, I find that robots decrease the share of non-employed individuals with healthcare coverage (see Column 8 of Table 5). This, in turn, increases the share of individuals who cannot afford to visit a doctor for cost reasons and who had no medical checkup in the previous two years (see Columns 9 to 11). The inability to be

\footnotetext{
${ }^{43}$ I define people that suffer from persistent problems as people who report physical or mental problems in at least 14 days of the 30 days prior to the interview. Table A13 shows that the results are robust to an increase of the threshold up to 21 days, while the effect on persistent mental problems loses significance and becomes economically small as I lower the threshold to 7 days.

${ }^{44}$ The subjective self-reported health condition may not fully reflect the underlying real health condition, since nonparticipants that want to apply for disability benefits could have an incentive to over-report physical and mental health problems. The same reasoning may hold for disability beneficiaries with mild conditions who report to suffer from severe health problems for fear of losing eligibility. In the following, I address these concerns with more objective measures of individual health conditions using hospitalization data from the NIS.

${ }^{45}$ Frank et al. (2019) argue that workers affected by pre-existing mental disorders are predominantly employed in routine task-intensive occupations. Work is often beneficial to them and has a therapeutic effect that leads to better general well-being. However, these workers are also mostly exposed to the recent technological advances, since most of the tasks they used to carry out are at high risk of automation (Autor and Dorn, 2013, Jaimovich et al., 2020). The job loss could aggravate their health impairments and force them to leave the labor force, and eventually apply for disability benefits.
} 
treated by a doctor in case of need may substantially worsen individuals' health conditions which, if neglected for too long, may become severe and require surgical intervention, eventually leading to a disability. If this mechanism takes place, one should observe an increase in hospitalization rates with acute health problems in areas that are more exposed to robots.

To analyze the effect of robots on hospitalization rates by diagnosis and severity, I use data from the NIS. Table 7 summarizes the results on the share of hospital admissions with a length of stay of more than seven days (they are most likely to be related to a severe health condition) and a disabilityrelated diagnosis. ${ }^{46}$ I find that robots increase the share of admissions with an acute health condition and, in particular, that they increase the share of admissions diagnosed with mental disorders. ${ }^{47,48}$ This result is driven by individuals that are younger than 44 years (see Figure A10) and is in line with the worse self-reported health conditions among non-employed individuals between 35 and 44 years presented previously. Interestingly, I also find that robots increase the share of severe hospital admissions related to substance abuse, such as alcohol, drug and tobacco abuse. ${ }^{49}$ These diagnoses are often related to mental disorders.

These results suggest that the increasing disability take-up in CZs that are more exposed to robots could be, at least partially, justified by a deterioration in individuals' health conditions, especially because of mental disorders. These disorders, however, are often hard to verify and leave some margin of error in the decision on whether to grant disability benefits, which could be misused by displaced workers whose real health condition does not prevent them from engaging in substan-

\footnotetext{
${ }^{46}$ The share of severe hospital admissions by diagnosis is calculated by dividing the count of hospital admissions with a length of stay of more than seven days and a particular diagnosis by the number of hospital admissions in a CZ in the year of reference.

47 The increase in hospital admissions related to severe mental disorders suggests that robots increase the share of people suffering from mental disorders or that they worsen the general health condition of people who are already suffering from these disorders. The latter interpretation is in line with the finding in Frank et al. (2019) discussed in footnote 45 of page 23.

${ }^{48}$ I consider hospital admissions with a length of stay of more than seven days to be serious and hence to be more likely to be related to a disability. Table A14 shows that the estimates of the effect of robots on mental disorders do not differ significantly when lowering the length-of-stay threshold for acute health conditions to 4 days or when increasing it up to 14 days. Unfortunately, the NIS does not provide individual identifiers and therefore does not allow me to identify the hospitalization of individuals who suffer from disability-related health problems that require repeated short-term treatments. Table A15 reports estimates of the effect of robots on the share of disability-related hospital admissions by diagnosis including all admissions, while Table A16 reports estimates of the effect of robots on the share of diagnoses which are not directly related to a disability. I find no evidence that robots are systematically affecting health outcomes of these individuals.

49 The result on alcohol abuse is in line with the finding that robots increase the share of individuals who drink in at least five days a week, while the result on tobacco abuse suggests that regular smokers are smoking more when they are exposed to robots.
} 
tial gainful activity. ${ }^{50}$ Therefore, I cannot exclude that SSDI may involuntarily act as a sort of permanent unemployment insurance against the risks of automation for some workers (Ford, 2015).

\subsection{Early retirement}

Firms often invest in job training programs of prime-age workers to keep up with technological progress (Bartel and Sicherman, 1998) and, even in case workers have been displaced, many of them reallocate towards other occupations in the labor market (Autor and Dorn, 2013). This reasoning may not hold for older workers who are close to the retirement age, since job training is often costly and of little gain due to their short career horizon. Moreover, most of these workers are eligible for some form of retirement income and, in case of employment termination, frequently opt for early retirement, leaving the labor force permanently. In the following, I break down the group of older non-participants (55 to 64 years) into individuals aged between 55 and 61, and between 62 and 64 years. The first are not eligible for Social Security early retirement benefits, while the latter are. Figure 8 reports the point estimates of the labor market effect of robots on the change in the elderly non-participation rate by income source, age and education.

Panel A shows that robots do not significantly affect the non-participation rate of college-educated men between 55 and 61 years. This result is in line with the trend observed for individuals between 45 and 54 and suggests that men between 45 and 61 years of age are least affected by the adoption of robots in their labor supply decision. The result is different once I consider individuals between 62 and 64 years. I find that robots have a strong positive impact on the non-participation rate of individuals in their early retirement age, who leave the labor force and start claiming Social Security retirement benefits.

Interestingly, Panel B shows that robots increase the non-participation rate of less educated individuals already between 55 and 61 years, with a third of the non-participants receiving disability benefits. This increase is not justified by a direct effect of robots on individuals' health condition and is in line with Ahituv and Zeira (2011), who show that SSDI involuntarily acts as a sort of

\footnotetext{
${ }^{50}$ Predictors that are often used in the literature as hard evidence of mental disorders are suicides and suicide attempts (Harris and Barraclough, 1997). Table A16 shows that the labor market effect of robots on suicide attempts is neither economically relevant nor statistically significant at conventional levels. Hence, I cannot ignore the suspicion that a fraction of disability claimants is misusing the margin of error in the evaluation process of hard-to-verify impairments.
} 
early retirement institution. ${ }^{51}$ The remaining two thirds do not enroll in disability insurance, but withdraw their retirement income from pension plans, since most plans waive penalties on early withdrawals from 55 years in case of employment termination. Similarly to Panel A, I find that robots have a strong positive effect on non-participation among individuals aged between 62 and 64 years, leading to a sharp increase in Social Security early retirement benefit claims.

This evidence shows that robots significantly reduce labor force participation among older workers, leading to a rise in premature retirement decisions (from 55 years, if less educated, and from 62 years, if college-educated). These individuals opt for early retirement and mainly live from disability benefits, pension plan income and early retirement benefits. ${ }^{52}$

\section{$7 \quad$ Robustness checks}

This section performs a set of robustness checks in support of my identification strategy. Further results are presented in Appendix A3.

\subsection{Competition from Europe}

As mentioned in Section 4, the adoption of robots in Europe could have affected US labor market conditions through increased international product market competition. This is an important threat to identification, since it could violate the exclusion restriction of my IV strategy. Although I cannot rule out this possibility, I show that it is rather unlikely that my results are driven by this causal link.

I control for international competition on the product market from European countries to the US by including a shift-share measure of US imports from Europe. Between the early 1990s and 2014, trade flows from Europe to the US have increased substantially. This increase is mainly driven by a rise in US imports of manufacturing goods that is positively related to the introduction of robots in Europe (see Figure A12). International competition on the product market may therefore

\footnotetext{
${ }^{51}$ Figure A9 shows that robots are increasing the share of older non-participants who report to suffer from physical problems. However, the effect is limited in magnitude and is not related to an increase in hospital admissions with acute health problems (see Figure A10).

${ }^{52}$ I further check to which extent older workers who leave the labor force because of robots rely on these income sources and find that Social Security and pension plan income account for more than 90 percent of their total income (see Figure A11). This result supports the hypothesis that these workers are leaving the labor force permanently to retire early.
} 
confound the effect of robots on US employment, and influence labor force participation accordingly. Similarly to robot adoption, US imports are also subject to domestic shocks that might influence the demand for labor. I account for this concern with a similar approach as Autor et al. (2013) for the China trade shock, using trade flows from Europe to Canada, a country with a comparable trade engagement with European countries as the US (see Figure A13). Table 8 illustrates the results. The estimates of the labor market effect of robots are economically and statistically unaffected by the inclusion of these measures, suggesting that they have not been driven by an increase in import competition from Europe.

In a second approach, I omit from the instrument European countries with a large trade engagement with the US, namely France, Italy, Spain and the United Kingdom. The instrument now includes only the stock of robots in Denmark, Finland and Sweden, i.e. the countries that are least likely to impact US labor market conditions through their national adoption of robots. The results lose some precision (because of the heavier exposure of the instrument to labor market shocks in Nordic countries) but are quantitatively almost identical to the results of my preferred specification. These findings suggest again that my estimates are unlikely to be driven by an increase in international product market competition through the heavier utilization of robots in Europe.

\subsection{Industry trends}

Another concern that I need to address is that my estimates could be driven by underlying industry trends. For instance, the high concentration of robots in the automotive industry might raise the concern that the results are affected by industry-specific shocks that influence the labor market conditions in CZs which are highly specialized in this industry. ${ }^{53}$ To address this concern, I decompose the stock of industrial robots into robots adopted in the automotive industry and robots adopted in other industries, and construct two separate measures of robot exposure. I extend this exercise by sequentially excluding each industry at a time from the shift-share measure to account for other industry-specific shocks that might confound the labor market effect of robots (Goldsmith-Pinkham

\footnotetext{
${ }^{53}$ Table A17 shows the average industry weights of the top eight industries of the shift-share measure (also known as Rotemberg weights, see Goldsmith-Pinkham et al., 2020) and the contribution of industries to the national change in the stock of robots between 1993 and 2014. The automotive industry has the highest Rotemberg weight and accounts for more than 50 percent of the change in robot adoption in these years. These results show that the exposure to the shock strongly depends on the development in robot adoption in this industry, which increases the sensibility of my estimates to other industry-specific shocks that affect labor markets which are specialized in the automotive industry.
} 
et al., 2020). Figure 9 reports 19 point estimates of the effect of robot adoption on labor force participation including all IFR industries but one. The point estimates are similar and statistically significant at conventional levels for all specifications. They are most sensitive to the exclusion of robots in the automotive industry, which is not surprising, considering that most robots are adopted in this industry. ${ }^{54}$ These results suggest that the labor market effect of robots on US labor force participation is not driven by unrelated industry-specific shocks.

\subsection{The Rust Belt}

Figure 3 of Section 3 illustrates that the robot shock is mostly concentrated in labor markets of the Rust Belt due to their specialization in the steel and automotive industry. This finding raises the question of whether the effect of robots on labor force non-participation is specific to these CZs or whether this is a US wide phenomenon. Table 9 reports the results when excluding from the sample the CZs with the highest robot exposure. First, I exclude the local labor market of Detroit, which is the CZs that is mostly exposed to the shock (between the mid-1990s and 2014 the stock of robots increases by about 11 robots per thousand workers). Second, I exclude the CZs in the top 1 percentile of the distribution of robot exposure. Besides Detroit, these CZs include the labor markets of Jackson, Lansing, Saginaw (Michigan), Richmond, Kokomo, Muncie (Indiana) and Defiance (Ohio). Third, I exclude all CZs around the Great Lakes that are in the states of Michigan, Indiana and Ohio. The estimates remain economically and statistically significant at conventional levels in all specifications, showing that the effect of robots is not limited to CZs in the Rust Belt. Interestingly, outside of the Great Lakes' CZs the effect of robots is larger, suggesting that, although they are adopted less frequently in those areas, the introduction of one additional robot has a stronger effect on labor force participation than in the Rust Belt.

\footnotetext{
${ }^{54}$ Furthermore, I separate CZs into three terciles that account for employment specialization in the automotive industry (high, middle and low specialization) and interact them with my measure of robot exposure. Table A18 summarizes the results. I find that the labor market effect of robots is positive and significant in all terciles of the distribution. This finding complements my results which show that the effect of robots is not solely driven by CZs with a high employment specialization in this industry.
} 


\section{$8 \quad$ Conclusion}

This paper analyzes the impact of the introduction of industrial robots in firms' production processes on US labor force participation between the mid-1990s and 2014, and investigates the margins of adjustment of displaced workers. Exploiting plausibly exogenous variation in robot adoption across labor markets and over time, I show that for every 10 workers that have been displaced by automation, 6 individuals are leaving the labor force, suggesting an average decrease of the labor force of two workers for each additional robot. Despite their adverse labor market impact, there is no evidence that robots are affecting migration flows from heavily exposed CZs to less affected areas, or that labor force dropouts of men have been compensated by the labor force participation of a family member. Instead, I find that the decline in labor force participation is mainly caused by older workers who leave the labor force prematurely to retire early, as well as

an increase in disability take-up and more frequent early withdrawals of pension plan income by prime-age workers. The increasing disability take-up comes along with robots affecting negatively workers' self-reported health conditions and an increasing share of hospital admissions diagnosed with acute mental disorders.

This is a policy-relevant issue with profound implications, since, unlike economic recessions, this trend is likely to intensify in the future, making an increasing number of workers obsolete. Even though evidence suggests that automation is also contributing to the creation of thousands of new occupations, the newly created jobs can often not be performed by the workers that have been displaced by automation due to a skill mismatch. These workers are likely to leave the labor force permanently and search for alternative income sources, such as disability and early retirement benefits. Only young individuals are out of the labor force temporarily to enroll in post-secondary education institutions and acquire the necessary skills to increase their competitiveness in the labor market, a response to the automation shock that should be extended also to older generations of workers. 


\section{References}

Abraham, Katharine G and Melissa S Kearney, "Explaining the decline in the US employment-to-population ratio: A review of the evidence," Journal of Economic Literature, 2020, $58(3), 585-643$.

Acemoglu, Daron and David Autor, "Skills, tasks and technologies: Implications for employment and earnings," in "Handbook of labor economics," Vol. 4, Elsevier, 2011, pp. 1043-1171.

_ and Pascual Restrepo, "Artificial intelligence, automation and work," Technical Report, National Bureau of Economic Research 2018.

_ and _ , "Automation and new tasks: how technology displaces and reinstates labor," Journal of Economic Perspectives, 2019, 33 (2), 3-30.

_ and _ , "Robots and jobs: Evidence from US labor markets," Journal of Political Economy, 2020, 128 (6), 2188-2244.

_ , David Autor, David Dorn, Gordon H Hanson, and Brendan Price, "Import competition and the great US employment sag of the 2000s," Journal of Labor Economics, 2016, 34 (1), 141198.

Adda, Jérôme and Yarine Fawaz, "The health toll of import competition," The Economic Journal, 2020, 130 (630), 1501-1540.

Aguiar, Mark, Mark Bils, Kerwin Kofi Charles, and Erik Hurst, "Leisure luxuries and the labor supply of young men," Technical Report, National Bureau of Economic Research 2017.

Ahituv, Avner and Joseph Zeira, "Technical progress and early retirement," The Economic Journal, 2011, 121 (551), 171-193.

Altonji, Joseph G, Lisa B Kahn, and Jamin D Speer, "Cashier or consultant? Entry labor market conditions, field of study, and career success," Journal of Labor Economics, 2016, 34 (1), $361-401$.

Anelli, Massimo, Osea Giuntella, and Luca Stella, "Robots, Labor Markets, and Family Behavior," 2019.

Autor, David, "Work of the Past, Work of the Future," Technical Report, National Bureau of Economic Research 2019. 
_ and David Dorn, "The growth of low-skill service jobs and the polarization of the US labor market," American Economic Review, 2013, 103 (5), 1553-97.

_, _, and Gordon Hanson, "The China syndrome: Local labor market effects of import competition in the United States," American Economic Review, 2013, 103 (6), 2121-68.

Autor, David H and Mark G Duggan, "The rise in the disability rolls and the decline in unemployment," The Quarterly Journal of Economics, 2003, 118 (1), 157-206.

Bartel, Ann P and Nachum Sicherman, "Technological change and retirement decisions of older workers," Journal of Labor Economics, 1993, 11 (1), 162-183.

_ and _ , "Technological change and the skill acquisition of young workers," Journal of Labor Economics, 1998, 16 (4), 718-755.

Belloni, Alexandre, Victor Chernozhukov, Lie Wang et al., "Pivotal estimation via squareroot lasso in nonparametric regression," The Annals of Statistics, 2014, 42 (2), 757-788.

Black, Dan, Kermit Daniel, and Seth Sanders, "The impact of economic conditions on participation in disability programs: Evidence from the coal boom and bust," American Economic Review, 2002, 92 (1), 27-50.

Borusyak, Kirill, Peter Hull, and Xavier Jaravel, "Quasi-experimental shift-share research designs," Technical Report, National Bureau of Economic Research 2018.

Browning, Martin and Eskil Heinesen, "Effect of job loss due to plant closure on mortality and hospitalization," Journal of health economics, 2012, 31 (4), 599-616.

Brynjolfsson, Erik and Andrew McAfee, The second machine age: Work, progress, and prosperity in a time of brilliant technologies, WW Norton \& Company, 2014.

Burlon, Lorenzo and Montserrat Vilalta-Bufí, "A new look at technical progress and early retirement," IZA Journal of Labor Policy, 2016, 5 (1), 5.

Cadena, Brian C and Brian K Kovak, "Immigrants equilibrate local labor markets: Evidence from the Great Recession," American Economic Journal: Applied Economics, 2016, 8 (1), 257-90.

Card, David and Thomas Lemieux, "Dropout and enrollment trends in the postwar period: What went wrong in the 1970s?," in "Risky behavior among youths: An economic analysis," University of Chicago Press, 2001, pp. 439-482.

Case, Anne and Angus Deaton, "Rising morbidity and mortality in midlife among white non- 
Hispanic Americans in the 21st century," Proceedings of the National Academy of Sciences, 2015, 112 (49), 15078-15083.

_ and _, "Mortality and morbidity in the 21st century," Brookings papers on economic activity, 2017, 2017 (1), 397-476.

Centers for Disease Control and Prevention, "Prevalence and most common causes of disability among adults-United States, 2005," MMWR: Morbidity and Mortality weekly report, 2009, 58 (16), 421-426.

Dauth, Wolfgang, Sebastian Findeisen, Jens Suedekum, and Nicole Woessner, "The adjustment of labor markets to robots," Journal of the European Economic Association, 2019.

Deshpande, Manasi and Lee Lockwood, "Beyond Health: Non-Health Risk and the Value of Disability Insurance," 2020.

Di Giacomo, Giuseppe and Benjamin Lerch, "Automation and Human Capital Accumulation: The Effect of Robots on College Enrollment," mimeo, 2021.

Eliason, Marcus and Donald Storrie, "Does job loss shorten life?," Journal of Human Resources, 2009, 44 (2), 277-302.

Faber, Marius, Andres Sarto, and Marco Tabellini, "The Impact of Technology and Trade on Migration: Evidence from the US," Harvard Business School BGIE Unit Working Paper, 2019, (20-071).

Foote, Andrew and Michel Grosz, "The effect of local labor market downturns on postsecondary enrollment and program choice," Education Finance and Policy, 2020, 15 (4), 593-622.

Ford, Martin, Rise of the Robots: Technology and the Threat of a Jobless Future, Basic Books, 2015 .

Frank, Richard G, Sherry A Glied, Keith Marple, and Morgan Shields, "Changing Labor Markets and Mental Illness: Impacts on Work and Disability," 2019.

Frey, Carl Benedikt and Michael A Osborne, "The future of employment: How susceptible are jobs to computerisation?," Technological forecasting and social change, 2017, 114, 254-280.

Friedberg, Leora and Anthony Webb, "Retirement and the evolution of pension structure," Journal of Human Resources, 2005, 40 (2), 281-308.

Gihleb, Rania, Osea Giuntella, Luca Stella, and Tianyi Wang, "Industrial Robots, Workers' 
Safety, and Health," 2020.

Goldsmith-Pinkham, Paul, Isaac Sorkin, and Henry Swift, "Bartik instruments: What, when, why, and how," American Economic Review, 2020, 110 (8), 2586-2624.

Goos, Maarten, Alan Manning, and Anna Salomons, "Job polarization in Europe," American economic review, 2009, 99 (2), 58-63.

Graetz, Georg and Guy Michaels, "Robots at work," Review of Economics and Statistics, 2018, $100(5), 753-768$.

Greenland, Andrew and John Lopresti, "Import exposure and human capital adjustment: Evidence from the US," Journal of International economics, 2016, 100, 50-60.

Grigoli, Francesco, Zsoka Koczan, and Petia Topalova, "Automation and labor force participation in advanced economies: Macro and micro evidence," European Economic Review, 2020, 126, 103443.

Harris, E Clare and Brian Barraclough, "Suicide as an outcome for mental disorders. A metaanalysis," British journal of psychiatry, 1997, 170 (3), 205-228.

Hickman, Daniel C and William W Olney, "Globalization and investment in human capital," ILR Review, 2011, 64 (4), 654-672.

Hollingsworth, Alex, Christopher J Ruhm, and Kosali Simon, "Macroeconomic conditions and opioid abuse," Journal of health economics, 2017, 56, 222-233.

Howard, Greg, "The migration accelerator: Labor mobility, housing, and demand," American Economic Journal: Macroeconomics, 2020, 12 (4), 147-79.

IFR, "World Robotics 2018," Technical Report, International Federation of Robotics 2018.

Jägger, Kirsten, "EU KLEMS Growth and Productivity Accounts 2017 release," Description of Methodology and General Notes 2017.

Jaimovich, Nir, Itay Saporta-Eksten, Henry E Siu, and Yaniv Yedid-Levi, "The macroeconomics of automation: Data, theory, and policy analysis," Technical Report, National Bureau of Economic Research 2020.

Jones, Stephen RG, William Craig Riddell et al., Unemployment and Non-employment Heterogeneities in Labour Market States, Department of Economics, University of British Columbia, 2002. 
Juhn, Chinhui and Simon Potter, "Changes in labor force participation in the United States," Journal of Economic Perspectives, 2006, 20 (3), 27-46.

Kahn, Lisa B, "The long-term labor market consequences of graduating from college in a bad economy," Labour economics, 2010, 17 (2), 303-316.

Krueger, Alan B, "Where have all the workers gone? An inquiry into the decline of the US labor force participation rate," Brookings papers on economic activity, 2017, 2017 (2), 1.

Lang, Matthew, T Clay McManus, and Georg Schaur, "The effects of import competition on health in the local economy," Health economics, 2019, 28 (1), 44-56.

Lerch, Benjamin, "From Blue to Steel-Collar Jobs: The Decline in Employment Gaps?," mimeo, 2021.

Liebman, Jeffrey B, "Understanding the increase in disability insurance benefit receipt in the United States," Journal of Economic Perspectives, 2015, 29 (2), 123-50.

Lundberg, Shelly, "The added worker effect," Journal of Labor Economics, 1985, 3 (1, Part 1), $11-37$.

Maestas, Nicole, Kathleen J Mullen, and Alexander Strand, "Disability insurance and the great recession," American Economic Review, 2015, 105 (5), 177-82.

Mazzonna, Fabrizio and Franco Peracchi, "Ageing, cognitive abilities and retirement," European Economic Review, 2012, 56 (4), 691-710.

Miller, Douglas L, Marianne E Page, Ann Huff Stevens, and Mateusz Filipski, "Why are recessions good for your health?," American Economic Review, 2009, 99 (2), 122-27.

Molloy, Raven, Christopher L Smith, and Abigail Wozniak, "Internal migration in the United States," Journal of Economic perspectives, 2011, 25 (3), 173-96.

Oreopoulos, Philip, Till Von Wachter, and Andrew Heisz, "The short-and long-term career effects of graduating in a recession," American Economic Journal: Applied Economics, 2012, 4 (1), 1-29.

Parsons, Donald O, "The decline in male labor force participation," Journal of political Economy, 1980, $88(1), 117-134$.

_ , "Racial trends in male labor force participation," The American Economic Review, 1980, 70 (5), 911-920. 
Peracchi, Franco and Finis Welch, "Trends in labor force transitions of older men and women," Journal of Labor Economics, 1994, 12 (2), 210-242.

Pierce, Justin and Peter Schott, "Trade Liberalization and Mortality: Evidence from U.S. Counties," American Economic Review: Insights, forthcoming, 2018.

Poterba, James M, "Retirement security in an aging population," American Economic Review, 2014, $104(5), 1-30$.

Raut, Lakshmi K, "Exits from the Disability Insurance Rolls: Estimates from a Competing-Risks Model," Soc. Sec. Bull., 2017, 77, 15.

Ruggles, Steven, Sarah Flood, Ronald Goeken, Josiah Grover, Erin Meyer, Jose Pacas, and Matthew Sobek, "IPUMS USA: Version 9.0 [dataset]. Minneapolis, MN, https://doi.org/10.18128/D010.V9.0," Technical Report 2019.

Ruhm, Christopher J, "Are recessions good for your health?," The Quarterly journal of economics, 2000, 115 (2), 617-650.

_ , "Good times make you sick," Journal of health economics, 2003, 22 (4), 637-658.

Schaller, Jessamyn and Ann Huff Stevens, "Short-run effects of job loss on health conditions, health insurance, and health care utilization," Journal of health economics, 2015, 43, 190-203.

Sullivan, Daniel and Till Von Wachter, "Job displacement and mortality: An analysis using administrative data," The Quarterly Journal of Economics, 2009, 124 (3), 1265-1306.

Tolbert, Charles M and Molly Sizer, "US commuting zones and labor market areas: A 1990 update," Technical Report 1996.

WEF, "The future of jobs report," Technical Report, World Economic Forum Geneva 2018. 


\section{Figures}

Figure 1: US labor force non-participation and robots

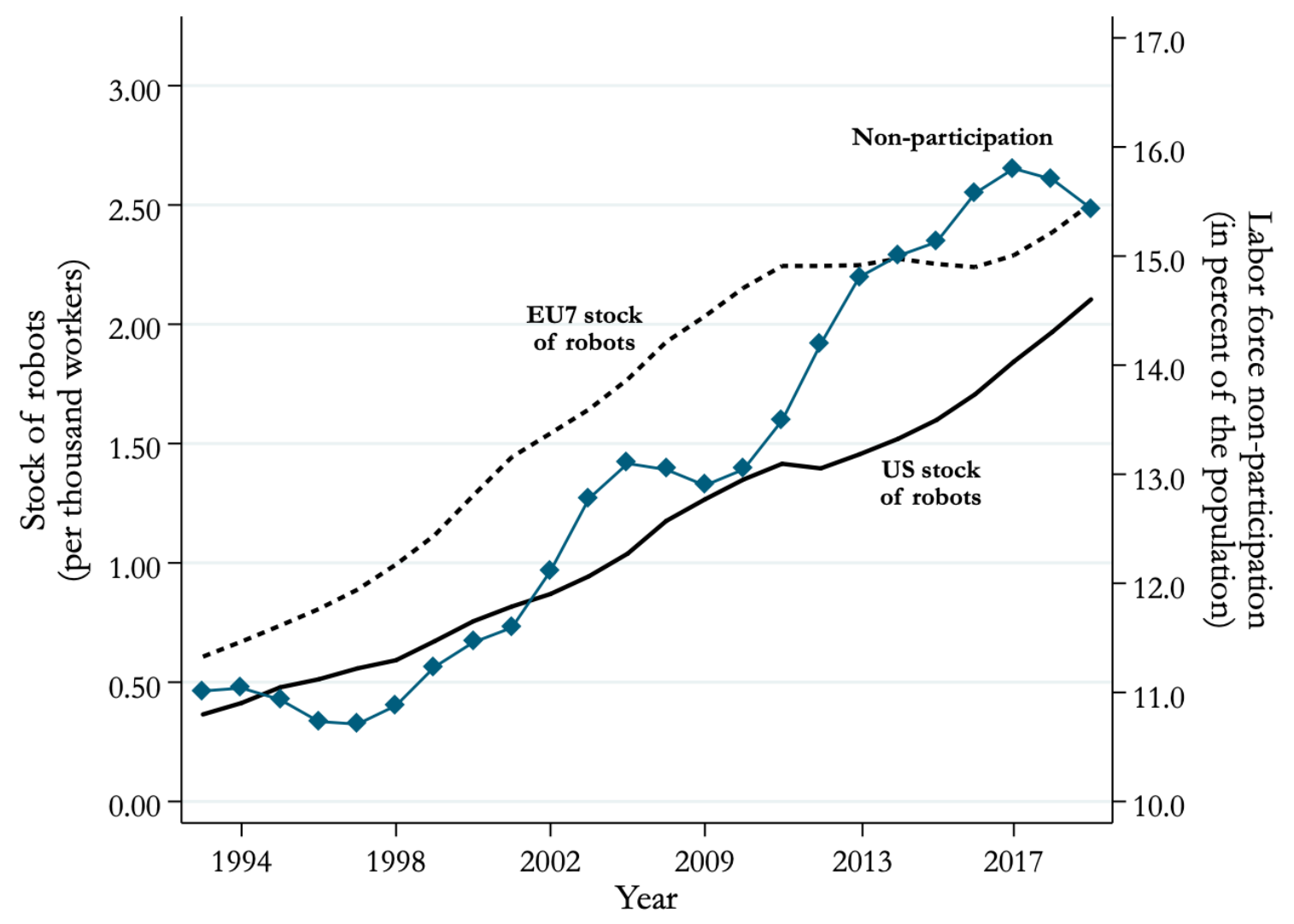

Note: This figure illustrates the US non-participation rate of white men between 25 and 64 years of age between 1993 and 2018 and the stock of industrial robots per thousand workers in the US and in seven European countries between 1993 and 2017.

The number of workers is kept constant at its 1993 level. Data on the monthly non-participation rate are used from the Current Population Survey. 
Figure 2: Industrial robots in the US and Europe

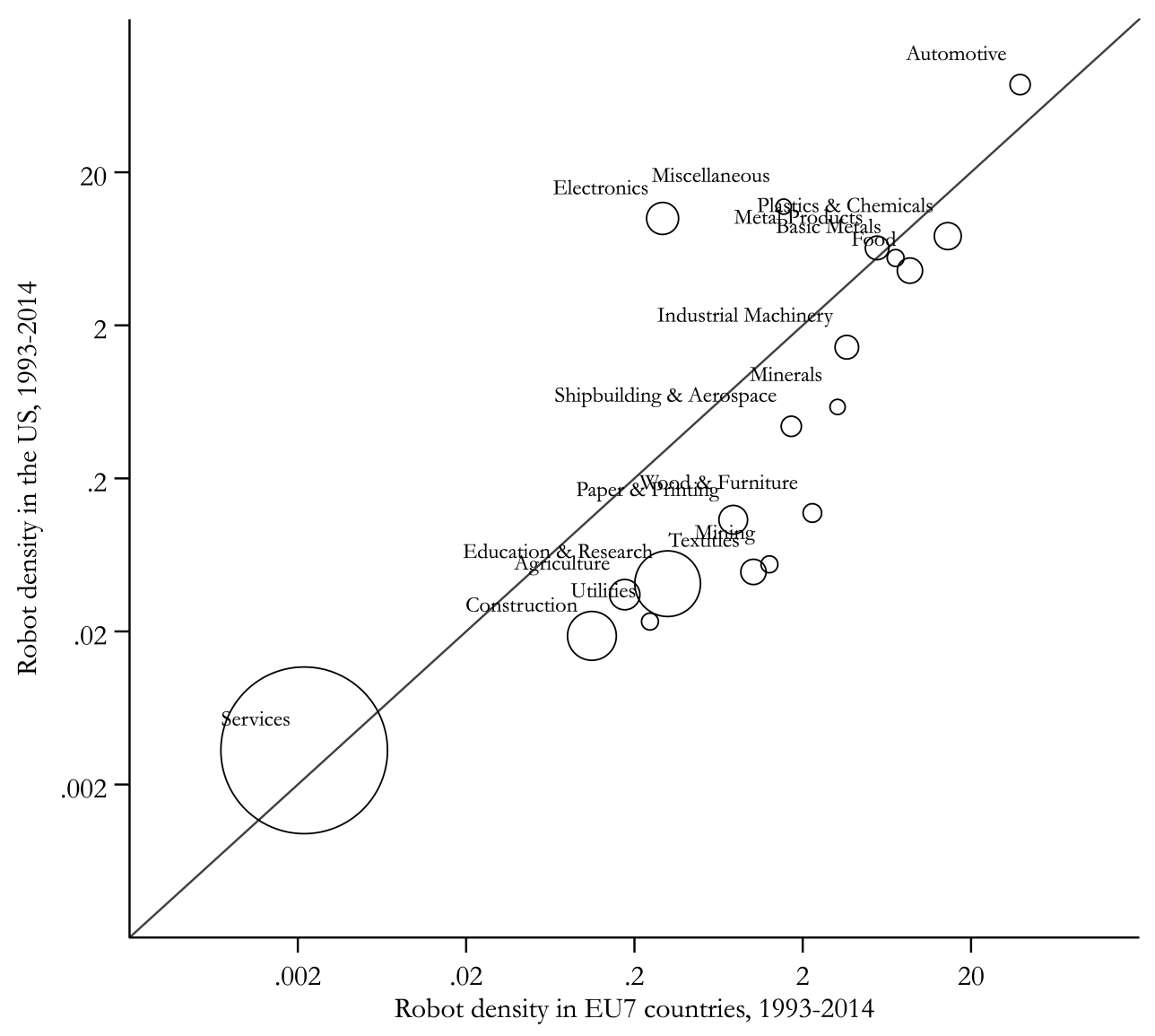

Note: This figure illustrates the unweighted correlation between changes in the stock of robots per thousand workers in the US and in Europe by IFR industries between 1993 and 2014 on a logarithmic scale. EU7 countries include Denmark, Finland, France, Italy, Spain, Sweden and the United Kingdom. The size of the circles represent the baseline US employment in the industry. The solid line corresponds to the $45^{\circ}$ line. This is a modified version of Figure 2 in Acemoglu and Restrepo (2020). 
Figure 3: US robot exposure at the commuting zone level

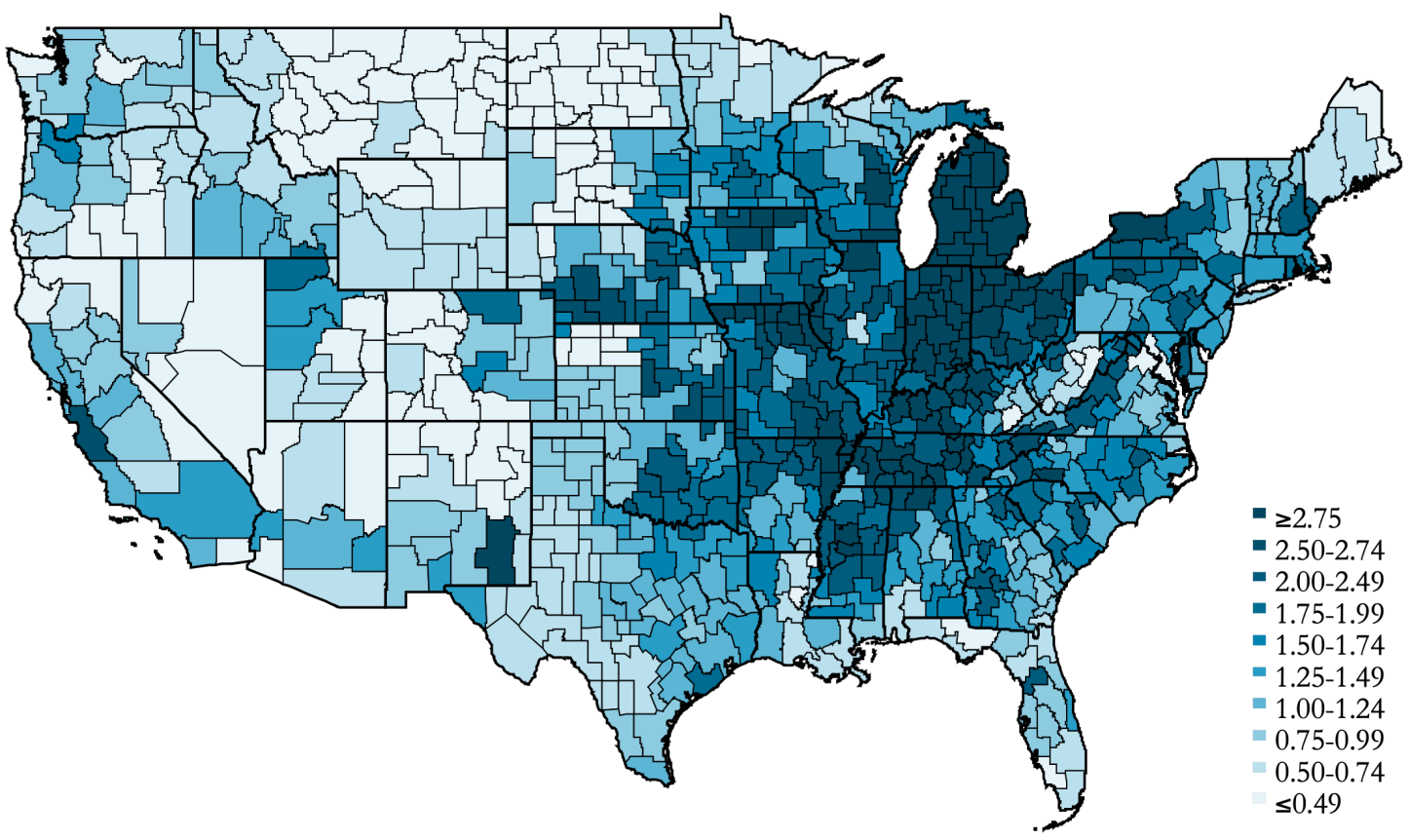

Note: This figure illustrates the geographic distribution of US robot exposure (in robots per thousand workers) at the commuting zone level between 1993 and 2014 . 
Figure 4: Effect of robots on employment and non-participation by age and education

Panel A: College degree or more

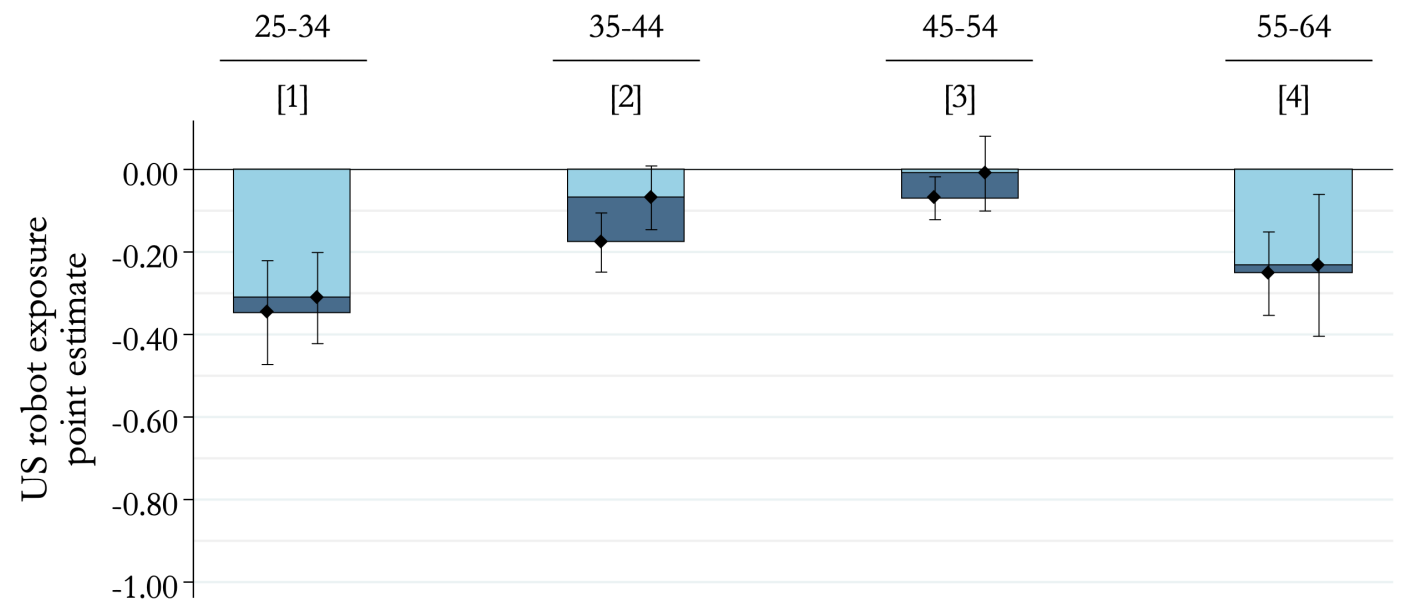

Panel B: Less than a college degree

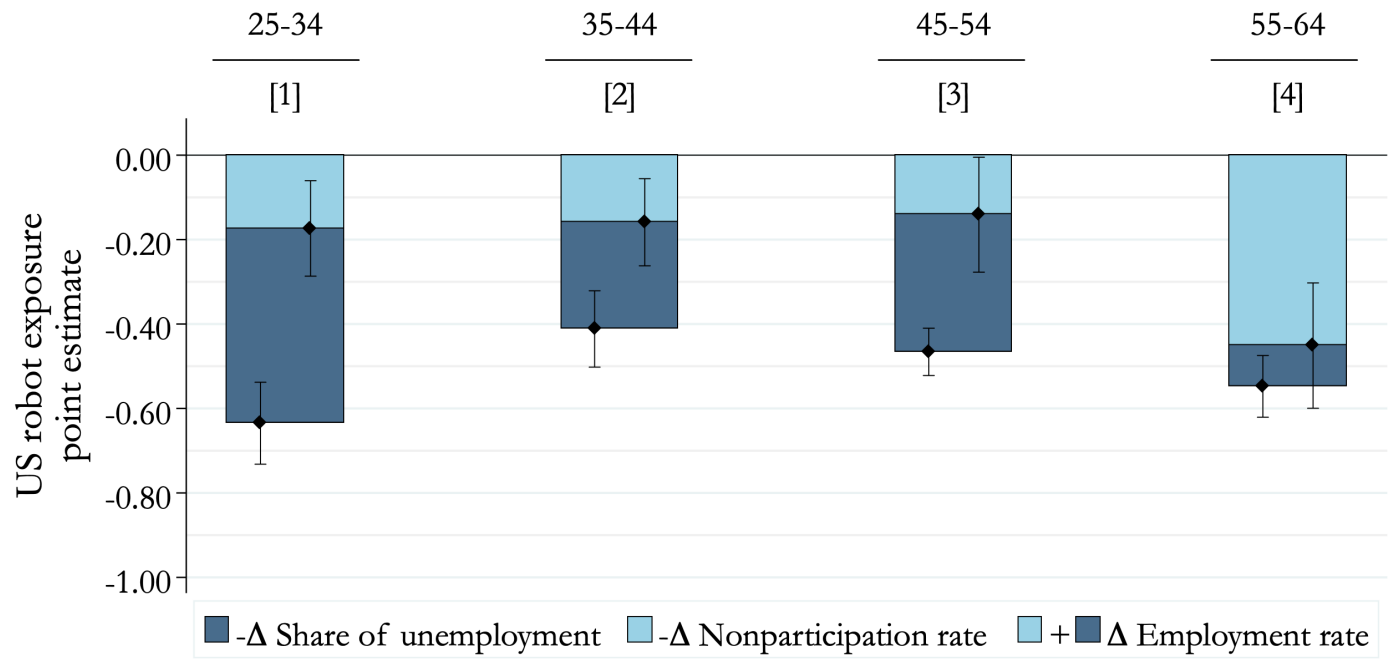

Note: This figure illustrates the point estimates of the effect of US robot exposure on the change in employment by age and education. Changes are expressed in percentage points of the population subgroup and are multiplied by 100 . Independent variables are standardized to have mean zero and standard deviation of one. There are three time periods and 722 CZs. In addition, the figure shows the fraction of the change in employment that flows into unemployment and non-participation. Analytically, $e_{i, t}=E_{i, t} / L_{i, t}, u_{i, t}=U_{i, t} / L_{i, t}$ and $n_{i, t}=N_{i, t} / L_{i, t}$, where $E_{i, t}$ is the number of employed, $U_{i, t}$ is the number of unemployed, $N_{i, t}$ is the number of non-participating individuals and $L_{i, t}=E_{i, t}+U_{i, t}+N_{i, t}$ is the number of individuals in ageeducation group $i$ at time $t$. By definition, $\Delta e_{i, t}=\left(-\Delta u_{i, t}\right)+\left(-\Delta n_{i, t}\right)$. Estimates for the share of unemployment are obtained by substracting the estimates on non-participation from the estimates on employment multiplied by $-1, \Delta u_{i, t}=-\Delta e_{i, t}-\Delta n_{i, t}$. Note that in this case $-\Delta e_{i, t}>0$. Panel A (Panel B) reports the point estimates of the effect of US robots robot exposure on the change in labor market outcomes among college-educated (less educated) individuals. Each Column reports the point estimates for a different age group. Standard errors are robust against heteroskedasticity and allow for clustering at the state level. Confidence intervals of the effects on unemployment (left CI) and non-participation (right CI) are at the $95 \%$ level. Regressions include covariates of my preferred specification and are weighted by CZ population in 1990. 
Figure 5: Robots, non-participation and the labor force participation of the partner

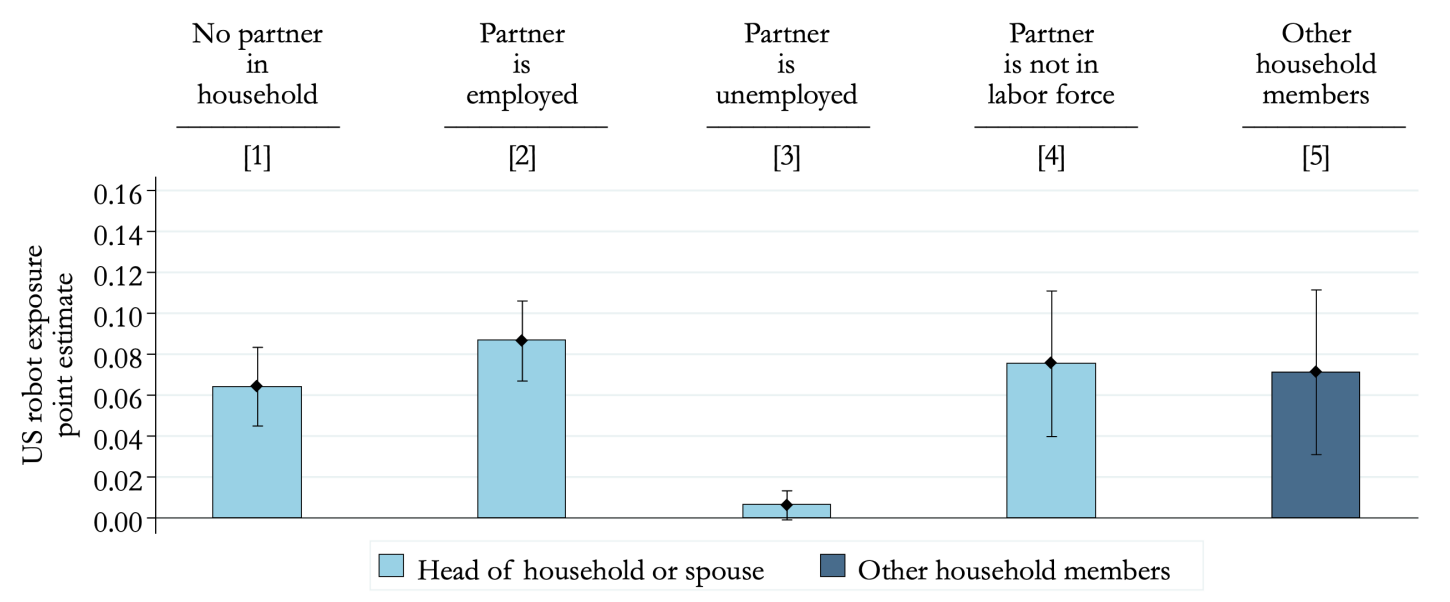

Note: This figure illustrates estimates of the effect of US robot exposure on the change in the non-participation rate by household members and employment status of the partner. Changes are expressed in percentage points of the working-age population and are multiplied by 100. Independent variables are standardized to have mean zero and standard deviation of one. There are three time periods and $722 \mathrm{CZs}$. Columns 1 to 4 report the shares of non-participants that are the household head or the spouse of the head. Column 1 includes individuals without a partner in the same household. Column 2 includes individuals with a partner that is employed. Column 3 includes individuals with a partner that is unemployed. Column 4 includes individuals with a partner that is not participating in the labor force. Column 5 includes other members of the household (children, parents, siblings or non-relatives) that live in the same household. Standard errors are robust against heteroskedasticity and allow for clustering at the state level. Confidence intervals are at the $95 \%$ level. Regressions include covariates of my preferred specification and are weighted by CZ population in 1990. 
Figure 6: Robots, non-participation and school enrollment

Panel A: College degree or more

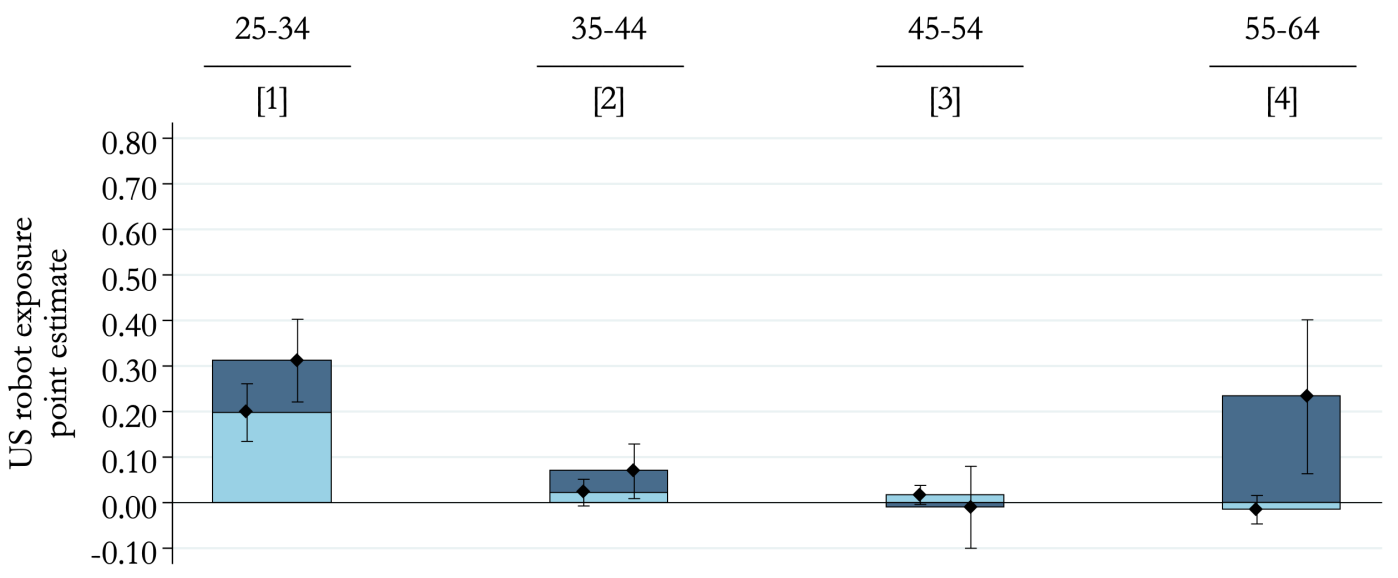

Panel B: Less than a college degree

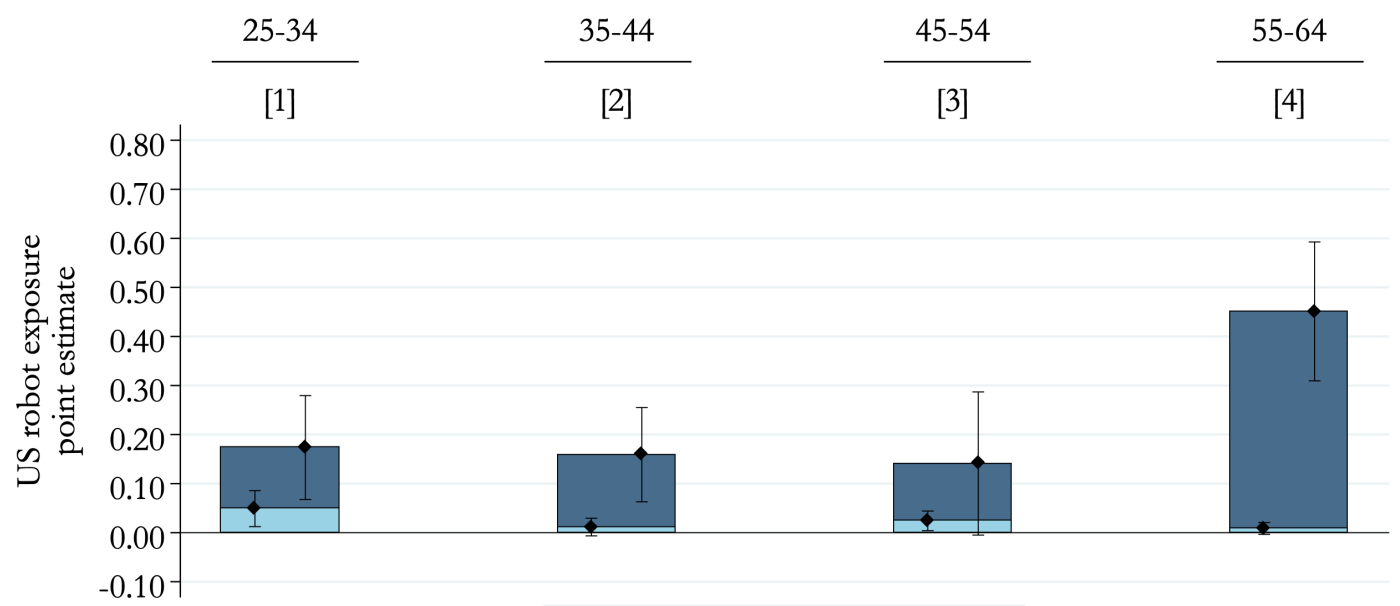

Not in school $\square$ In school

Note: This figure illustrates the point estimates of the effect of US robot exposure on the change in the non-participation rate by age and education. Changes are expressed in percentage points of the population subgroup and are multiplied by 100 . Independent variables are standardized to have mean zero and standard deviation of one. There are three time periods and 722 CZs. The figure further illustrates the fraction of the change in non-participants by school enrollment. Less than a college degree and in school include students enrolled in high school, individuals doing the GED test or students enrolled in undergraduate college, while not in school include high school dropouts, undergraduate college dropouts and high school graduates that are not enrolled in school. College degree or more and in school include individuals enrolled in graduate or professional schools, while not in school include college graduates that are not enrolled in school. Standard errors are robust against heteroskedasticity and allow for clustering at the state level. Confidence intervals of the effects on non-participants that are in school (left CI) and are not in school (right CI) are at the $95 \%$ level. Regressions include covariates of my preferred specification and are weighted by $\mathrm{CZ}$ population in 1990 
Figure 7: Robots, non-participation, and Social Security and pension plan income by age and education

Panel A: College degree or more

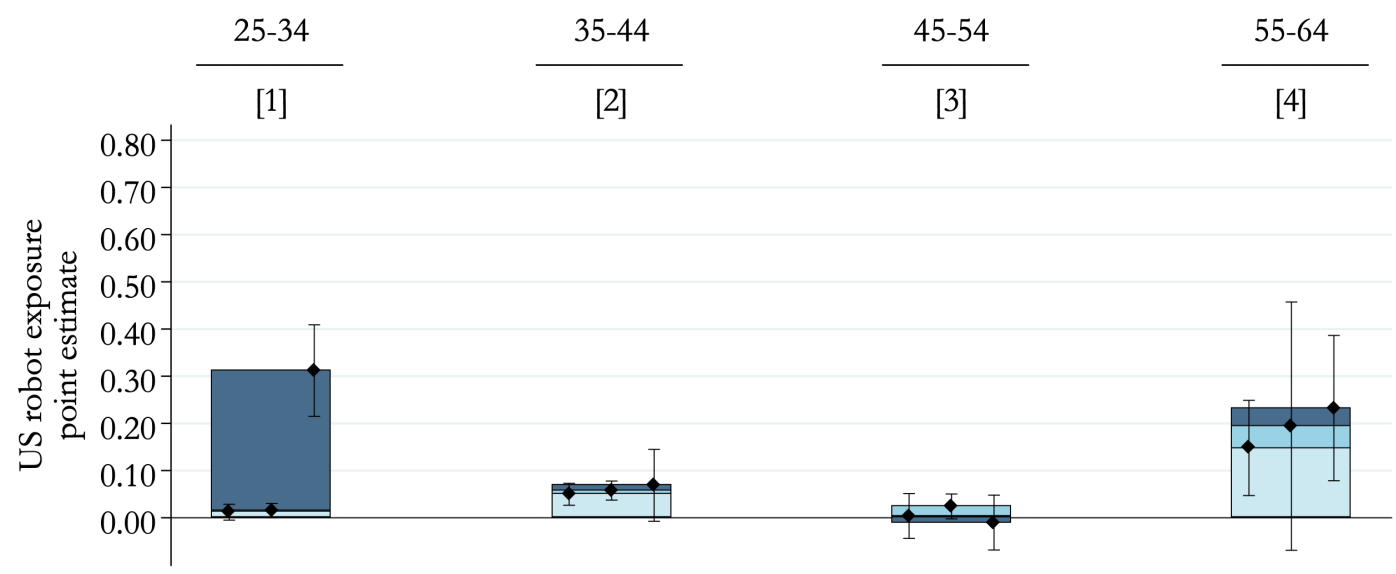

Panel B: Less than a college degree

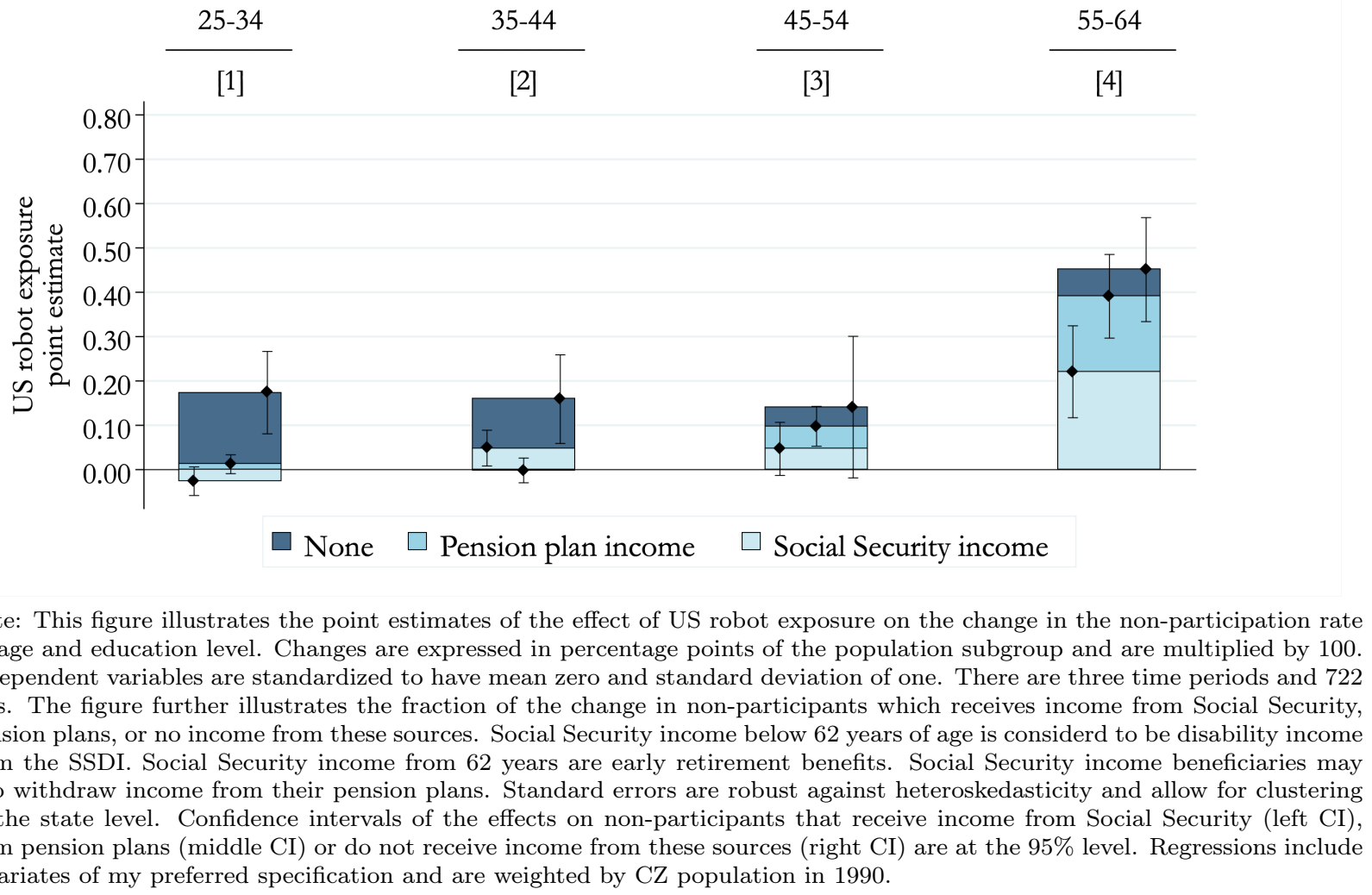


Figure 8: Robots, non-participation of older workers, and Social Security and pension plan income by age and education

Panel A: College degree or more

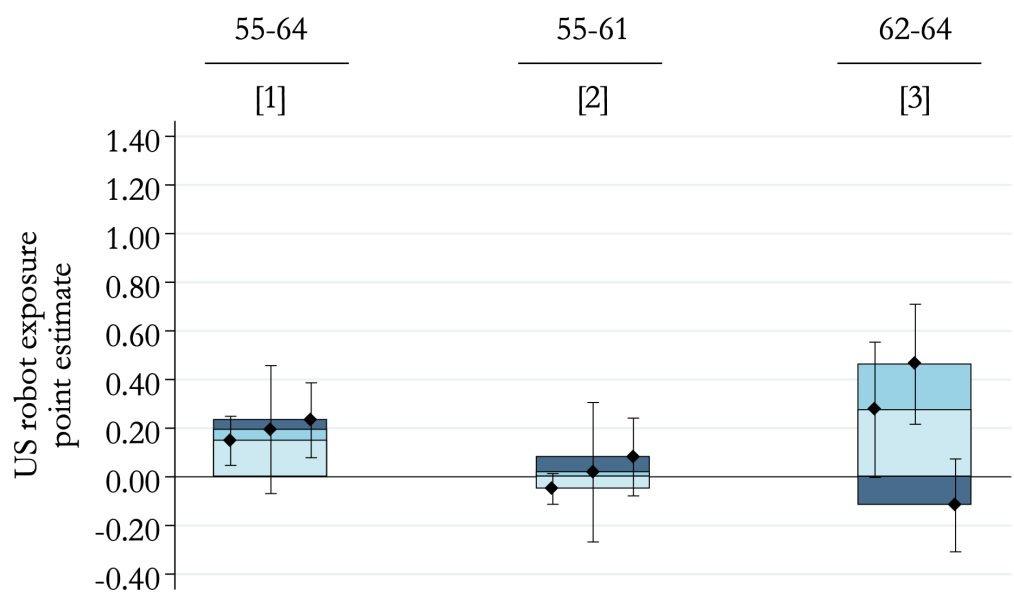

Panel B: Less than a college degree

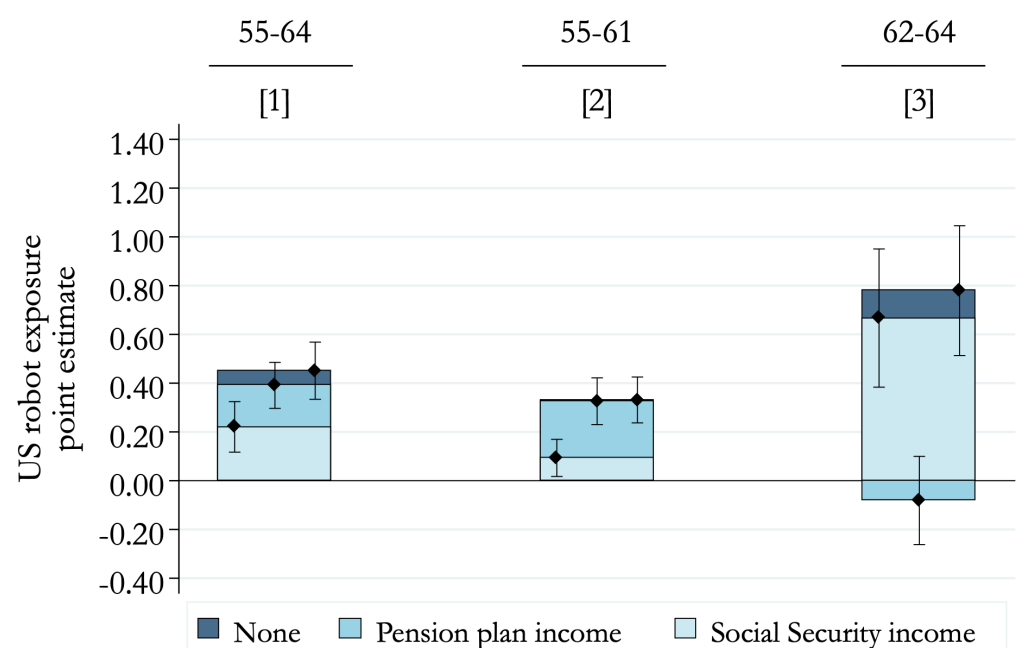

Note: This figure illustrates the point estimates of the effect of US robot exposure on the change in the non-participation rate by age and education level. Changes are expressed in percentage points of the population subgroup and are multiplied by 100 . Independent variables are standardized to have mean zero and standard deviation of one. There are three time periods and 722 CZs. The figure further illustrates the fraction of the change in non-participants which receives income from Social Security, pension plans, or no income from these sources. Social Security income below 62 years of age is considerd to be disability income from the SSDI. Social Security income from 62 years are early retirement benefits. Social Security income beneficiaries may also withdraw income from their pension plans. Standard errors are robust against heteroskedasticity and allow for clustering at the state level. Confidence intervals of the effects on non-participants that receive income from Social Security (left CI), from pension plans (middle CI) or do not receive income from these sources (right CI) are at the $95 \%$ level. Regressions include covariates of my preferred specification and are weighted by CZ population in 1990. 
Figure 9: Robot exposure by industry exclusion

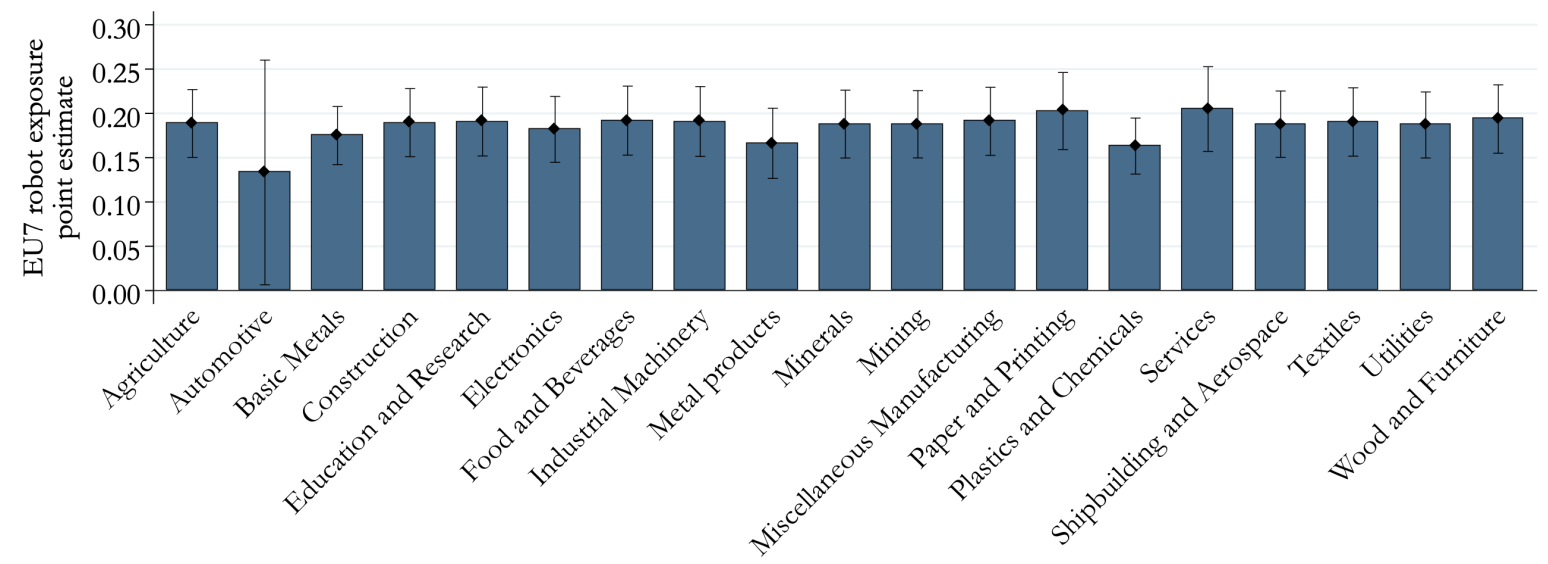

Note: This figure illustrates the reduced form point estimates of the effect of robot exposure on the change in the nonparticipation rate by excluding each industry from the shift-share measure one at a time. For example, Automotive excludes robots adopted in the automotive industry. Changes are expressed in percentage points of the population and are multiplied by 100. Independent variables are standardized to have mean zero and standard deviation of one. There are three time periods and $722 \mathrm{CZs}$. Standard errors are robust against heteroskedasticity and allow for clustering at the state level. Confidence intervals are at the $95 \%$ level. Regressions include covariates of my preferred specification and are weighted by CZ population in 1990 . 


\section{Tables}

Table 1: Descriptive statistics: Main variables

\begin{tabular}{|c|c|c|c|c|c|}
\hline & \multirow[b]{2}{*}{ All } & \multicolumn{4}{|c|}{$\begin{array}{c}\text { US robot exposure } \\
1993-2014\end{array}$} \\
\hline & & Q1 & Q2 & Q3 & Q4 \\
\hline & {$[1]$} & {$[2]$} & {$[3]$} & {$[4]$} & {$[5]$} \\
\hline \multicolumn{6}{|c|}{ Panel A: Labor force non-participation rate } \\
\hline 1990 & 10.2 & 11.8 & 10.9 & 9.12 & 10.5 \\
\hline$\Delta_{2014-1990}$ & 4.82 & 4.60 & 4.48 & 4.73 & 5.40 \\
\hline 1970 & 7.41 & 9.28 & 8.12 & 6.83 & 6.83 \\
\hline$\Delta_{1990-1970}$ & 2.82 & 2.51 & 2.78 & 2.28 & 3.76 \\
\hline \multicolumn{6}{|c|}{ Panel B: Robot and trade shock } \\
\hline US robot exposure & 1.90 & 0.52 & 0.94 & 1.53 & 3.99 \\
\hline EU7 robot exposure & 1.98 & 0.79 & 1.26 & 1.70 & 3.63 \\
\hline US import exposure & 5.22 & 2.25 & 3.48 & 6.15 & 6.83 \\
\hline OT8 import exposure & 3.68 & 1.65 & 2.57 & 4.28 & 4.75 \\
\hline \multicolumn{6}{|c|}{ Panel C: Labor market covariates } \\
\hline \multicolumn{6}{|l|}{ Demographics } \\
\hline 25-34 years & 33.6 & 32.8 & 33.7 & 34.4 & 32.7 \\
\hline $35-44$ years & 29.4 & 29.8 & 29.6 & 29.3 & 29.2 \\
\hline $45-54$ years & 20.0 & 20.2 & 19.8 & 19.9 & 20.4 \\
\hline Black & 10.1 & 10.8 & 10.3 & 10.8 & 8.61 \\
\hline Hispanic & 6.37 & 10.1 & 8.41 & 6.99 & 1.86 \\
\hline Women & 51.1 & 51.0 & 51.1 & 51.0 & 51.3 \\
\hline Less than college & 77.5 & 77.4 & 76.6 & 75.9 & 80.7 \\
\hline Log population & 13.2 & 12.4 & 13.2 & 13.6 & 12.7 \\
\hline \multicolumn{6}{|l|}{ Industries } \\
\hline Construction & 6.18 & 7.59 & 6.86 & 5.93 & 5.28 \\
\hline Manufacturing & 24.9 & 13.1 & 19.4 & 26.7 & 32.8 \\
\hline Mining & 1.03 & 3.25 & 1.34 & 0.57 & 0.55 \\
\hline Research & 1.91 & 1.84 & 1.86 & 2.04 & 1.79 \\
\hline Services & 62.5 & 69.0 & 66.6 & 61.8 & 56.5 \\
\hline Utilities & 1.51 & 1.81 & 1.62 & 1.39 & 1.45 \\
\hline \multicolumn{6}{|l|}{ Occupations } \\
\hline Offshorable & 36.9 & 36.4 & 37.2 & 37.5 & 35.9 \\
\hline Routine & 34.9 & 32.5 & 34.5 & 35.5 & 35.5 \\
\hline Replaceable by robots & 9.60 & 6.16 & 7.33 & 9.71 & 13.2 \\
\hline Observations & 722 & 181 & 180 & 181 & 180 \\
\hline
\end{tabular}

Note: This table presents averages of the main outcome and a set of covariates mostly weighted by CZ population. Panel A reports the non-participation rate in 1990 and in 1970 and the change in the non-participation rate between 1990 and 2014 and between 1970 and 1990 among 25 to 64 year old white males. Panel B reports the unweighted average of US and EU7 robot exposure and import exposure from China in the US and other industrialized countries between 1993 and 2014 . Panel $\mathrm{C}$ reports a set of covariates that represent the structure of CZs by population and employment in 1990. The covariates are divided in three groups. Demographics include variables about age, race, women and education, all expressed in shares of the $\mathrm{CZ}$ population, and the log population of the CZ. Industries include the average industry employment shares across CZs. Occupations include the average share of occupations that are offshorable, routine task-intensive and repleaceable. Column 1 reports averages over all $722 \mathrm{CZs}$ in the sample. Columns 2 to 5 split the sample into four quartiles, accounting for a labor market's exposure to robots between 1993 and 2014. 
Table 2: Effect of robots on employment and non-participation

\begin{tabular}{|c|c|c|c|c|c|}
\hline & {$[1]$} & {$[2]$} & {$[3]$} & {$[4]$} & {$[5]$} \\
\hline \multicolumn{6}{|l|}{ Panel A: Employment } \\
\hline US robot exposure & $\begin{array}{c}-0.439^{* * *} \\
(0.074)\end{array}$ & $\begin{array}{c}-0.463^{* * *} \\
(0.081)\end{array}$ & $\begin{array}{c}-0.461^{* * *} \\
(0.073)\end{array}$ & $\begin{array}{c}-0.461^{* * *} \\
(0.047)\end{array}$ & $\begin{array}{c}-0.734^{* * *} \\
(0.154)\end{array}$ \\
\hline Observations & 2166 & 2166 & 2166 & 2166 & 2166 \\
\hline \multicolumn{6}{|c|}{ Panel B: Manufacturing employment } \\
\hline US robot exposure & $\begin{array}{c}-0.439^{* * *} \\
(0.151)\end{array}$ & $\begin{array}{c}-0.392^{* * *} \\
(0.124)\end{array}$ & $\begin{array}{c}-0.387^{* * *} \\
(0.104)\end{array}$ & $\begin{array}{c}-0.255^{* * *} \\
(0.066)\end{array}$ & $\begin{array}{c}-0.497^{* * *} \\
(0.155)\end{array}$ \\
\hline Observations & 2166 & 2166 & 2166 & 2166 & 2166 \\
\hline \multicolumn{6}{|c|}{ Panel C: Non-participation } \\
\hline US robot exposure & $\begin{array}{c}0.256^{* * *} \\
(0.059)\end{array}$ & $\begin{array}{c}0.279^{* * *} \\
(0.067)\end{array}$ & $\begin{array}{c}0.277^{* * *} \\
(0.060)\end{array}$ & $\begin{array}{c}0.257^{* * *} \\
(0.035)\end{array}$ & $\begin{array}{c}0.361^{* * *} \\
(0.121)\end{array}$ \\
\hline Observations & 2166 & 2166 & 2166 & 2166 & 2166 \\
\hline \multicolumn{6}{|l|}{ Panel D: First-stage } \\
\hline EU7 robot exposure & $\begin{array}{c}0.772^{* * *} \\
(0.052)\end{array}$ & $\begin{array}{c}0.793^{* * *} \\
(0.040)\end{array}$ & $\begin{array}{c}0.789^{* * *} \\
(0.051)\end{array}$ & $\begin{array}{c}0.740^{* * *} \\
(0.044)\end{array}$ & $\begin{array}{c}0.580^{* * *} \\
(0.059)\end{array}$ \\
\hline Kleibergen-Paap F stat & 221.7 & 385.7 & 134.2 & 142.7 & 48.6 \\
\hline Observations & 2166 & 2166 & 2166 & 2166 & 2166 \\
\hline \multicolumn{6}{|l|}{ Covariates: } \\
\hline Divisions & $\checkmark$ & $\checkmark$ & $\checkmark$ & $\checkmark$ & $\checkmark$ \\
\hline Years & $\checkmark$ & $\checkmark$ & $\checkmark$ & $\checkmark$ & $\checkmark$ \\
\hline Pre-trends & & $\checkmark$ & $\checkmark$ & $\checkmark$ & $\checkmark$ \\
\hline Chinese imports & & & $\checkmark$ & $\checkmark$ & $\checkmark$ \\
\hline Demographics & & & & $\checkmark$ & $\checkmark$ \\
\hline Industries & & & & $\checkmark$ & $\checkmark$ \\
\hline Occupations & & & & $\checkmark$ & $\checkmark$ \\
\hline Unweighted & & & & & $\checkmark$ \\
\hline
\end{tabular}

Note: This table presents IV estimates of the effect of US robot exposure on the change in the share of employment (Panel A), manufacturing employment (Panel B) and non-participation (Panel C) at the CZ level. Changes are expressed in percentage points of the working-age population and are multiplied by 100. Panel D presents first-stage results. Independent variables are standardized to have mean zero and standard deviation of one. There are three time periods and 722 CZs. Column 1 includes year dummies, nine census divisions and their interactions. Column 2 includes also changes in the non-participation rate and in the manufacturing employment rate between 1970 and 1990. Column 3 includes also exposure to Chinese imports. Columns 4 and 5 control also for demographic (share of individuals aged between 25 and 34 years, 35 and 44 years, 45 and 54 years, the share of Blacks, Hispanics, women and individuals with less than a college degree and logarithmic population), industry (shares of employment in the contruction, manufacturing, mining, research, service and utilities sector) and occupation (share of offshorable occupations, routine task-intensive occupations and occupations replaceable by robots) characteristics of $\mathrm{CZ}$ in 1990. Standard errors are robust against heteroskedasticity and allow for clustering at the state level. Regressions are weighted by CZ population in 1990 in Columns 1 to 4 and are unweighted in Column 5. Coefficients with ***, ${ }^{* *}$ and ${ }^{*}$ are significant at the $1 \%, 5 \%$ and $10 \%$ confidence level. 
Table 3: Robots and non-participation: Breakdown by age and education

\begin{tabular}{|c|c|c|c|c|c|}
\hline & $25-64$ & $25-34$ & $35-44$ & $45-54$ & $55-64$ \\
\hline & {$[1]$} & {$[2]$} & {$[3]$} & {$[4]$} & {$[5]$} \\
\hline \multicolumn{6}{|c|}{ Panel A: College degree or more } \\
\hline US robot exposure & $\begin{array}{c}0.040^{* * *} \\
(0.009)\end{array}$ & $\begin{array}{c}0.016^{* *} \\
(0.006)\end{array}$ & $\begin{array}{c}0.006^{* *} \\
(0.002)\end{array}$ & $\begin{array}{c}0.001 \\
(0.004)\end{array}$ & $\begin{array}{c}0.017 \\
(0.012)\end{array}$ \\
\hline$\%$ of total effect & 15.62 & 6.25 & 2.34 & 0.39 & 6.64 \\
\hline Observations & 2166 & 2166 & 2166 & 2166 & 2166 \\
\hline \multicolumn{6}{|c|}{ Panel B: Less than a college degree } \\
\hline US robot exposure & $\begin{array}{c}0.217^{* * *} \\
(0.032)\end{array}$ & $\begin{array}{c}0.015 \\
(0.012)\end{array}$ & $\begin{array}{c}0.030^{* *} \\
(0.012)\end{array}$ & $\begin{array}{c}0.043^{* * *} \\
(0.015)\end{array}$ & $\begin{array}{c}0.128^{* * *} \\
(0.012)\end{array}$ \\
\hline$\%$ of total effect & 84.38 & 5.86 & 11.72 & 16.80 & 50.00 \\
\hline Observations & 2166 & 2166 & 2166 & 2166 & 2166 \\
\hline Covariates: & $\checkmark$ & $\checkmark$ & $\checkmark$ & $\checkmark$ & $\checkmark$ \\
\hline
\end{tabular}

Note: This table presents IV estimates of the effect of robot exposure on the change in the share of non-participation at the CZ level. Changes are expressed in percentage points of the working-age population and are multiplied by 100 . Independent variables are standardized to have mean zero and standard deviation of one. There are three time periods and 722 CZs. Every regression includes year dummies, nine census divisions and their interactions, changes in the non-participation rate and the manufacturing employment rate between 1970 and 1990, exposure to Chinese imports and demographic (share of individuals aged between 25 and 34 years, 35 and 44 years, 45 and 54 years, the share of Blacks, Hispanics, women and individuals with less than a college degree and logarithmic population), industry (shares of employment in the contruction, manufacturing, mining, research, service and utilities sector) and occupation (share of offshorable occupations, routine task-intensive occupations and occupations replaceable by robots) characteristics of CZ in 1990. Standard errors are robust against heteroskedasticity and allow for clustering at the state level. Regressions are weighted by CZ population in 1990 . Coefficients with ${ }^{* * *},{ }^{* *}$ and ${ }^{*}$ are significant at the 1\%,5\% and 10\% confidence level. Percentages of the total effect of robot exposure on non-participation are calculated by dividing the estimates of the effect by subgroup by the estimates of the effect on the working-age population from my preferred specification in Table $2(0.257)$. 
Table 4: Robots and migration across CZs

\begin{tabular}{lccccc}
\hline & {$[1]$} & {$[2]$} & {$[3]$} & {$[4]$} & {$[5]$} \\
\hline Panel A: Outflows & & & & & \\
US robot exposure & 0.099 & 0.146 & 0.142 & 0.045 & 1.426 \\
& $(0.094)$ & $(0.104)$ & $(0.093)$ & $(0.159)$ & $(1.031)$ \\
Observations & 2166 & 2166 & 2166 & 2166 & 2166 \\
& & & & & \\
Panel B: Inflows & & & & & \\
US robot exposure & $-0.187^{* * *}$ & $-0.187^{* *}$ & $-0.190^{* *}$ & $-0.283^{* *}$ & -0.510 \\
& $(0.062)$ & $(0.076)$ & $(0.080)$ & $(0.109)$ & $(0.315)$ \\
Observations & 2166 & 2166 & 2166 & 2166 & 2166 \\
\hline Covariates: & & & & & \\
Divisions & $\checkmark$ & $\checkmark$ & $\checkmark$ & $\checkmark$ & $\checkmark$ \\
Years & $\checkmark$ & $\checkmark$ & $\checkmark$ & $\checkmark$ & $\checkmark$ \\
Pre-trends & & $\checkmark$ & $\checkmark$ & $\checkmark$ & $\checkmark$ \\
Chinese imports & & & $\checkmark$ & $\checkmark$ & $\checkmark$ \\
Demographics & & & & $\checkmark$ & $\checkmark$ \\
Industries & & & & $\checkmark$ & $\checkmark$ \\
Occupations & & & & & $\checkmark$ \\
Unweighted & & & & & $\checkmark$ \\
\hline
\end{tabular}

Note: This table presents IV estimates of the effect of US robot exposure on migration in- and outflows at the CZ level using data from the IPUMS. Changes are expressed in percentage points of the population and are multiplied by 100 . Independent variables are standardized to have mean zero and standard deviation of one. There are three time periods and $722 \mathrm{CZs}$. Column 1 includes year dummies, nine census divisions and their interactions. Column 2 includes also changes in the non-participation rate and in the manufacturing employment rate between 1970 and 1990. Column 3 includes also exposure to Chinese imports. Columns 4 and 5 control also for demographic (share of individuals aged between 25 and 34 years, 35 and 44 years, 45 and 54 years, the share of Blacks, Hispanics, women and individuals with less than a college degree and logarithmic population), industry (shares of employment in the contruction, manufacturing, mining, research, service and utilities sector) and occupation (share of offshorable occupations, routine task-intensive occupations and occupations replaceable by robots) characteristics of $\mathrm{CZ}$ in 1990. Standard errors are robust against heteroskedasticity and allow for clustering at the state level. Regressions are weighted by $\mathrm{CZ}$ population in 1990 in Columns 1 to 4 and are unweighted in Column 5 . Coefficients with ${ }^{* * *},{ }^{* *}$ and ${ }^{*}$ are significant at the $1 \%, 5 \%$ and $10 \%$ confidence level. 
Table 5: Robots, health and access to healthcare services

\begin{tabular}{|c|c|c|c|c|c|c|c|c|c|c|c|}
\hline & \multicolumn{3}{|c|}{$\begin{array}{l}\text { Self-reported } \\
\text { health }\end{array}$} & \multicolumn{2}{|c|}{$\begin{array}{c}\text { Smoking and } \\
\text { drinking habits }\end{array}$} & \multicolumn{2}{|c|}{$\begin{array}{l}\text { Physical shape } \\
\text { and activity }\end{array}$} & \multicolumn{4}{|c|}{$\begin{array}{c}\text { Access to healthcare } \\
\text { services }\end{array}$} \\
\hline & $\begin{array}{l}\text { No good } \\
\text { health }\end{array}$ & $\begin{array}{l}\text { Physical } \\
\text { problems } \\
\end{array}$ & $\begin{array}{c}\text { Mental } \\
\text { problems }\end{array}$ & Smoke & Drink & Obese & $\begin{array}{l}\text { Regular } \\
\text { exercise }\end{array}$ & $\begin{array}{c}\text { Health } \\
\text { coverage }\end{array}$ & $\begin{array}{l}\text { Checkup } \\
\text { last } 12 \\
\end{array}$ & $\begin{array}{c}\text { Checkup } \\
\text { too costly }\end{array}$ & $\begin{array}{l}\text { Checkup } \\
\text { more } 24\end{array}$ \\
\hline & [1] & {$[2]$} & {$[3]$} & {$[4]$} & {$[5]$} & {$[6]$} & {$[7]$} & {$[8]$} & {$[9]$} & {$[10]$} & [11] \\
\hline \multicolumn{12}{|l|}{ Panel A: Employed } \\
\hline US robot exposure & $\begin{array}{l}-0.093 \\
(0.074)\end{array}$ & $\begin{array}{l}-0.189^{*} \\
(0.108)\end{array}$ & $\begin{array}{l}-0.008 \\
(0.119)\end{array}$ & $\begin{array}{l}-0.398 \\
(0.253)\end{array}$ & $\begin{array}{c}0.196^{* * *} \\
(0.065)\end{array}$ & $\begin{array}{l}-0.001 \\
(0.263)\end{array}$ & $\begin{array}{c}-2.014^{* * *} \\
(0.698)\end{array}$ & $\begin{array}{l}0.268 \\
(0.230)\end{array}$ & $\begin{array}{l}2.372^{* *} \\
(0.902)\end{array}$ & $\begin{array}{l}0.080 \\
(0.064)\end{array}$ & $\begin{array}{l}0.481^{* *} \\
(0.210)\end{array}$ \\
\hline Observations & 1274 & 1274 & 1274 & 1274 & 1274 & 1274 & 1274 & 1274 & 1274 & 1274 & 1274 \\
\hline \multicolumn{12}{|c|}{ Panel B: Non-employed } \\
\hline US robot exposure & $\begin{array}{l}1.009^{* *} \\
(0.416)\end{array}$ & $\begin{array}{c}1.078^{* * *} \\
(0.239)\end{array}$ & $\begin{array}{c}0.409 \\
(0.267)\end{array}$ & $\begin{array}{c}0.863 \\
(0.731)\end{array}$ & $\begin{array}{c}0.271^{* * *} \\
(0.066)\end{array}$ & $\begin{array}{l}0.882^{* *} \\
(0.337)\end{array}$ & $\begin{array}{c}-1.837^{* * *} \\
(0.494)\end{array}$ & $\begin{array}{c}-1.201^{* *} \\
(0.567)\end{array}$ & $\begin{array}{c}1.345 \\
(1.155)\end{array}$ & $\begin{array}{l}1.604^{* *} \\
(0.716)\end{array}$ & $\begin{array}{c}0.949^{* * *} \\
(0.241)\end{array}$ \\
\hline Observations & 1238 & 1238 & 1238 & 1238 & 1238 & 1238 & 1238 & 1238 & 1238 & 1208 & 1238 \\
\hline Covariates: & $\checkmark$ & $\checkmark$ & $\checkmark$ & $\checkmark$ & $\checkmark$ & $\checkmark$ & $\checkmark$ & $\checkmark$ & $\checkmark$ & $\checkmark$ & $\checkmark$ \\
\hline
\end{tabular}

Note: This table presents IV estimates of the effect of US robot exposure on the change in self-reported health, smoking and drinking habits, physical shape and exercises and access to healthcare services among employed and non-employed individuals. Changes are expressed in percentage points of the respective employment group and are multiplied by 100. Column 1 reports individuals that report fair or poor health. Columns 2 and 3 report individuals that suffered from physical or mental problems in more than 14 days of the previous 30 days. Columns 4 and 5 report smokers and individuals that consume alcohol in at least five days per week. Column 6 reports individuals that suffer from

obesity, i.e. a BMI of over 30. Column 7 reports individuals that did physical activity outside of the work environment in at least one day in the previous 30 days. Column 8 reports individuals with healthcare coverage. Column 9 reports individuals that had a medical checkup in the previous year (12 months). Column 10 reports individuals that could not visit a doctor when needed for cost reasons. Column 11 reports individuals that had no medical checkup in the previous two years (24 months). Independent variables are standardized to have mean zero and standard deviation of one. All regressions include year dummies, nine census divisions and their interactions, as well as changes in the non-participation rate and the manufacturing employment rate between 1970 and 1990, exposure to Chinese imports and demographic (share of individuals aged between 25 and 34 years, 35 and 44 years, 45 and 54 years, the share of Blacks, Hispanics, women and individuals with less than a college degree and logarithmic population), industry (shares of employment in the contruction, manufacturing, mining, research, service and utilities sector) and occupation (share of offshorable occupations, routine task-intensive occupations and occupations replaceable by robots) characteristics of CZ in 1990. Standard errors are robust against heteroskedasticity and allow for clustering at the state level. Regressions are weighted by CZ population in 1990 . Coefficients with ${ }^{* * *},{ }^{* *}$ and ${ }^{*}$ are significant at the $1 \%, 5 \%$ and $10 \%$ confidence level. 
Table 6: Robots and health conditions of non-employed individuals

\begin{tabular}{|c|c|c|c|c|}
\hline & All & $\begin{array}{l}\text { No good } \\
\text { health }\end{array}$ & $\begin{array}{l}\text { Physical } \\
\text { problems }\end{array}$ & $\begin{array}{c}\text { Mental } \\
\text { problems }\end{array}$ \\
\hline & [1] & [2] & {$[3]$} & \\
\hline US robot exposure & $\begin{array}{c}0.335^{* *} \\
(0.153)\end{array}$ & $\begin{array}{c}0.245^{* * *} \\
(0.069)\end{array}$ & $\begin{array}{c}0.261^{* * *} \\
(0.044)\end{array}$ & $\begin{array}{c}0.132^{* *} \\
(0.057)\end{array}$ \\
\hline Observations & 1276 & 1276 & 1276 & 1276 \\
\hline Covariates: & $\checkmark$ & $\checkmark$ & $\checkmark$ & $\checkmark$ \\
\hline
\end{tabular}

Note: This table presents IV estimates of the effect of US robot exposure on the change in the share of non-employed individuals by self-reported health. Changes are expressed in percentage points of the working-age population and are multiplied by 100. Column 1 includes all non-employed individuals. Column 2 reports individuals that report fair or poor health. Columns 3 and 4 report only non-employed individuals that suffered from physical or mental problems in more than 14 days of the previous 30 days. Independent variables are standardized to have mean zero and standard deviation of one. All regressions include year dummies, nine census divisions and their interactions, as well as changes in the non-participation rate and the manufacturing employment rate between 1970 and 1990, exposure to Chinese imports and demographic (share of individuals aged between 25 and 34 years, 35 and 44 years, 45 and 54 years, the share of Blacks, Hispanics, women and individuals with less than a college degree and logarithmic population), industry (shares of employment in the contruction, manufacturing, mining, research, service and utilities sector) and occupation (share of offshorable occupations, routine task-intensive occupations and occupations replaceable by robots) characteristics of CZ in 1990. Standard errors are robust against heteroskedasticity and allow for clustering at the state level. Regressions are weighted by CZ population in 1990 . Coefficients with ${ }^{* * *},{ }^{* *}$ and ${ }^{*}$ are significant at the $1 \%, 5 \%$ and $10 \%$ confidence level. 
Table 7: Robots and hospital admissions with disability-related disorders

\begin{tabular}{|c|c|c|c|c|c|c|c|c|}
\hline & $\begin{array}{c}\text { All } \\
\text { admissions }\end{array}$ & $\begin{array}{l}\text { All disability- } \\
\text { related } \\
\text { admissions }\end{array}$ & $\begin{array}{l}\text { Arthritis } \\
\text { \& rheu- } \\
\text { matology }\end{array}$ & $\begin{array}{l}\text { Back or } \\
\text { spine } \\
\text { problems }\end{array}$ & $\begin{array}{l}\text { Ciculato- } \\
\text { ry system } \\
\text { diseases }\end{array}$ & $\begin{array}{l}\text { Respira- } \\
\text { tory system } \\
\text { diseases }\end{array}$ & $\begin{array}{c}\text { Mental } \\
\text { disorders }\end{array}$ & Diabetes \\
\hline & {$[1]$} & {$[2]$} & {$[3]$} & {$[4]$} & {$[5]$} & {$[6]$} & {$[7]$} & [8] \\
\hline US robot exposure & $\begin{array}{l}1.115^{* *} \\
(0.537)\end{array}$ & $\begin{array}{l}1.147^{* *} \\
(0.516)\end{array}$ & $\begin{array}{c}0.555 \\
(0.352)\end{array}$ & $\begin{array}{c}0.197 \\
(0.226)\end{array}$ & $\begin{array}{c}0.621 \\
(0.428)\end{array}$ & $\begin{array}{l}0.548^{*} \\
(0.281)\end{array}$ & $\begin{array}{c}1.458^{* * *} \\
(0.515)\end{array}$ & $\begin{array}{c}0.204 \\
(0.219)\end{array}$ \\
\hline Observations & 469 & 469 & 469 & 469 & 469 & 469 & 469 & 469 \\
\hline Covariates: & $\checkmark$ & $\checkmark$ & $\checkmark$ & $\checkmark$ & $\checkmark$ & $\checkmark$ & $\checkmark$ & $\checkmark$ \\
\hline
\end{tabular}

Note: This table presents IV estimates of the effect of US robot exposure on the change in the share of hospital admissions with a length of stay of more than seven days and a diagnosis related to a cause of disability. Changes are expressed in percentage points of CZ hospital admissions multiplied by 100. Column 1 reports all admissions with a length of stay of more than seven days. Column 2 reports all disability-related admissions with a length of stay of more than seven days. Columns 3 to 8 report admissions diagnosed with arthritis or rheumatology, back or spine problems, circulatory system diseases, respiratory system diseases, mental disorders and diabetes with a length of stay of more than seven days. All variables are standardized to have mean zero and standard deviation of one. All regressions include year dummies, nine census divisions and their interactions, as well as changes in the non-participation rate and in the manufacturing employment rate between 1970 and 1990 , exposure to Chinese imports and demographic (share of individuals aged between 25 and 34 years, 35 and 44 years, 45 and 54 years, the share of Blacks, Hispanics, women and individuals with less than a college degree and logarithmic population), industry (shares of employment in the contruction, manufacturing, mining, research, service and utilities sector) and occupation (share of offshorable occupations, routine task-intensive occupations and occupations replaceable by robots) characteristics of CZ in 1990. Standard errors are robust against heteroskedasticity and allow for clustering at the state level. Regressions are weighted by CZ hospital admissions. Coefficients with ${ }^{* * *},{ }^{* *}$ and ${ }^{*}$ are significant at the $1 \%, 5 \%$ and $10 \%$ confidence level. 
Table 8: Robots and non-participation: Product market competition from Europe

\begin{tabular}{|c|c|c|c|c|c|}
\hline & {$[1]$} & {$[2]$} & {$[3]$} & {$[4]$} & {$[5]$} \\
\hline \multicolumn{6}{|c|}{ Panel A: Import competition in the US } \\
\hline US robot exposure & $\begin{array}{c}0.262^{* * *} \\
(0.058)\end{array}$ & $\begin{array}{c}0.287^{* * *} \\
(0.067)\end{array}$ & $\begin{array}{c}0.286^{* * *} \\
(0.059)\end{array}$ & $\begin{array}{c}0.268^{* * *} \\
(0.034)\end{array}$ & $\begin{array}{c}0.364^{* * *} \\
(0.121)\end{array}$ \\
\hline US imports from EU7 & $\begin{array}{l}-0.037 \\
(0.045)\end{array}$ & $\begin{array}{l}-0.046 \\
(0.045)\end{array}$ & $\begin{array}{l}-0.058 \\
(0.049)\end{array}$ & $\begin{array}{c}-0.087^{*} \\
(0.049)\end{array}$ & $\begin{array}{l}-0.012 \\
(0.046)\end{array}$ \\
\hline Observations & 2166 & 2166 & 2166 & 2166 & 2166 \\
\hline \multicolumn{6}{|c|}{ Panel B: Import competition in Canada } \\
\hline US robot exposure & $\begin{array}{c}0.252^{* * *} \\
(0.057)\end{array}$ & $\begin{array}{c}0.276^{* * *} \\
(0.065)\end{array}$ & $\begin{array}{c}0.274^{* * *} \\
(0.058)\end{array}$ & $\begin{array}{c}0.256^{* * *} \\
(0.035)\end{array}$ & $\begin{array}{c}0.352^{* * *} \\
(0.116)\end{array}$ \\
\hline CAN imports from EU7 & $\begin{array}{c}0.159 \\
(0.097)\end{array}$ & $\begin{array}{c}0.143 \\
(0.099)\end{array}$ & $\begin{array}{c}0.135 \\
(0.099)\end{array}$ & $\begin{array}{c}0.051 \\
(0.095)\end{array}$ & $\begin{array}{c}0.140 \\
(0.088)\end{array}$ \\
\hline Observations & 2166 & 2166 & 2166 & 2166 & 2166 \\
\hline \multicolumn{6}{|c|}{ Panel C: EU3 countries (Denmark, Finland, Sweden) } \\
\hline US robot exposure & $\begin{array}{l}0.265^{*} \\
(0.153)\end{array}$ & $\begin{array}{l}0.305^{*} \\
(0.169)\end{array}$ & $\begin{array}{l}0.291^{*} \\
(0.160)\end{array}$ & $\begin{array}{l}0.213^{*} \\
(0.122)\end{array}$ & $\begin{array}{c}0.677^{*} \\
(0.344)\end{array}$ \\
\hline Observations & 2166 & 2166 & 2166 & 2166 & 2166 \\
\hline \multicolumn{6}{|l|}{ Covariates: } \\
\hline Divisions & $\checkmark$ & $\checkmark$ & $\checkmark$ & $\checkmark$ & $\checkmark$ \\
\hline Years & $\checkmark$ & $\checkmark$ & $\checkmark$ & $\checkmark$ & $\checkmark$ \\
\hline Pre-trends & & $\checkmark$ & $\checkmark$ & $\checkmark$ & $\checkmark$ \\
\hline Chinese imports & & & $\checkmark$ & $\checkmark$ & $\checkmark$ \\
\hline Demographics & & & & $\checkmark$ & $\checkmark$ \\
\hline Industries & & & & $\checkmark$ & $\checkmark$ \\
\hline Occupations & & & & $\checkmark$ & $\checkmark$ \\
\hline Unweighted & & & & & $\checkmark$ \\
\hline
\end{tabular}

Note: This table presents estimates of the effect of US robot exposure on the change in the non-participation rate at the CZ level. Changes are expressed in percentage points of the working-age population and are multiplied by 100 . Independent variables are standardized to have mean zero and standard deviation of one. There are three time periods and 722 CZs. Panel A reports IV estimates using the standard instrument with seven European countries and estimates of the effect of US imports from these countries. Panel B reports IV estimates using the standard instrument with seven European countries and estimates of the effect of Canadian imports from these countries. Panel C reports IV estimates using an instrument that includes only the three European countries with the lowest trade engagement with the US (Denmark, Finland and Sweden). Column 1 includes year dummies, nine census divisions and their interactions. Column 2 includes also changes in the non-participation rate and in the manufacturing employment rate between 1970 and 1990. Column 3 includes also exposure to Chinese imports. Columns 4 and 5 control also for demographic (share of individuals aged between 25 and 34 years, 35 and 44 years, 45 and 54 years, the share of Blacks, Hispanics, women and individuals with less than a college degree and logarithmic population), industry (shares of employment in the contruction, manufacturing, mining, research, service and utilities sector) and occupation (share of offshorable occupations, routine task-intensive occupations and occupations replaceable by robots) characteristics of $\mathrm{CZ}$ in 1990. Standard errors are robust against heteroskedasticity and allow for clustering at the state level. Regressions are weighted by CZ population in 1990 in Columns 1 to 4 and are unweighted in Column 5 . Coefficients with ${ }^{* * *},{ }^{* *}$ and ${ }^{*}$ are significant at the $1 \%, 5 \%$ and $10 \%$ confidence level. 
Table 9: Robots and non-participation: Exclusion of the CZs with the highest robot exposure

\begin{tabular}{|c|c|c|c|c|c|}
\hline & [1] & {$[2]$} & {$[3]$} & {$[4]$} & {$[5]$} \\
\hline \multicolumn{6}{|c|}{ Panel A: Exclusion of Detroit } \\
\hline US robot exposure & $\begin{array}{c}0.393^{* * *} \\
(0.101)\end{array}$ & $\begin{array}{c}0.440^{* * *} \\
(0.116)\end{array}$ & $\begin{array}{c}0.426^{* * *} \\
(0.114)\end{array}$ & $\begin{array}{c}0.334^{* * *} \\
(0.103)\end{array}$ & $\begin{array}{c}0.376^{* * *} \\
(0.136)\end{array}$ \\
\hline Observations & 2163 & 2163 & 2163 & 2163 & 2163 \\
\hline \multicolumn{6}{|c|}{ Panel B: Exclusion of CZs in top 1 percentile of robot exposure } \\
\hline US robot exposure & $\begin{array}{c}0.495^{* * *} \\
(0.142)\end{array}$ & $\begin{array}{c}0.559^{* * *} \\
(0.152)\end{array}$ & $\begin{array}{c}0.548^{* * *} \\
(0.166)\end{array}$ & $\begin{array}{c}0.451^{* *} \\
(0.184)\end{array}$ & $\begin{array}{l}0.459^{*} \\
(0.233)\end{array}$ \\
\hline Observations & 2142 & 2142 & 2142 & 2142 & 2142 \\
\hline \multicolumn{6}{|c|}{ Panel C: Exclusion of CZs around Great Lakes } \\
\hline US robot exposure & $\begin{array}{c}0.664^{* * *} \\
(0.117)\end{array}$ & $\begin{array}{c}0.737^{* * *} \\
(0.123)\end{array}$ & $\begin{array}{c}0.763^{* * *} \\
(0.159)\end{array}$ & $\begin{array}{c}0.778^{* * *} \\
(0.230)\end{array}$ & $\begin{array}{c}0.915^{* * *} \\
(0.280)\end{array}$ \\
\hline Observations & 2010 & 2010 & 2010 & 2010 & 2010 \\
\hline \multicolumn{6}{|l|}{ Covariates: } \\
\hline Divisions & $\checkmark$ & $\checkmark$ & $\checkmark$ & $\checkmark$ & $\checkmark$ \\
\hline Years & $\checkmark$ & $\checkmark$ & $\checkmark$ & $\checkmark$ & $\checkmark$ \\
\hline Pre-trends & & $\checkmark$ & $\checkmark$ & $\checkmark$ & $\checkmark$ \\
\hline Chinese imports & & & $\checkmark$ & $\checkmark$ & $\checkmark$ \\
\hline Demographics & & & & $\checkmark$ & $\checkmark$ \\
\hline Industries & & & & $\checkmark$ & $\checkmark$ \\
\hline Occupations & & & & $\checkmark$ & $\checkmark$ \\
\hline Unweighted & & & & & $\checkmark$ \\
\hline
\end{tabular}

Note: This table presents IV estimates of the effect of US robot exposure on the change in the non-participation rate at the CZ level excluding a set of outliers. Changes are expressed in percentage points of the working-age population and are multiplied by 100. Independent variables are standardized to have mean zero and standard deviation of one. There are three time periods and 722 CZs. Panel A reports estimates excluding Detroit from the sample. Panel B reports estimates excluding the CZs in the top 1 percentile of US robot exposure between 1993 and 2014. Panel C reports estimates excluding CZs in the most exposed states around the Great Lakes (Indiana, Michigan and Ohio). Column 1 includes year dummies, nine census divisions and their interactions. Column 2 includes also changes in the non-participation rate and in the manufacturing employment rate between 1970 and 1990. Column 3 includes also exposure to Chinese imports. Columns 4 and 5 control also for demographic (share of individuals aged between 25 and 34 years, 35 and 44 years, 45 and 54 years, the share of Blacks, Hispanics, women and individuals with less than a college degree and logarithmic population), industry (shares of employment in the contruction, manufacturing, mining, research, service and utilities sector) and occupation (share of offshorable occupations, routine taskintensive occupations and occupations replaceable by robots) characteristics of CZ in 1990. Standard errors are robust against heteroskedasticity and allow for clustering at the state level. Regressions are weighted by CZ population in 1990 in Columns 1 to 4 and are unweighted in Column 5 . Coefficients with ${ }^{* * *},{ }^{* *}$ and ${ }^{*}$ are significant at the $1 \%, 5 \%$ and $10 \%$ confidence level. 


\section{Online Appendix: \\ Robots and non-participation in the US: \\ Where Have All the Workers Gone? \\ Benjamin Lerch}

\section{A1 Institutional background}

US Social Security is the largest and one of the most successful anti-poverty programs in the United States. In 2019, the Social Security Administration (SSA) paid benefits for more than 1 trillion US dollars to more than 64 million American citizens, of which $75.3 \%$ received retirement benefits, 15.5\% disability benefits and 9.2\% survivor benefits (Social Security Beneficiary Statistics, 2019).

Individuals qualify for Social Security disability benefits if they have a physical or mental impairment that prevents them from engaging in any substantial gainful activity. The impairment is expected to last at least twelve months or result in death. Individuals have to be aged not more than 64 years and they must have paid enough contributions in form of labor taxes during their work life. Moreover, together with people who are blind or are older than 64 years, disabled individuals with limited income and few resources qualify for monthly payments from the Supplemental Security Income (SSI) program, also provided by the SSA.

Social Security survivors benefits are paid to widows, widowers, and dependents of eligible workers. Individuals qualify for survivor benefits from 50 years of age if they are disabled and from 60 years if they are not disabled.

Individuals qualify for Social Security retirement benefits after reaching the official retirement age. The full retirement age varies from 66 to 67 years depending on the year of birth of the claimant, conditional on having worked and paid Social Security taxes for at least 10 years. The US Social Security early retirement age starts at 62 years.

Retirees usually have access to other retirement income sources already before the age of 62 years, for example by withdrawing early their retirement income from pension plans. The most common pension plans are employed-sponsored plans, i.e. defined benefit (DB) and defined contribution (DC) plans. DB plans promise specified benefits at retirement that are predetermined according to an employee's earning history, tenure of service and age. Individuals with a DB plan become eligible to receive benefits when they reach 65 years or the retirement age specified in their plan. Early withdrawals are possible when they turn 62 years or earlier in case of employment termination for reasons such as disability or early retirement. DC plans, such as 401(k) plans, pay retirement benefits according to contributions corrected for investment gains or losses. Retirement income from DC plans can usually be withdrawn from the age of 59 and a half years. Withdrawals before 
the official age are subject to an early distribution penalty. However, early withdrawals are often exempted from the penalty in case of employment termination after the age of 55 years or in case of a disability. Other employer-provided plans are Individual Retirement Accounts (IRA), which are similar to 401(k) plans, but have lower contribution limits, and Keogh plans, which are pension plans for the self-employed.

In the last decades, the US have experienced an increasing popularity of DC plans, in particular 401(k) plans, leading to a shift from DB to DC plans (Poterba, 2014). This shift has a positive impact on the average retirement age, since workers with a DC plan retire on average 21 months later than comparable workers with a DB plan (Friedberg and Webb, 2005).

A shortcoming in the data from the IPUMS is that I cannot distinguish between pension plan types. In particular, I cannot identify whether workers withdraw retirement income from DB or DC plans. This shortcoming raises some concerns about a potential channel of correlation between the introduction of industrial robots and the local share of workers that have a DB or a DC plan. In this case, omitted variables that account for the type of plan of older workers may bias my estimates of the effect of robots on early retirement.

Using data from the 2010 Consumer Finance Survey, I find that workers of the manufacturing sector are more likely to have DC plans than workers from other sectors (see Figure A14). Since workers with a DC plan retire later (Friedberg and Webb, 2005) and robots are mostly adopted in manufacturing industries, the potential correlation between robot exposure and the pension plan type through a sector channel would bias my estimates downwards. This, in turn, would imply that the true effect of robots on early retirement would be even stronger than what I estimate.

\section{A2 Data sources and cleaning}

This section provides further details about the data cleaning and the construction of covariates.

\section{A2.1 Health outcomes}

I measure health outcomes using data from the Behavioral Risk Factor Surveillance System (BRFSS) of the Centers for Disease Control and Prevention (CDC) and the National Inpatient Sample (NIS) of the Healthcare Cost and Utilization Project (HCUP) for 1993, 2000, 2007 and 2011. After 2011, the BRFSS and NIS datasets do not provide geographic indicators that allow me to identify observations at the CZ level.

The BRFSS is a health-related telephone survey that collects 400'000 adult interviews each year on health-related risk behaviors, chronic health conditions, and the use of preventive services. For each individual, I have information on basic demographics, employment status, self-reported health, smoking and drinking habits, body height and weight, physical activity, healthcare coverage and 
the use of healthcare services. Interviewees are also asked about their physical and mental health condition and report whether they suffered from physical illness or injuries, or from stress, depression or problems with emotions in the 30 days prior to the interview. Similarly to the IPUMS data, I aggregate BRFSS data at the local labor market level and have information on $634 \mathrm{CZs}$. I use the approach explained in footnote 13 to increase the sample size of each year including data of adjacent years. I construct representative individual weights by computing CZ gender-race-age shares from the BRFSS (NIS) and Census/ACS. Following Adda and Fawaz (2020), I divide the shares from the Census/ACS by the corresponding BRFSS (NIS) shares and multiply this ratio by the CZ share in the population for each sample year. The weights reflect the proportions of individuals according to the gender-race-age cell in the Census/ACS. Counties with a low population are anonymized and cannot be identified.

I build measures of health-related issues using these data by dividing the number of working-age individuals with given health characteristics and employment status in a CZ by all individuals with the same employment status in that CZ. For example, a CZ's share of non-employed individuals who suffer from a fair or bad health is computed as the number of individuals who report to suffer from fair or bad health and that are not employed divided by all individuals that are not employed. The NIS collects information on more than seven million hospital stays each year using a 20-percent stratified sample of discharges from US community hospitals. For each discharge, among others, I observe patients' basic demographics, the length of stay and information on up to 15 diagnoses using classification codes from the International Classification of Diseases, Ninth Revision (ICD-9). I group ICD-9 codes into six disability-related conditions (arthritis and rheumatism; back and spine problems; circulatory system diseases; respiratory system diseases; mental disorders; and diabetes) and 13 conditions that are not directly related to a disability (infectious and parasitic diseases; cancer, endocrine, nutritional and metabolic diseases; nervous system diseases; digestive system diseases; diseases of the skin and subcutaneous tissue; unclassified pain; alcohol abuse; tobacco abuse; drug abuse; opioid abuse; injuries; suicide attempts; and accidents). These data include hospital identifiers and county codes which allow me to match hospitals to CZs and to obtain information on 2'217 hospitals in $322 \mathrm{CZs}$.

I build measures of the hospitalization rate by diagnosis by dividing the number of admissions with a certain diagnosis with the total number of admissions over all hospitals in a CZ in a given year. For example, I compute a CZ's share of severe admissions with mental disorders as the number of admissions diagnosed with severe mental disorders divided by all hospital admissions in that CZ. I cannot compute the hospitalization rate in terms of the local population because the sample of US community hospitals is changing from year to year, which makes a comparison across years infeasible. 


\section{A2.2 Import exposure}

China Following Autor et al. (2013), I use a shift-share approach to measure a labor market's exposure to imports from China. I interact CZs' industry employment shares in the manufacturing sector prior to the admission of China to the World Trade Organization in 2001 with the growth in product trade flows from China to the US:

$$
\text { US import exposure }{ }_{c,\left(t_{0}, t_{1}\right)}=\sum_{j \in J} \ell_{c, j}^{1990} \Delta I M_{j,\left(t_{0}, t_{1}\right)}^{U S}
$$

where $\Delta I M_{j,\left(t_{0}, t_{1}\right)}^{U S}$ is the change in US imports from China in thousand dollars per worker. Analogously to Equation 4, I exploit plausibly exogenous variation in the trade shock by instrumenting the shift-component of the measure with trade flows from China to other industrialized countries with a similar trade development as the US:

$$
\text { OT8 import exposure } c,\left(t_{0}, t_{1}\right)=\sum_{j \in J} \frac{1}{8} \sum_{i \in O T 8} \ell_{c, j}^{1990} \Delta I M_{j,\left(t_{0}, t_{1}\right)}^{i}
$$

where $i \in O T 8$ include Australia, Denmark, Finland, Germany, Japan, New Zealand, Spain, and Switzerland. I keep the baseline employment shares constant to avoid endogeneity and serial correlation concerns.

I collect product-level data at the six-digit Harmonized System (HS) on Chinese imports from the UN Comtrade Database which I match with industry employment shares from the 1991 County Business Pattern (CBP). The CBP classifies industry employment according to the Standard Classification System (SIC) until 1997 and according to the North American Industry Classification System (NAICS) afterwards. These systems are more detailed than the industrial classification system used in the IPUMS. I use crosswalks from Dorn's website to convert SIC and NAICS manufacturing industries and six-digit HS product-level trade data to 392 four-digit SIC industries. I construct the import penetration measure by matching local employment shares with converted product-level trade data on imports from China. For confidentiality reasons, county-industry observations with few cases are reported as ranges. In reconstructing these data, I follow Acemoglu et al. (2016).

Europe I build a measure of international product market competition from Europe using a shiftshare approach, as outlined previously. The share component is unchanged and corresponds to $\ell_{c, j}^{1990}$ in Equation 6, while the shift-component does not account anymore for imports from China, but includes the change in average trade flows from Denmark, Finland, France, Italy, Spain, Sweden and the United Kingdom to the US. Since US imports could be subject to domestic shocks that affect also the local demand for labor (demand shocks), I instrument imports to the US with trade flows from Europe to Canada, an industrialized country with a comparable trade engagement with European countries as the US (see Figure A13), but whose import intensity is less affected by US 
domestic shocks than the US itself.

\section{A2.3 Industry employment and output}

I obtain data about employment and aggregate output at the industry level in the US and in European countries from the Integrated Industry-Level Production Account (KLEMS) of the Bureau of Economic Affairs (BEA) and from the EU KLEMS database (Jägger, 2017). I use these data to build measures of robot density at the industry level in the shift components of Equations 3 and 4.

\section{A2.4 CZ characteristics}

I obtain individual-level data on a variety of demographic characteristics and labor market information of the US population from the IPUMS. I use these data to build measures of CZs' demographics and their industrial and occupational composition of employment. These variables include the share of female, Black and Hispanic individuals, the share of college-educated individuals, and the $\log$ population size and age structure of the population (25-34, 35-44 and 45-54 years). Moreover, I account for the share of employment in construction, education and research, manufacturing, mining, services, and utilities industries, as well as the share of routine task-intensive, offshorable and robot-replaceable jobs (Autor and Dorn, 2013, Graetz and Michaels, 2018). I keep CZ characteristics constant at their 1990 levels to avoid contamination by the endogenous adjustments in the structure of labor markets in response to robot adoption. I provide summary statistics of these covariates in Table 1.

\section{A2.5 Migration}

I construct measures of migration flows across CZs using data from two sources. First, I obtain county-level data on migration flows from the Internal Revenue Service (IRS) provided by Howard (2020). The data include detailed information on yearly migration flows across US counties. I aggregate the flows at the $\mathrm{CZ}$ level and aggregate $\mathrm{CZs}$ ' in- and out-flows in each subperiod of my sample (1993-2000, 2000-07, 2007-14). Finally, I divide the absolute flows for the beginning-ofsubperiod population to obtain measures of in-migration and out-migration as a percentage of the local population.

Second, following Di Giacomo and Lerch (2021), I obtain information on the migration status of individuals from the Census and ACS to construct changes in aggregate in- and out-flows of migrants at the $\mathrm{CZ}$ level, as described above. A major limitation in these data is that information about individuals' migration status changes over time. In particular, the Census asks whether a person changed its residence in the previous 5 years, while the ACS asks whether a person changed its residence in the previous year. Hence, an individual who moved twice in the previous 5 years is considered to be a one-time mover in the Census, but would be counted twice in the ACS (conditional 
on the fact that the moves occurred in different years). For comparability, I follow Molloy et al. (2011) and build measures of 5-year migration flows from the ACS by using four times the annual migration flow of a CZ.

\section{A2.6 Robots and student mobility}

Accounting only for robot exposure in the $\mathrm{CZ}$ in which the college is located could bias the estimates of the effect of robots, since students may have decided to enroll in college because of the shock in their CZ of origin. To account for the mobility of students across CZs, Di Giacomo and Lerch (2021) adjust the measures in Equation 3 and 4 for students' migration flows. Considering all possible cross-CZ migration flow combinations $(722 \times 722)$, they reconstruct the shock for the $\mathrm{CZ}$ in which students are enrolled in college, $c_{d}$ (previously denoted with $c$ ), as a weighted average of the shocks in students' CZs of origin, $c_{o}$. The shocks are weighted by the share of students living in $c_{d}$ who come from $c_{o}$ :

$$
\text { US robot exposure }{\left(c_{o}, c_{d}\right),\left(t_{0}, t_{1}\right)}=\sum_{c_{o}} \psi_{\left(c_{o}, c_{d}\right)}^{{ }^{9}} \text { US robot exposure }{ }_{c_{o},\left(t_{0}, t_{1}\right)}
$$

where $\psi_{c_{(o, d)}}^{900}=\frac{S_{c_{o}}^{c 00}}{S_{c_{d}}^{90}}$ is the share of students living in $\mathrm{CZ} c_{d}$ that comes from $c_{o}$. Note that for non-movers, $c_{d}=c_{o}$.

\section{A2.7 Institution controls}

To control for the educational supply that could have influenced the demand for schooling of nonparticipants, I build measures of the local supply of post-secondary education institutions using data from the Integrated Postsecondary Education Data System (IPEDS) provided by Di Giacomo and Lerch (2021). They include the number of public institutions, for-profit institutions, non-profit institutions, community colleges and the number of top 20 US educational institutions in the 2020 university ranking in each $\mathrm{CZ}$.

\section{A2.8 Technology shocks}

I control for technology shocks other than industrial robots using Bartik-style measures of the adoption of personal computers and IT capital intensity. I obtain data about the number of individuals that are using a computer in each industry from the 1993 Current Population Survey. Following Acemoglu and Restrepo (2020), I build a measure of exposure to computers by interacting the share of employees using a computer with CZ baseline employment shares in each industry. Analogously, I obtain data about the share of IT investments at the industry level from the 1992 American Survey of Manufacturing and build a measure of IT capital intensity by interacting the share of IT investments (available at the 4-digit SIC87) with the baseline CZ employment shares in each 
industry. I keep the shares constant at their 1990s levels to avoid contamination by the endogenous adjustments in the structure of labor markets in response to robot adoption.

\section{A3 Additional robustness checks}

This section provides further robustness checks in support of the identification strategy and of my preferred specification.

\section{A3.1 Cross-sectional and temporal variation}

The preferred specification of this paper analyzes the labor market effect of robots by exploiting both cross-sectional variation in robot exposure across CZs and temporal variation in robot exposure within CZs. I verify the relative importance of these sources of variation using a single long-difference specification over the 1990-2014 period and using a stacked first-difference specification with CZ fixed effects respectively. The latter specification is more demanding and accounts also for unobserved time-invariant differences in $\mathrm{CZ}$ characteristics which could influence the adoption of robots and labor market outcomes. The results are summarized in Table A8. In the first part of the table, I observe that between-CZs variation in robot exposure accounts for most of the overall variation, suggesting that the adoption of robots is mainly driven by the secular industry specialization of local labor markets. The second part of Table A8 reports estimates of the labor market effect of robots by exploiting each source of variation individually. I find that robots have a similar impact on labor force participation in both specifications. ${ }^{55}$ These results support the use of the stacked first-difference model as in my preferred specification, since cross-sectional variation is an important source of the overall variation in robot exposure and unobserved heterogeneity across CZs does not bias my estimates of the labor market effect of robots.

\section{A3.2 Construction of the shift-share measure}

Table A19 shows that the exact construction of the shift-share measures in Equations 3 and 4 do not affect my results. Panels $\mathrm{A}$ and $\mathrm{B}$ report estimates of two more mixes of European countries that are used in the construction of the instrument. First, I exclude from my instrument Spain and the United Kingdom and replicate the measure of Acemoglu and Restrepo (2020). Second, I include Germany, a country that is ahead of the US in the adoption of robots. Panel C reports estimates using an instrument with 1990 industry employment shares, $\ell_{c, j}^{1990}$, rather than from 1970. Panel D reports estimates using a measure of US robot exposure and an instrument without adjusting

\footnotetext{
${ }^{55}$ In Table A8, the estimate of the effect within CZs is almost three times as large as the estimate of the effect across $\mathrm{CZs}$, i.e. a one standard deviation increase in robot exposure within the same $\mathrm{CZ}$ has a stronger impact on the non-participation rate than the same difference across CZs. However, when multiplying the estimates with the respective standard deviations of the variable, I obtain similar results. The long-difference estimate is equal to $0.219(0.238 \times 0.921)$ and the stacked first-difference specification with CZ fixed effects is equal to $0.277(0.708 \times$ $0.391)$.
} 
for industry growth, $g_{j,\left(t_{0}, t_{1}\right)} \frac{R_{j, t_{0}}}{L_{j, 1990}}$. The estimates of the labor market effect of robots on nonparticipation do not differ economically or statistically from my preferred specification's results.

\section{A3.3 Logarithmic outcomes}

Table A20 illustrates the estimates of the effect of robots on labor market outcomes in logarithmic changes rather than in shares of the working-age population. I find robust estimates of the labor market effects of robots that are in line with my preferred specification's results. The estimates suggest that a one standard deviation increase in US robot exposure decreases labor force participation by $1.659 \log$ points.

\section{A3.4 Robust standard errors}

Borusyak et al. (2018) argue that standard errors need to consider also potential correlations across CZs resulting from common industry-level shocks. Table A21 reports the estimates of the effect of robots on US employment allowing for clustering at the IFR industry level. I find that employment decreased relatively more in industries that experienced high robot growth and that this result is robust to the inclusion of industry fixed effects. Table A22 further reports results on the effect of robots on employment and non-participation at the $\mathrm{CZ}$ level allowing for arbitrary clustering at the division level. This specification considers also the potential correlation of the residuals between neighboring CZs that belong to different states. The standard errors are almost identical to my baseline specification and do not affect the significance of my results.

\section{A3.5 Alternative covariates}

Table A23 shows that also the choice of covariates included in the vector of regional characteristics and economic variables in Equation 2 does not alter my results. Panel A reports estimates of the effect of robots when including a set of state fixed effects to control for state specific labor market conditions and policies that could affect my outcomes. Panel B includes shift-share measures of technology shocks (computer adoption and IT capital investments) that may confound the labor market effect of robots. The results show that the inclusion of these controls does not affect the economic and statistical significance of my results. Interestingly, I also do not find evidence that these technology shocks or that the share of routine task-intensive and offshorable occupations is affecting labor force participation (see Table A24). Panel C includes time-varying covariates of the demographic characteristics of CZs and the industrial and occupational composition of employment (1990, 2000 and 2007) rather than fixed at 1990 levels. Panel D reports estimates using a twostep LASSO procedure for the selection of covariates (Belloni et al., 2014). Again, the estimates of the labor market effect of robots are quantitatively and qualitatively similar as in my preferred specification. 


\section{A3.6 Stock of robots using the perpetual inventory method}

The IFR estimates the operational stock of robots assuming no depreciation of robot capital in the first 12 years of service and full depreciation in the 13th year. I stress this assumption and, following Graetz and Michaels (2018), I build measures of the stock of robots based on yearly shipments using the perpetual inventory method at different depreciation rates. Table A25 illustrates the results of the effect of robots on non-participation assuming a depreciation rate of robot capital of $5 \%, 10 \%$ and $15 \%$. The alternative measures provide estimates of the labor market effect of robots that are quantitatively and qualitatively similar to my preferred specification.

\section{A4 Additional figures and tables}

Figure A1: Robots, non-participation and the manufacturing sector

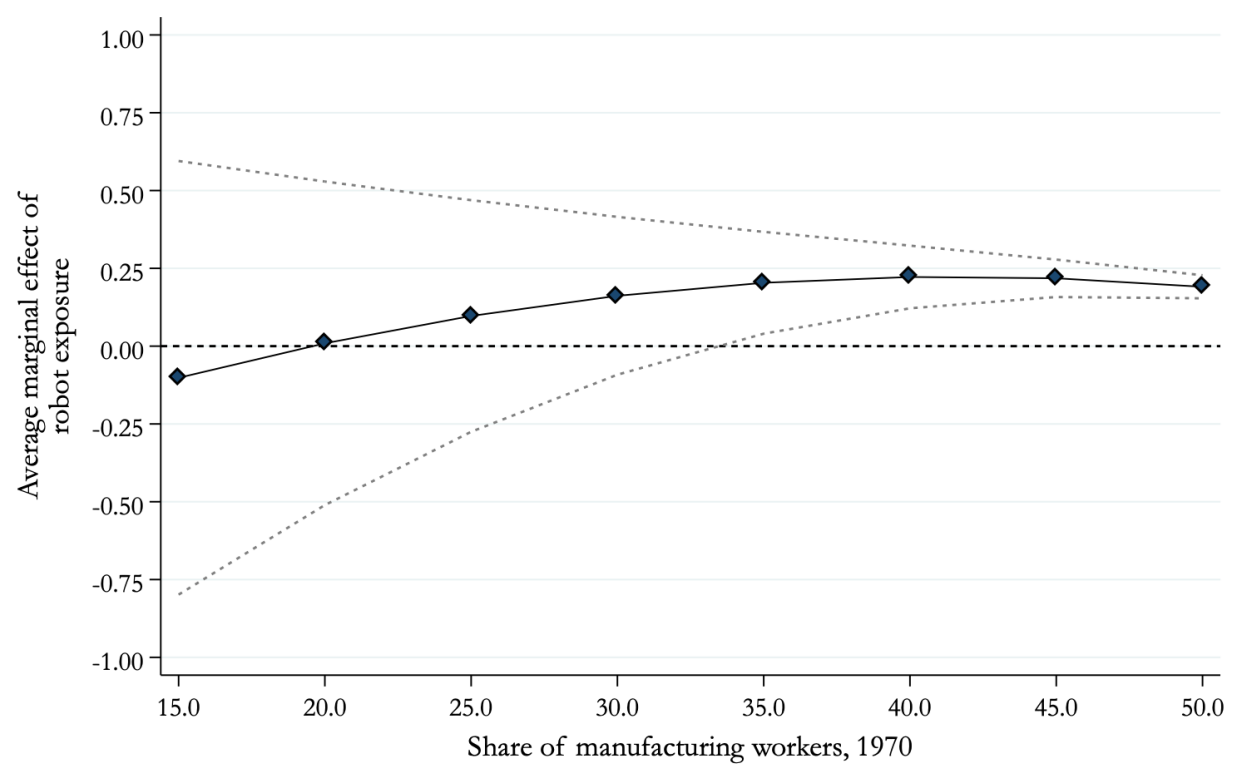

Note: This figure illustrates reduced form estimates of the average marginal effect of robot exposure with respect to the share of employment in the manufacturing sector in 1970 on the change non-participation rate. Changes are expressed in percentage points of the working-age population and are multiplied by 100. Independent variables are standardized to have mean zero and standard deviation of one. There are three time periods and 722 CZs. Standard errors are robust against heteroskedasticity and allow for clustering at the state level. Confidence intervals are at the $95 \%$ level. Regressions include covariates of my preferred specification and are weighted by CZ population in 1990. 
Figure A2: Robots, non-participation and detailed school enrollment of young individuals

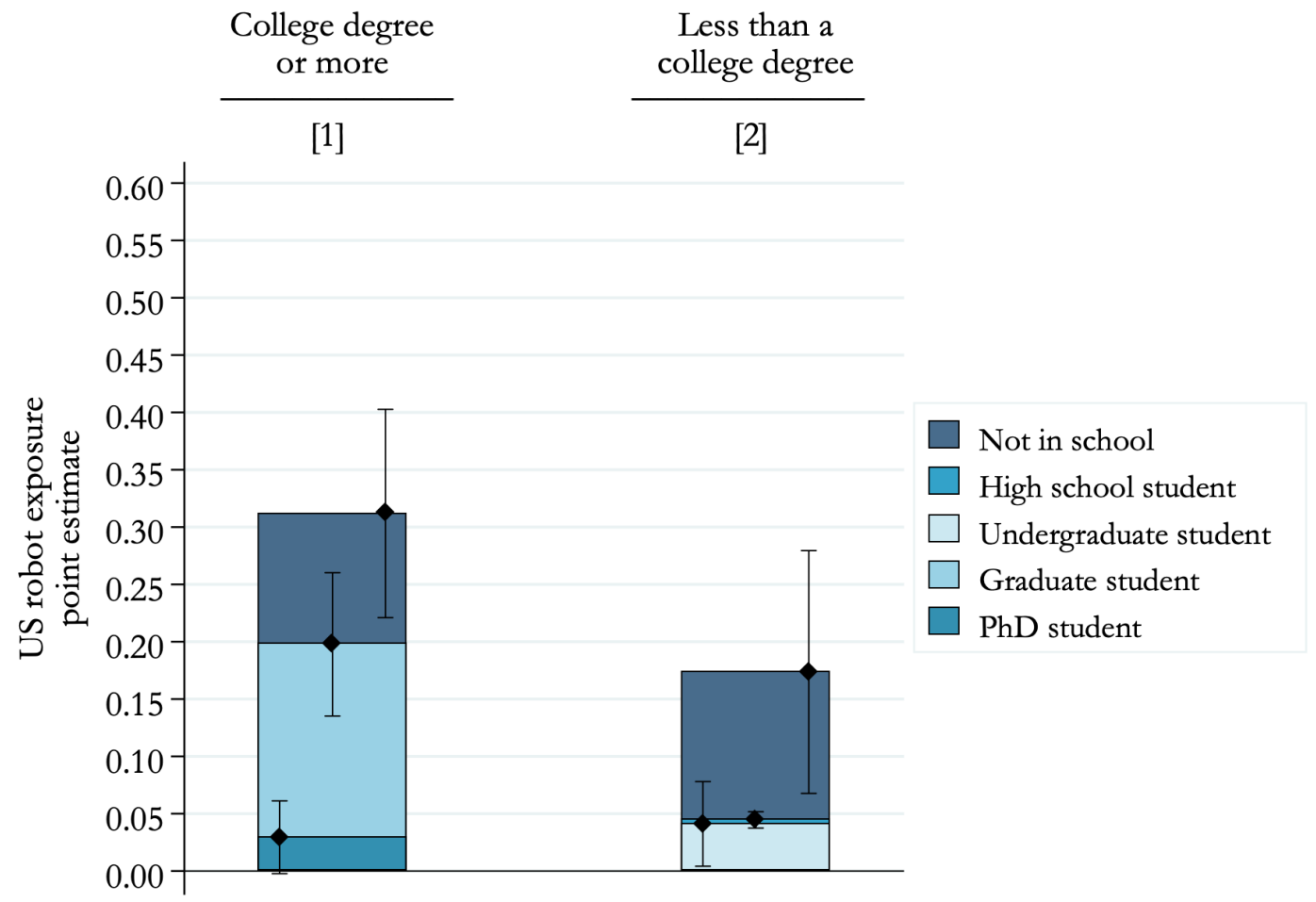

Note: This figure illustrates the point estimates of the effect of US robot exposure on the change in the non-participation rate of individuals between 25 and 34 years of age by education level. Changes are expressed in percentage points of the population subgroup and are multiplied by 100. Independent variables are standardized to have mean zero and standard deviation of one. There are three time periods and $722 \mathrm{CZs}$. The figure further illustrates the fraction of the change in non-participants by school enrollment. High school student include students enrolled in high school or individuals doing the GED test. Undergraduate student includes students enrolled in undergraduate college. Less than a college degree and not in school include high school dropouts and undergraduate college dropouts. Graduate student include individuals enrolled in graduate or professional schools. PhD student include PhD students. College degree or more and not in school include college graduates that are not enrolled in school. Standard errors are robust against heteroskedasticity and allow for clustering at the state level. Confidence intervals of the effects on non-participants that are in school (left CI) and are not in school (right CI) are at the 95\% level. Regressions include covariates of my preferred specification and are weighted by CZ population in 1990. 
Figure A3: Robots, non-participation and idle individuals

Panel A: College degree or more

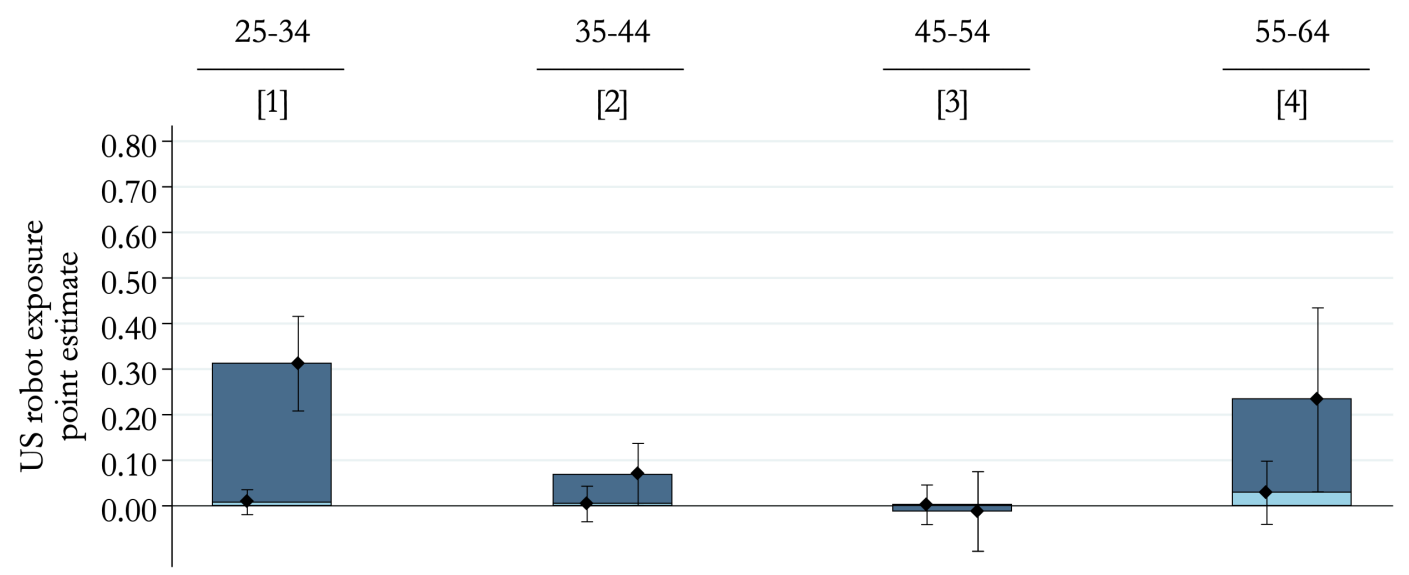

Panel B: Less than a college degree

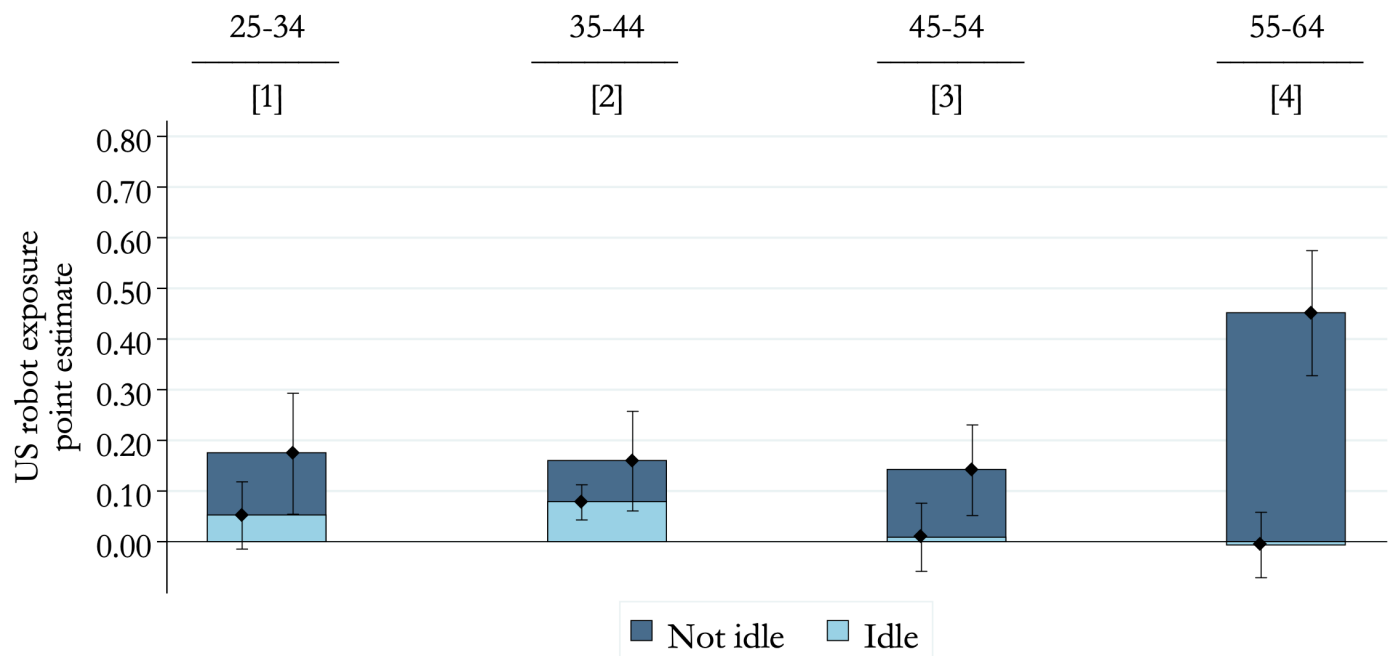

Note: This figure illustrates the point estimates of the effect of US robot exposure on the change in the non-participation rate by age and education. Changes are expressed in percentage points of the population subgroup and are multiplied by 100. Independent variables are standardized to have mean zero and standard deviation of one. There are three time periods and $722 \mathrm{CZs}$. The figure further separates between non-participants that are idle and those who are enrolled in school or have earned some income in the previous twelve months (e.g. Social Security income; pension plan income; wage income; business or farm income; welfare (public assistance) income; or interest, dividend and rental income). Standard errors are robust against heteroskedasticity and allow for clustering at the state level. Confidence intervals of the effects on non-participants that idle (left CI) and non-idle (right CI) are at the 95\% level. Regressions include covariates of my preferred specification and are weighted by $\mathrm{CZ}$ population in 1990 . 
Figure A4: Robots, non-participation and income sources

Panel A: College degree or more

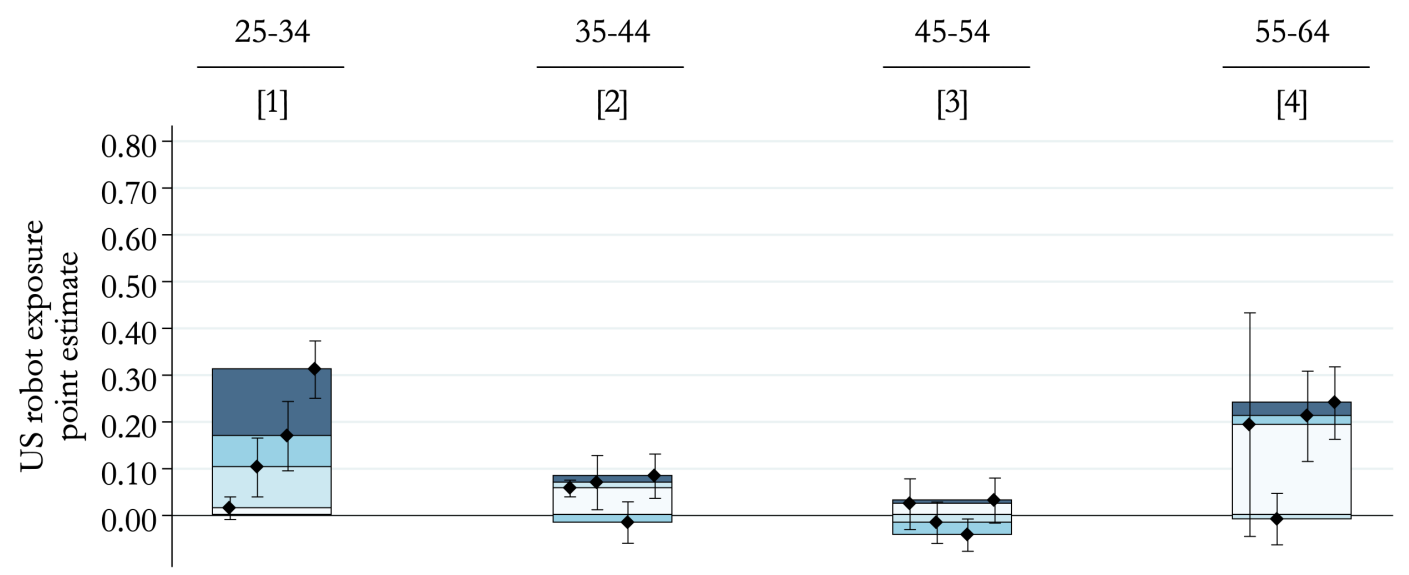

Panel B: Less than a college degree

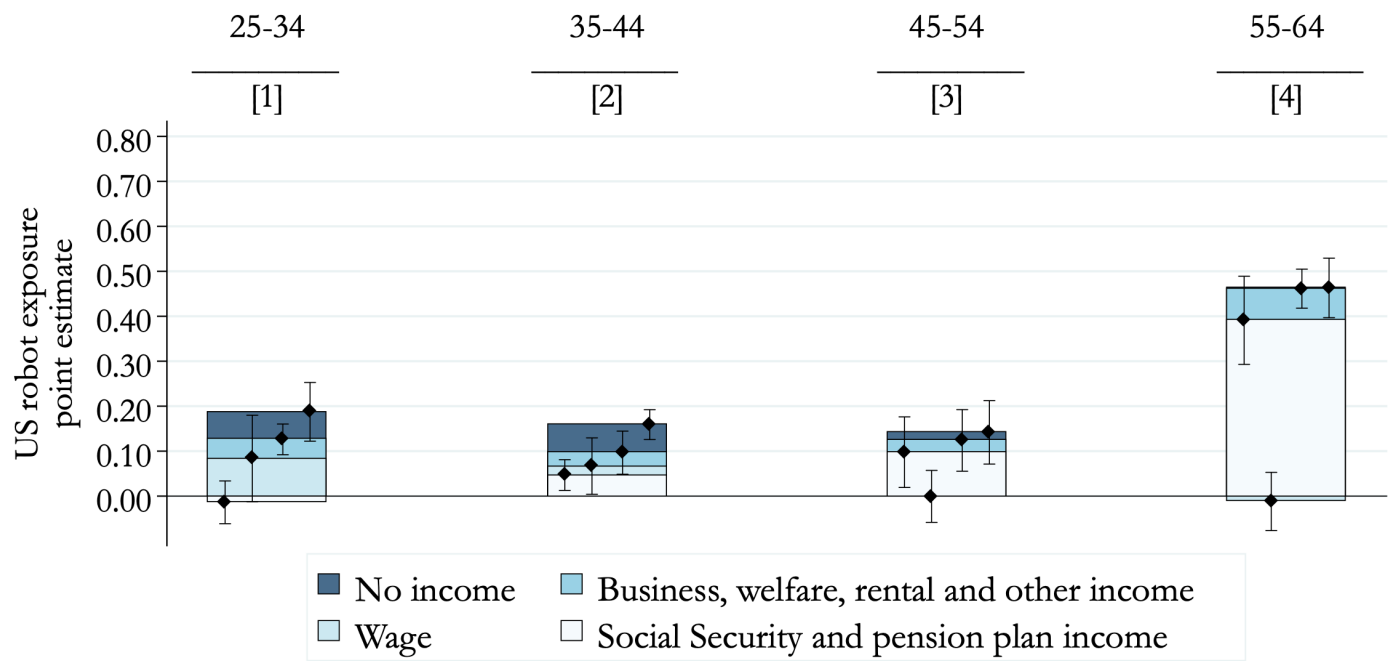

Note: This figure illustrates the point estimates of the effect of US robot exposure on the change in the non-participation rate by age and education level. Changes are expressed in percentage points of the population subgroup and are multiplied by 100 . Independent variables are standardized to have mean zero and standard deviation of one. There are three time periods and 722 CZs. The figure further illustrates the fraction of the change in non-participants which receives Social Security or pension plan income; wage income; business or farm income; welfare (public assistance) income; interest, dividend and rental income; and no income in the previous twelve months. Standard errors are robust against heteroskedasticity and allow for clustering at the state level. Confidence intervals of the effects on non-participants with Social security and pension plan income (left CI), wage income (middle-left CI), income from other sources (middle-right CI) and no income (right CI) are at the $95 \%$ level. Regressions include covariates of my preferred specification and are weighted by CZ population in 1990. 
Figure A5: Robots, non-participation and household membership

Panel A: College degree or more

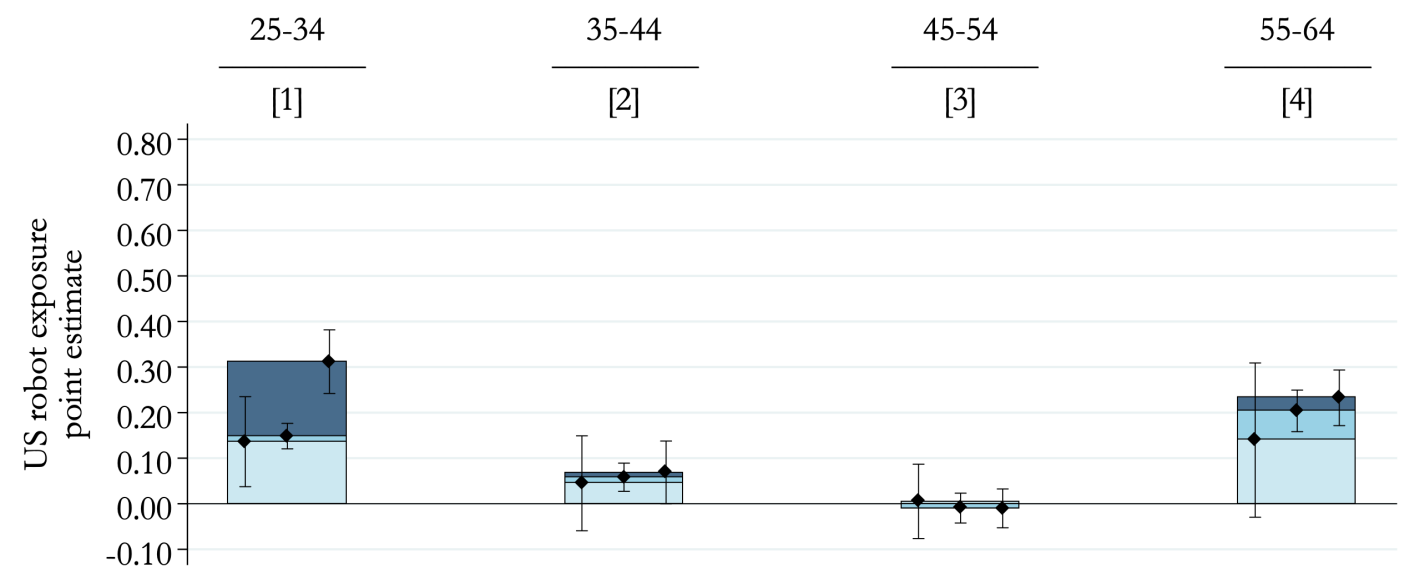

Panel B: Less than a college degree

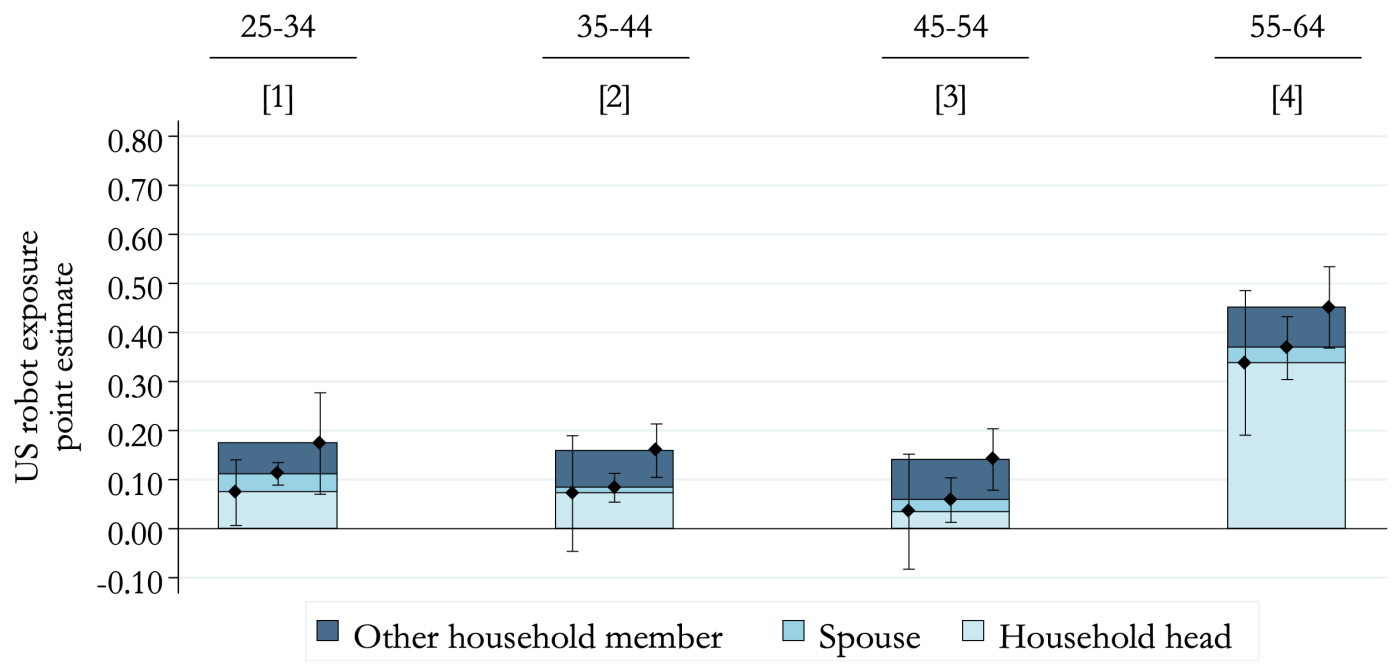

Note: This figure illustrates the point estimates of the effect of US robot exposure on the change in the non-participation rate of individuals that are the household head, the spouse or another member in the household by age and education. Changes are expressed in percentage points of the population subgroup and are multiplied by 100. Independent variables are standardized to have mean zero and standard deviation of one. There are three time periods and $722 \mathrm{CZs}$. The figure further separates between young non-participants that are household heads/spouses or other members (children, parents, siblings or non-relatives) that live in the same household. Standard errors are robust against heteroskedasticity and allow for clustering at the state level. Confidence intervals of the effects on non-participants that are household heads (left CI), spouses (middle CI) and other household members (right CI) are at the $95 \%$ level. Regressions include covariates of my preferred specification and are weighted by $\mathrm{CZ}$ population in 1990 . 
Figure A6: Robots, non-participation and employment of partner

Panel A: College degree or more

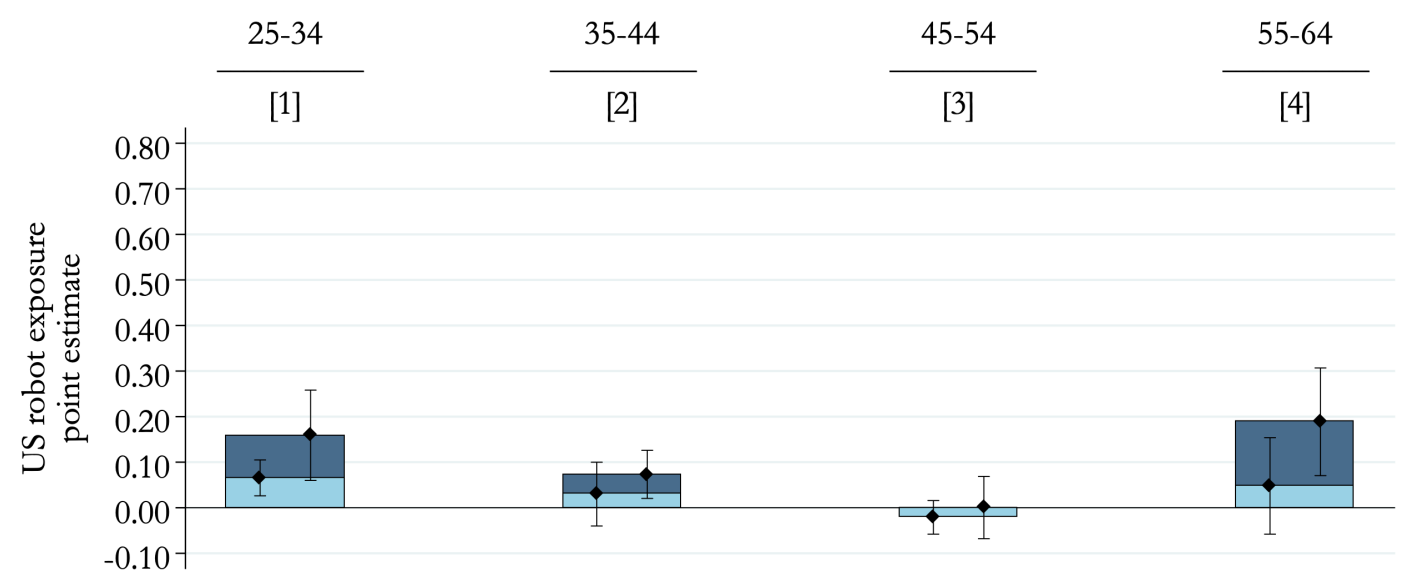

Panel B: Less than a college degree

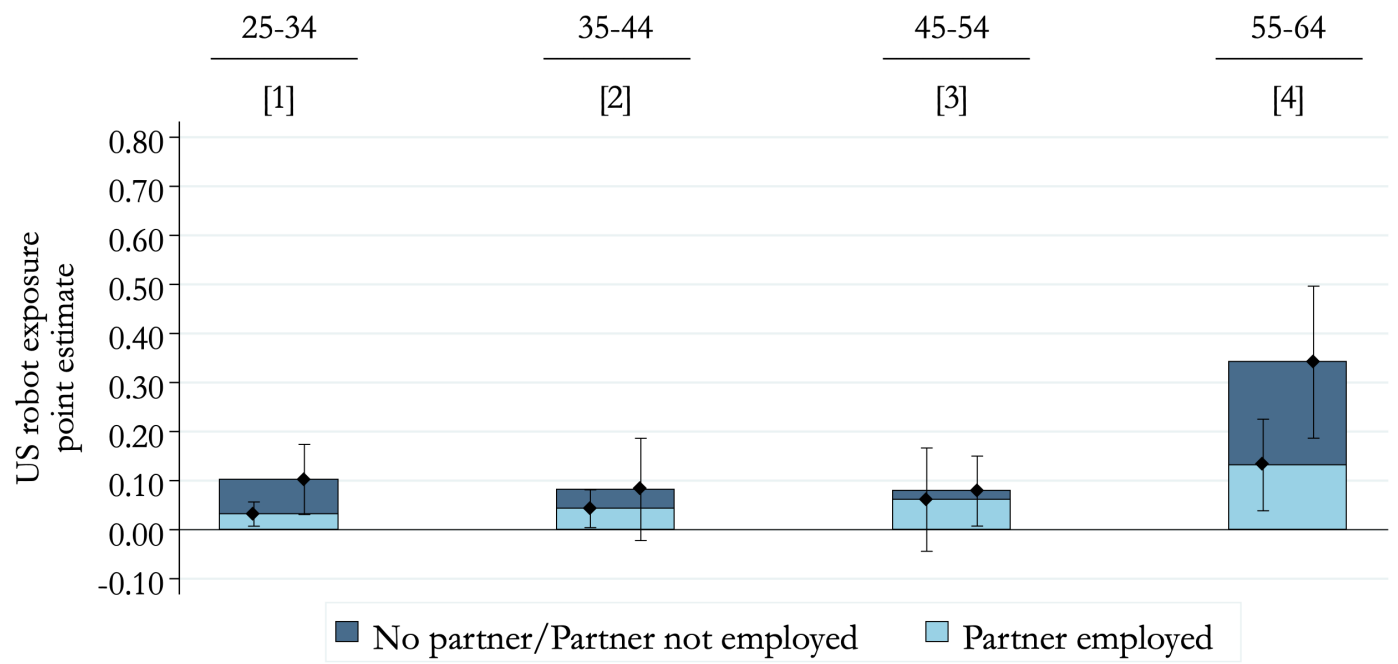

Note: This figure illustrates the point estimates of the effect of US robot exposure on the change in the non-participation rate by age and education. Changes are expressed in percentage points of the population subgroup and are multiplied by 100. Independent variables are standardized to have mean zero and standard deviation of one. There are three time periods and 722 CZs. The figure further separates between non-participants that have a partner that is employed and those without a partner or with a partner who is not employed. Standard errors are robust against heteroskedasticity and allow for clustering at the state level. Confidence intervals of the effects on non-participants that have a partner who is employed (left CI) and those without an employed partner (right CI) are at the $95 \%$ level. Regressions include covariates of my preferred specification and are weighted by CZ population in 1990. 
Figure A7: Robots, non-participation and work history of young students

Panel A: College degree or more

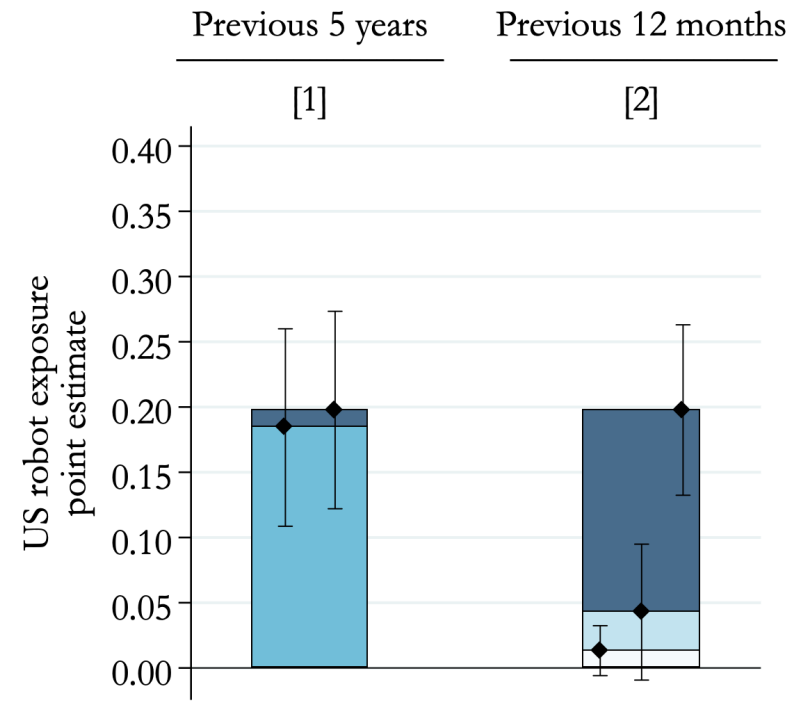

Panel B: Less than a college degree

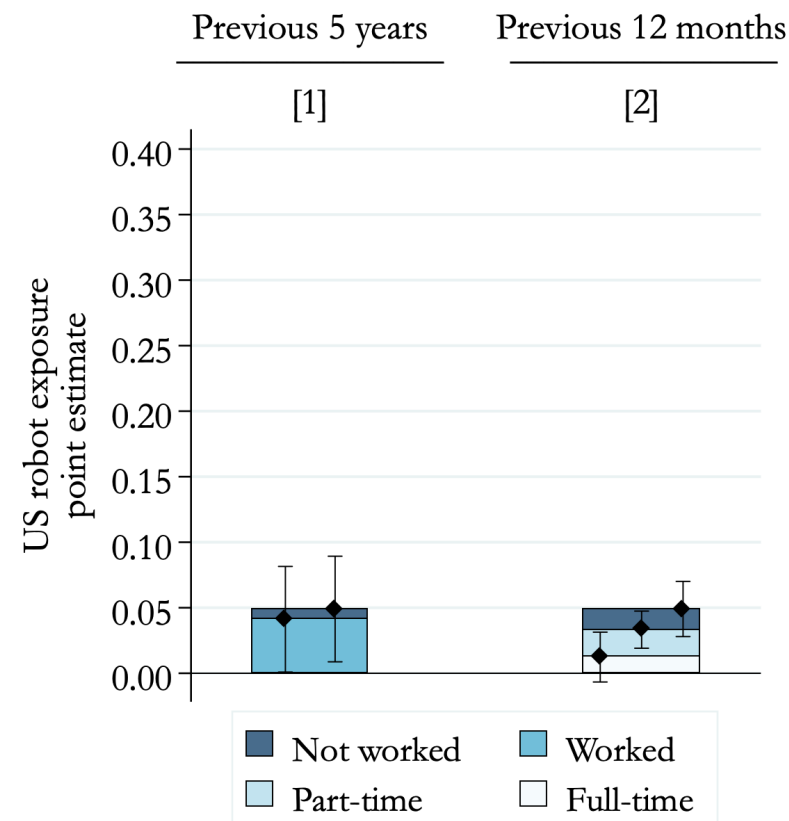

Note: This figure illustrates the point estimates of the effect of US robot exposure on the change in the non-participation rate of individuals between 25 and 34 years of age by education level. Changes are expressed in percentage points of the population subgroup and are multiplied by 100. Independent variables are standardized to have mean zero and standard deviation of one. There are three time periods and $722 \mathrm{CZs}$. The figure further illustrates the fraction of the change in non-participants which have worked in the last five years (Column 1) and individuals that worked in the last twelve months (Column 2). The latter differentiates also between part-time and full-time employment. I consider workers with an average working week of less than 30 hours (or less than 1560 hours a year) as being employed part time. Standard errors are robust against heteroskedasticity and allow for clustering at the state level. Confidence intervals of the effects on non-participants that have a work history (left CI) and have not worked (right CI) are at the $95 \%$ level. Regressions include covariates of my preferred specification and are weighted by CZ population in 1990 . 
Figure A8: Robots, non-participation and Supplemental Security Income

Panel A: College degree or more

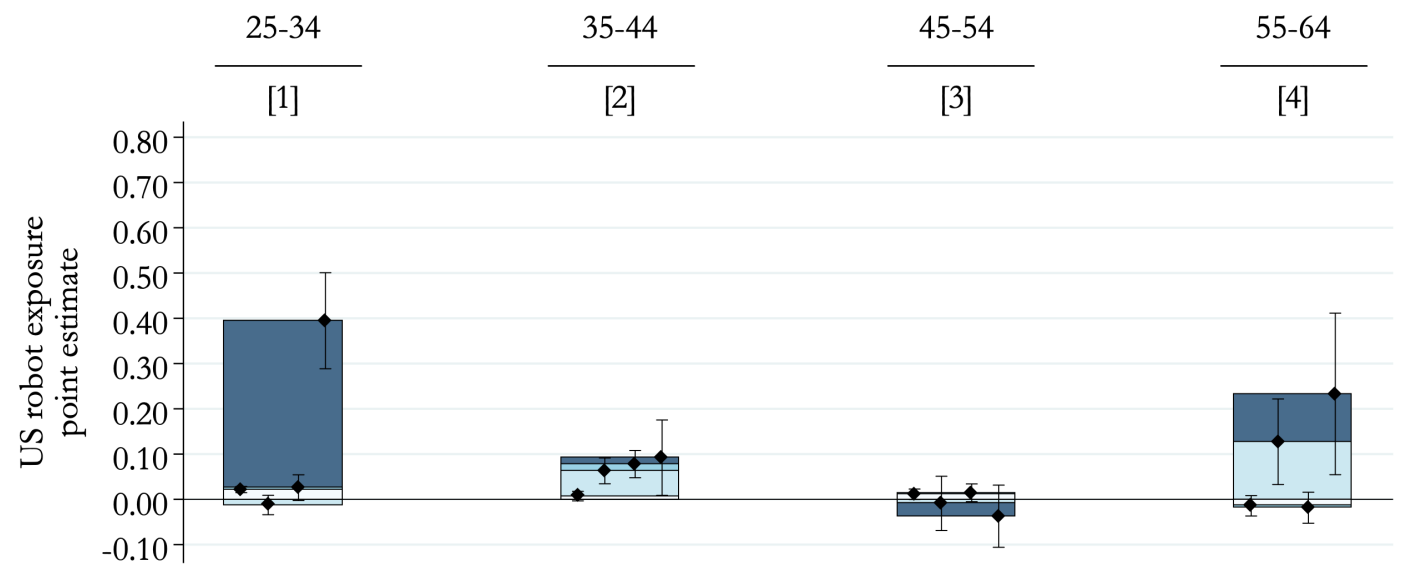

Panel B: Less than a college degree

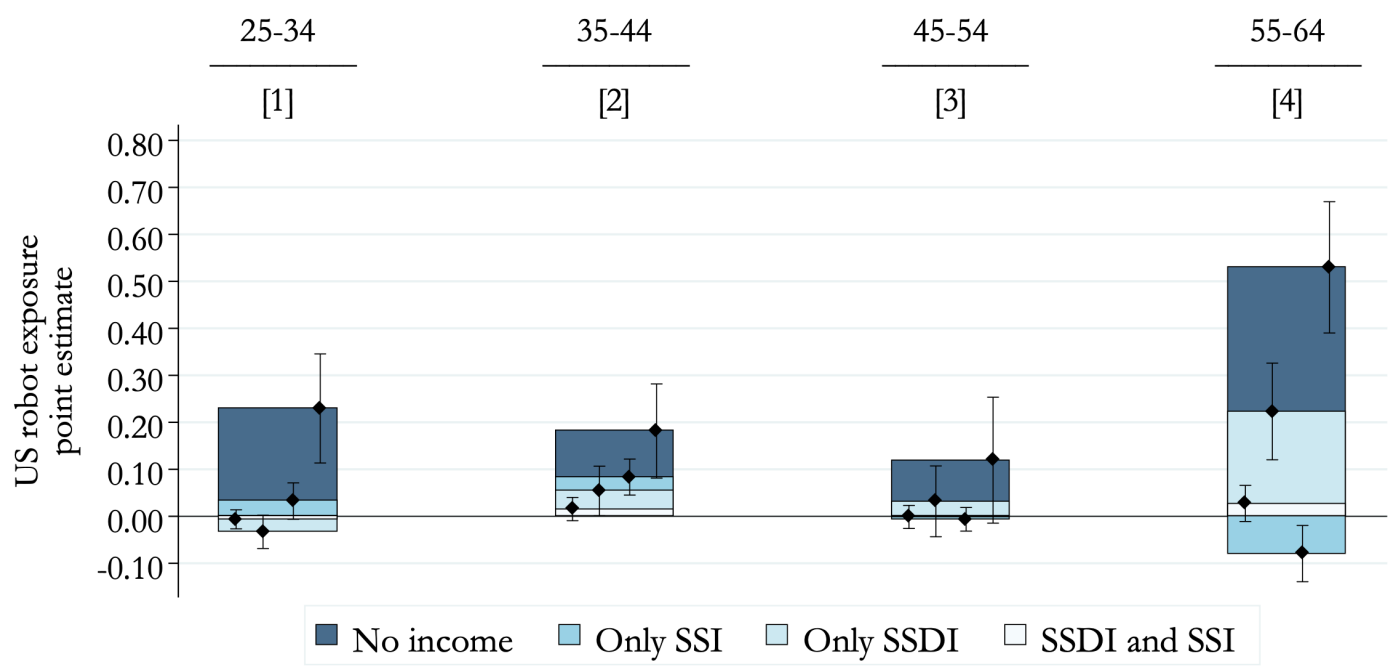

Note: This figure illustrates the point estimates of the effect of US robot exposure on the change in the non-participation rate by age and education level. Changes are expressed in percentage points of the population subgroup and are multiplied by 100 . Independent variables are standardized to have mean zero and standard deviation of one. There are $722 \mathrm{CZs}$ and two time periods (2000-07 and 2007-14), since information on SSI are not available in the 1990 census. The figure further illustrates the fraction of the change in non-participants which receives Social Security Disability Insurance income and Supplemental Security Income; only disability income; only Supplemental Security Income; and no income from the Social Security Administration. Standard errors are robust against heteroskedasticity and allow for clustering at the state level. Confidence intervals of the effects on non-participants with SSDI benefits and SSI (left CI), only SSDI benefits (middle-left CI), only SSI (middle-right CI) and no income (right CI) are at the $95 \%$ level. Regressions include covariates of my preferred specification and are weighted by CZ population in 1990 . 
Figure A9: Robots, nonemployment and health by age

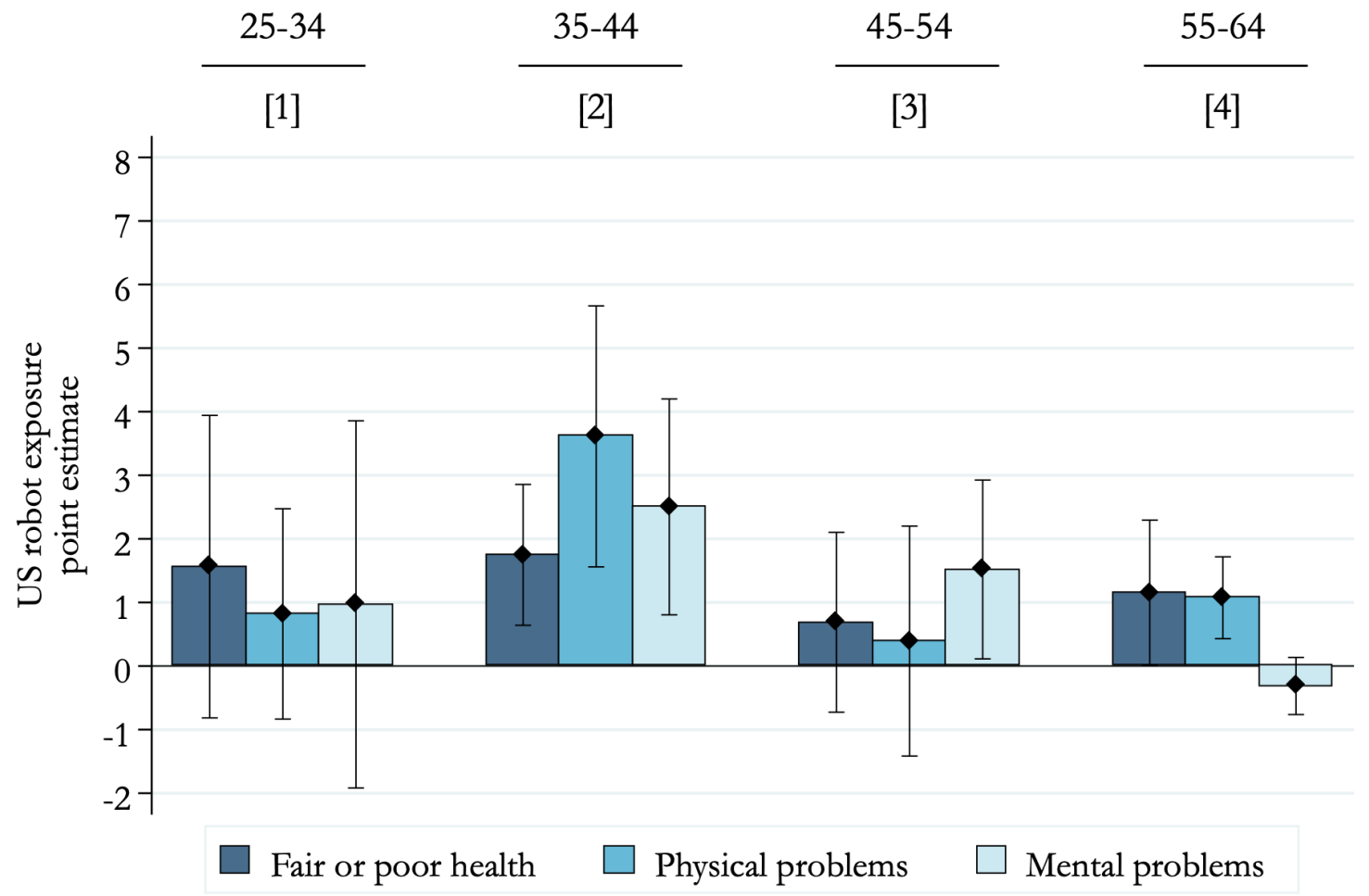

Note: This figure illustrates the point estimates of the effect of US robot exposure on the change in the share of non-employed individuals that report a fair or poor health condition, and individuals that have suffered from physical or mental health problems in 14 days of the 30 days prior to the interview by age. Changes are expressed in percentage points of non-employed individuals of the respective age group and are multiplied by 100. Independent variables are standardized to have mean zero and standard deviation of one. Every bar reports the estimate for general health, physical health or mental health problems among non-employed individuals of a specific age group. Standard errors are robust against heteroskedasticity and allow for clustering at the state level. Regressions include covariates of my preferred specification and are weighted by CZ population in the first period in which it appears in the sample. Confidence intervals are at the $95 \%$ level. 
Figure A10: Robots and hospital admissions with mental or respiratory disorders by age

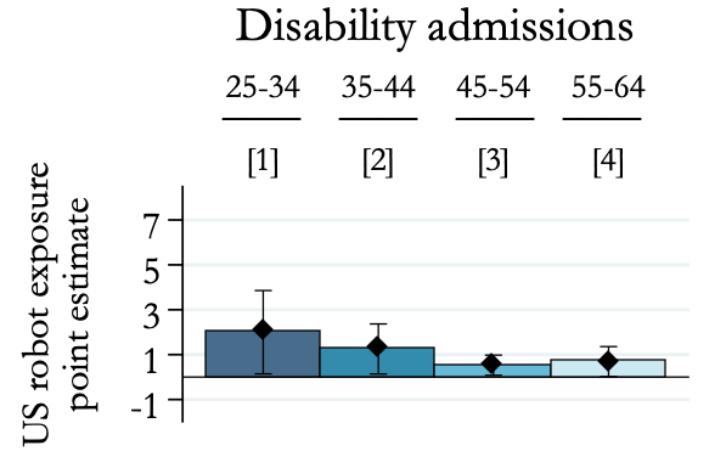

Alcohol abuse

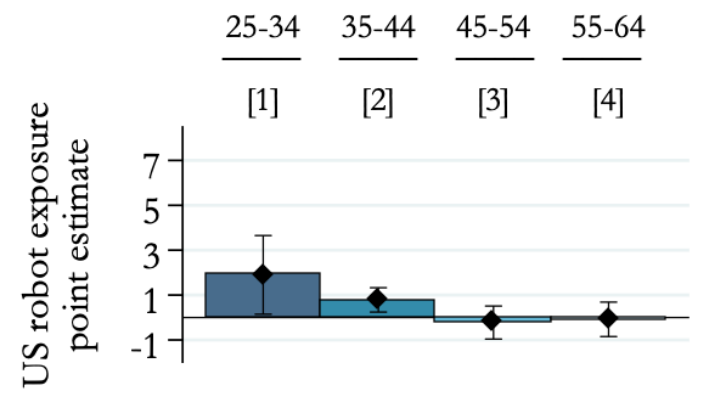

Drug abuse

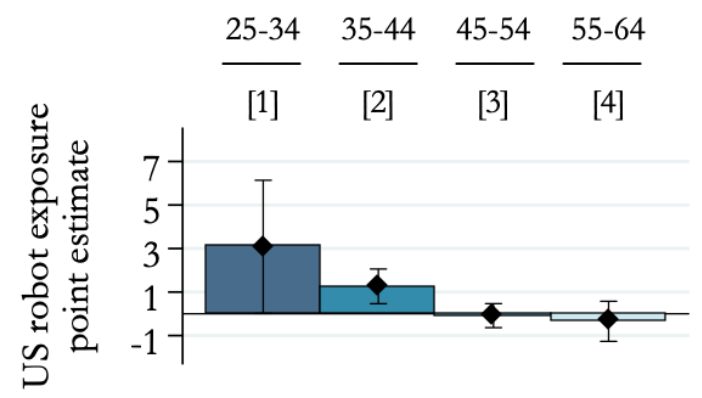

Mental disorders

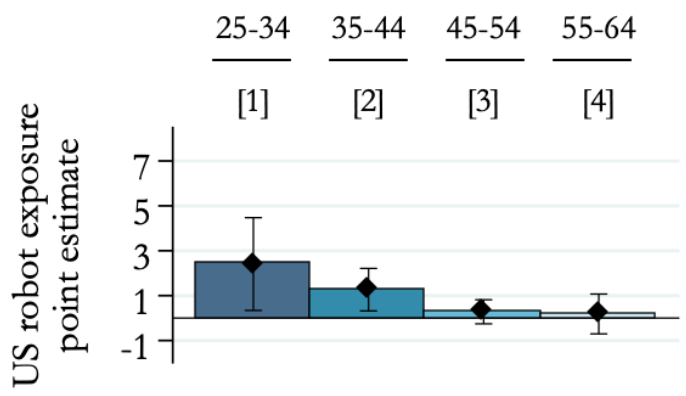

Tobacco abuse

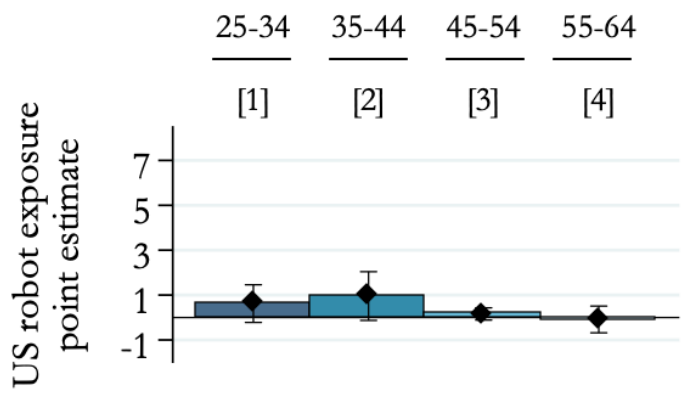

Opioid abuse

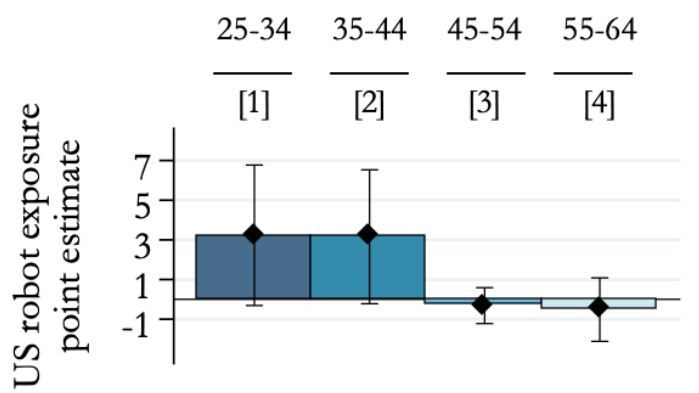

Note: This figure illustrates the point estimates of the effect of US robot exposure on the change in the share of hospital admissions with a length of stay of more than seven days by diagnosis and age. Changes are expressed in percentage points of total hospital admissions of the age group and are multiplied by 100. All variables are standardized to have mean zero and standard deviation of one. Every barplot reports the effect for a specific diagnosis for different age groups. Standard errors are robust against heteroskedasticity and allow for clustering at the state level. Regressions include covariates of my preferred specification and are weighted by CZ hospital admissions. Confidence intervals are at the $95 \%$ level. 
Figure A11: Robots, non-participation of older workers, and reliance on Social Security and pension plan income by age and education

Panel A: College degree or more

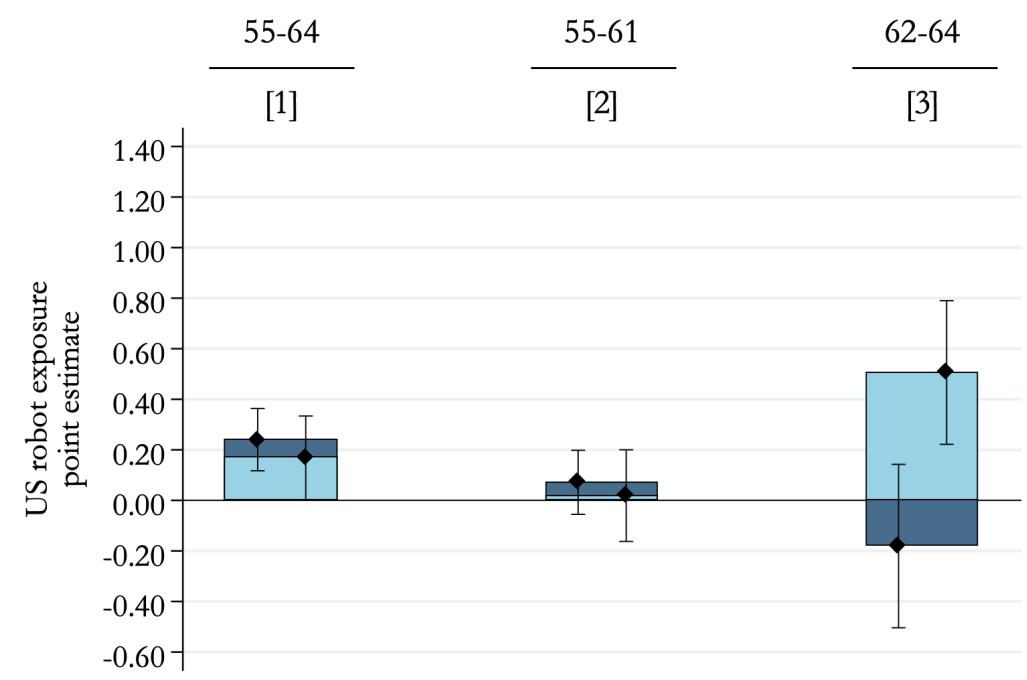

Panel B: Less than a college degree

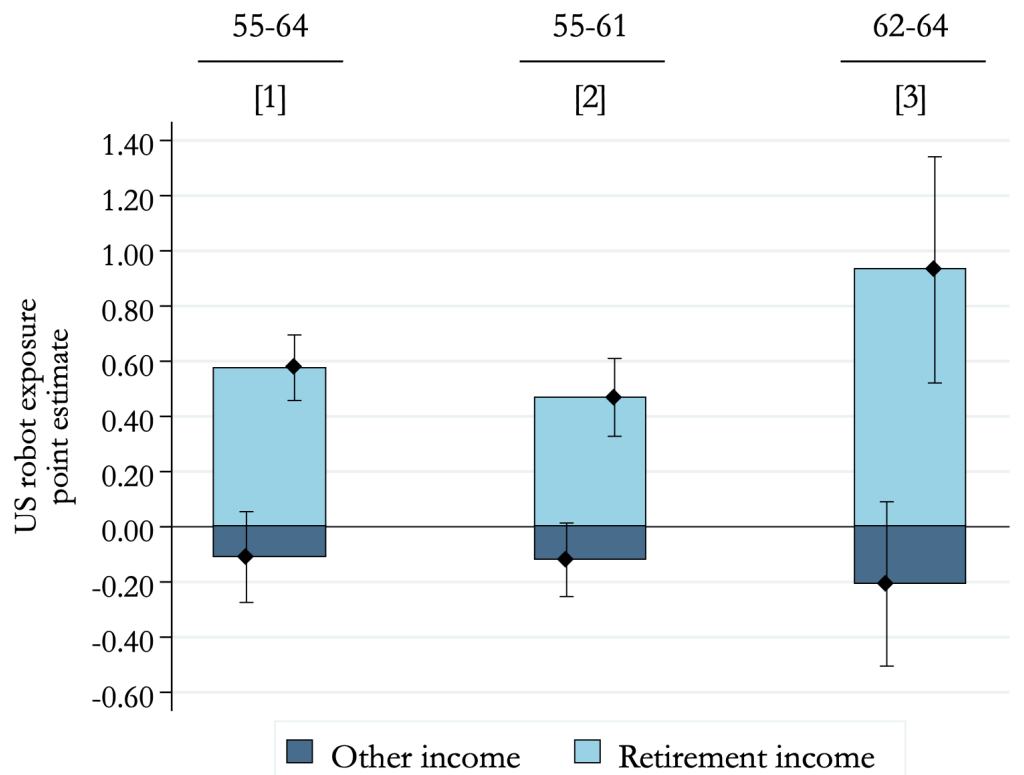

Note: This figure illustrates the point estimates of the effect of US robot exposure on the change in the non-participation rate by age and education level. Changes are expressed in percentage points of the population subgroup and are multiplied by 100 . Independent variables are standardized to have mean zero and standard deviation of one. There are three time periods and 722 CZs. The figure further illustrates the fraction of the change in non-participants which fully relies on retirement income from Social Security and/or pension plans. Social Security income below 62 years of age is considerd to be disability income from the SSDI. Social Security income from 62 years are early retirement benefits. Individuals fully rely on these income sources, if retirement income accounts for more than 90 percent of their total income. Standard errors are robust against heteroskedasticity and allow for clustering at the state level. Confidence intervals of the effects on non-participants that do not rely on retirement income (left CI) and that fully rely on retirement income (right CI) are at the $95 \%$ level. Regressions are weighted by CZ population in 1990 . 
Figure A12: European robot exposure and imports to the US

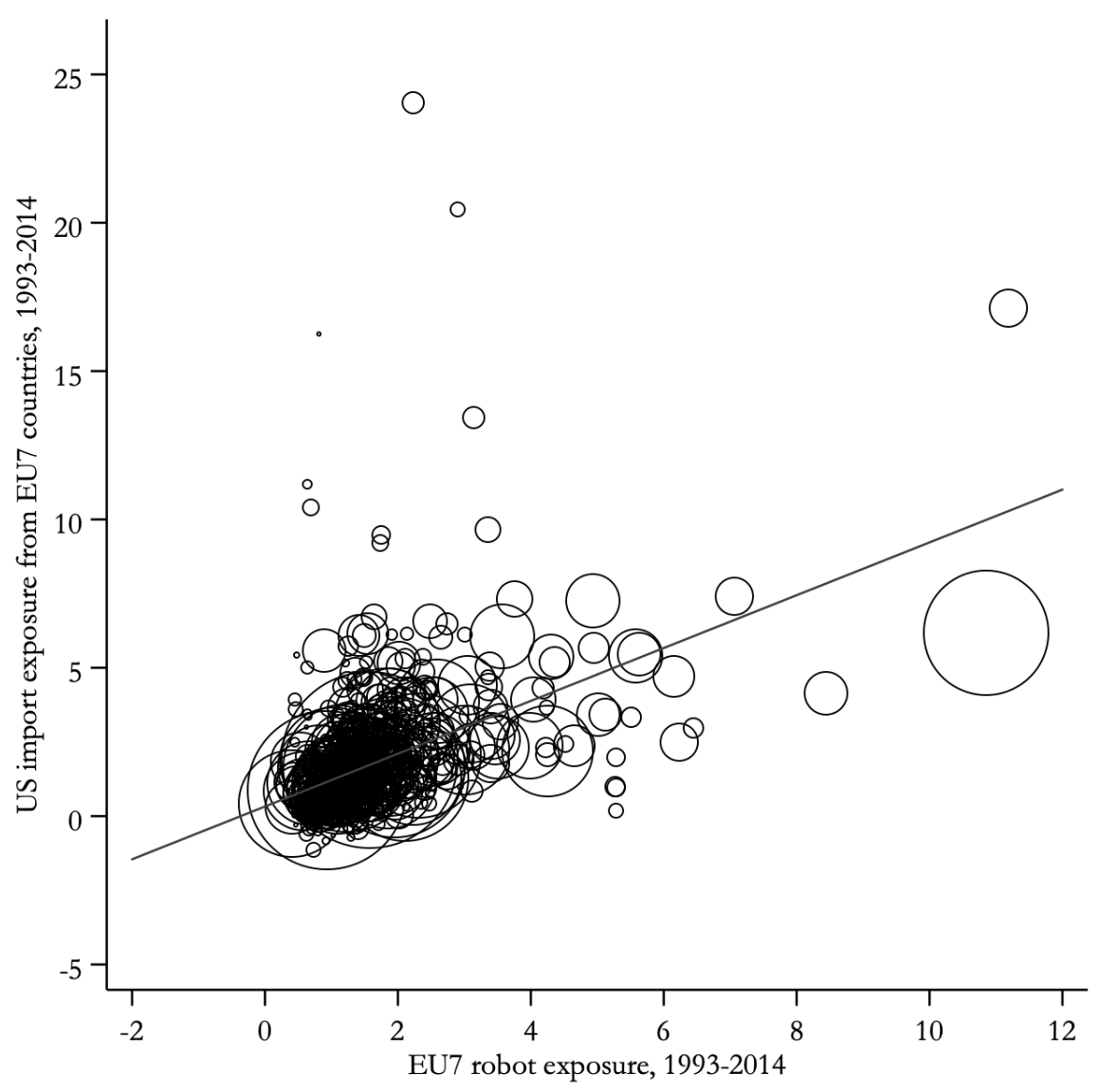

Note: This figure illustrates the unweighted correlation between robot exposure in European countries, as presented in Equation 4, and a shift-share measure of imports from these countries to the US. The size of the circles represent a labor market's size in terms of population in 1990. The solid line represents a prediction for US import exposure from European countries from a linear regression on robot exposure in Europe. 
Figure A13: Trade flows from Europe to the US and Canada by industry

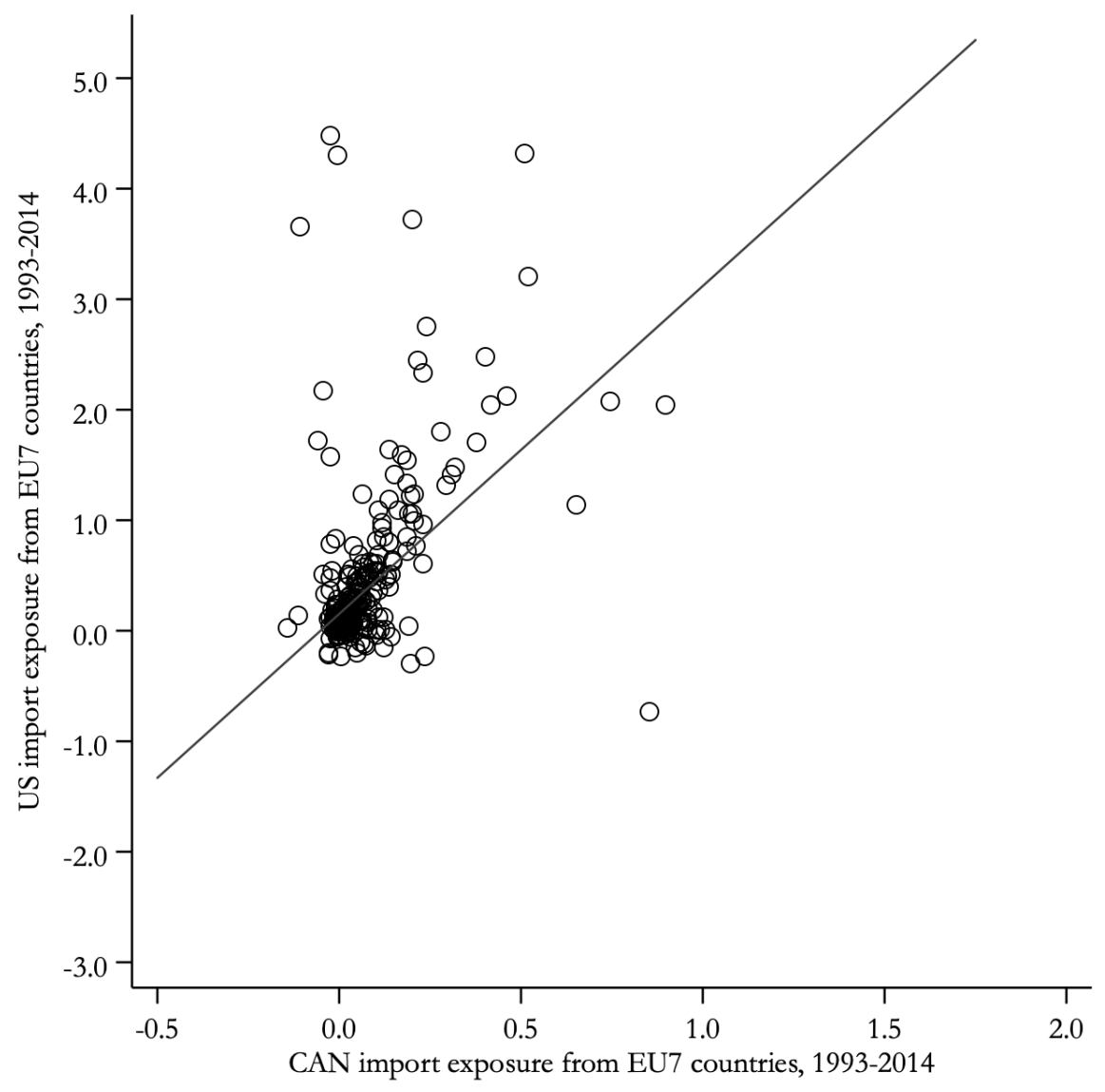

Note: This figure illustrates the unweighted correlation between imports from seven European countries (Denmark, Finland, France, Italy, Spain, Sweden and the United Kingdom) to the US and Canada. Imports are represented by SIC industry of the manufacturing sector (392) in billions of US dollars in 2017 prices. For visibility reasons, for either country I omitt outlying industries with imports that exceed six billion US dollars in the US, Canada or both. These industries are yarn spinning mills (2281), fiber cans, drums and similar products (2655), pharmaceutical preparations (2834), petroleum refining (2911), gypsum products (3275), minerals, ground or treated (3295), primary nonferrous metals, nec (3339), valves and pip fittings, nec (3494), machine tool accessories (3545), welding apparatus (3548) food products machinety (3556), noncurrent-carrying wiring devices (3644), motor vehicles and car bodies (3711), motor vehicle parts and accessories (3714), aircraft (3721). The solid line represents a prediction for US import exposure from European countries from a linear regression on Canadian import exposure from European countries based on all 392 SIC industries of the manufacturing sector. 
Figure A14: DB and DC plans by sector

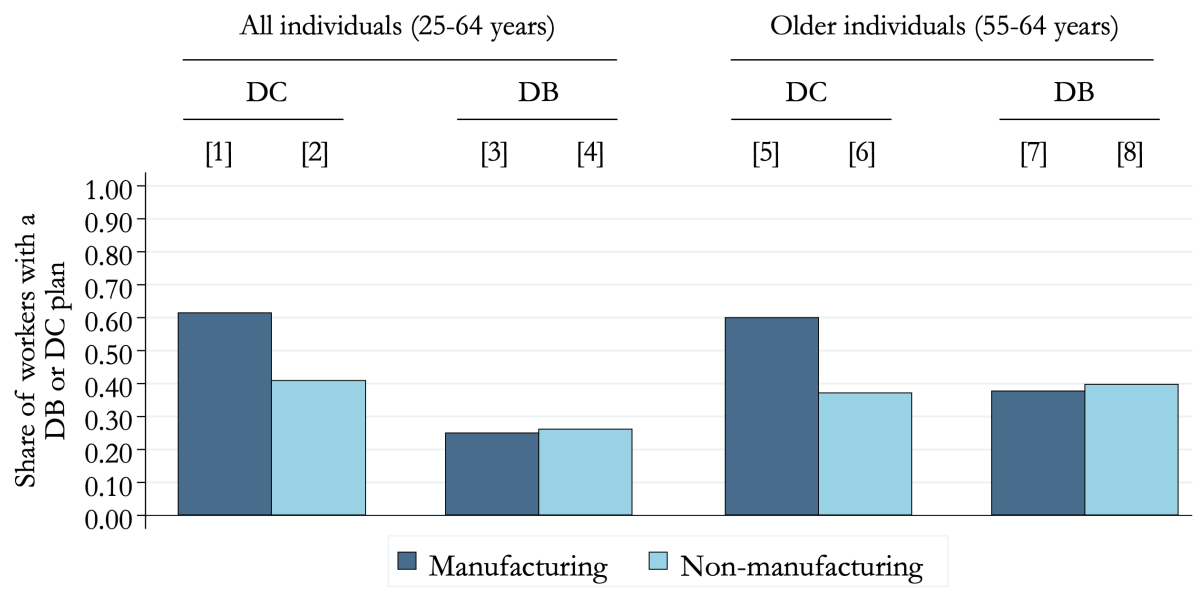

Note: This figure illustrates the shares of workers with a DB or a DC pension plan by industry group. The bars represent the average share of workers in the manufacturing sector and in industries of other sectors with one particular type of plan. Columns 1 and 2 and Columns 5 and 6 are statistically different from each other. 
Table A1: Descriptive statistics: Non-participation by gender and race/ethnicity

\begin{tabular}{|c|c|c|c|c|}
\hline & \multicolumn{2}{|c|}{ White } & \multicolumn{2}{|c|}{ Non-white } \\
\hline & Male & Female & Male & Female \\
\hline & {$[1]$} & [2] & [3] & {$[4]$} \\
\hline 1990 & 10.2 & 29.9 & 14.4 & 32.0 \\
\hline$\Delta_{2014-1990}$ & 4.82 & -3.20 & 1.84 & -2.60 \\
\hline$\% \Delta_{2014-1990}$ & 47.2 & -10.7 & 12.8 & -8.12 \\
\hline
\end{tabular}

Note: This table presents means of the non-participation rate in 1990 and the change in the non-participation rate between 1990 and 2014 by demographic group. Variables are multiplied by 100 and are weighted by the CZ population of the respective subgroup. I distinguish between four demographic groups: white males, white females, non-white males and non-white females. Non-whites include Blacks, Hispanic, American Indians, Asian and other races not elsewhere classified. 
Table A2: Descriptive statistics: Non-participation by age and education

\begin{tabular}{|c|c|c|c|c|c|}
\hline & \multicolumn{5}{|c|}{ Age groups } \\
\hline & $25-64$ & $25-34$ & $35-44$ & $45-54$ & $55-64$ \\
\hline & [1] & {$[2]$} & {$[3]$} & {$[4]$} & {$[5]$} \\
\hline \multicolumn{6}{|l|}{ Panel A: All } \\
\hline 1990 & 10.2 & 5.15 & 5.02 & 7.96 & 31.5 \\
\hline$\Delta_{2014-1990}$ & 6.01 & 2.02 & 1.95 & 9.63 & 16.8 \\
\hline Population $_{1990}$ & 100 & 28.4 & 29.0 & 23.8 & 18.6 \\
\hline Population $_{2014}$ & 100 & 20.7 & 23.6 & 27.9 & 27.6 \\
\hline \multicolumn{6}{|c|}{ Panel B: College degree or more } \\
\hline 1990 & 5.51 & 3.61 & 2.00 & 3.36 & 21.0 \\
\hline$\Delta_{2014-1990}$ & 6.03 & 1.69 & 0.98 & 4.90 & 30.4 \\
\hline Population $_{1990}$ & 16.1 & 4.14 & 5.96 & 3.60 & 2.43 \\
\hline Population $_{2014}$ & 19.9 & 4.67 & 4.13 & 5.56 & 5.55 \\
\hline \multicolumn{6}{|c|}{ Panel C: Less than a college degree } \\
\hline 1990 & 11.9 & 5.60 & 6.40 & 9.63 & 34.5 \\
\hline$\Delta_{2014-1990}$ & 5.97 & 2.09 & 2.29 & 11.3 & 13.2 \\
\hline Population $_{1990}$ & 83.8 & 24.2 & 23.0 & 20.2 & 16.2 \\
\hline Population $_{2014}$ & 80.0 & 16.1 & 19.4 & 22.4 & 22.0 \\
\hline
\end{tabular}

Note: This table presents counterfactual means of the white male non-participation rate in 1990 and the change in the nonparticipation rate between 1990 and 2014 keeping the working-age population fixed at 1990 levels by education level and age. Variables are multiplied by 100. Panel A presents means for all individuals by age group, Panel B for individuals that have achieved at least a college degree and Panel $\mathrm{C}$ for individuals without a college degree. Panels report also the subgroup population for 1990 and 2014 as a share of the normalized working-age. Column 1 reports variables for white males in their working age population. Columns 2 to 5 report variables for four 10-year age subgroups. 
Table A3: Descriptive statistics: Industrial robots

\begin{tabular}{|c|c|c|c|c|c|}
\hline & \multicolumn{2}{|c|}{$\begin{array}{c}\text { Robots in the US } \\
\text { per thousand } \\
\text { workers }\end{array}$} & \multicolumn{2}{|c|}{$\begin{array}{l}\text { Robots in EU7 } \\
\text { countries per } \\
\text { thousand workers }\end{array}$} & \multirow{2}{*}{$\begin{array}{c}\text { Employment } \\
\text { in } \\
\text { thousands }\end{array}$} \\
\hline & 1993 & $\Delta_{14-93}$ & 1993 & $\Delta_{14-93}$ & \\
\hline & {$[1]$} & {$[2]$} & {$[3]$} & {$[4]$} & {$[5]$} \\
\hline \multicolumn{6}{|c|}{ Panel A: Manufacturing industries } \\
\hline Automotive & 24.25 & 82.69 & 18.2 & 57.12 & 1111 \\
\hline Basic Metals & 1.39 & 5.37 & 0.84 & 7.34 & 712 \\
\hline Electronics & 2.01 & 10.99 & 2.34 & 3.31 & 2868 \\
\hline Food and Beverages & 1.02 & 4.62 & 0.38 & 8.93 & 1862 \\
\hline Industrial Machinery & 0.39 & 1.52 & 3.01 & 6.18 & 1541 \\
\hline Metal Products & 1.69 & 6.51 & 6.91 & 11.13 & 1689 \\
\hline Minerals & 0.04 & 0.58 & 0.60 & 3.64 & 558 \\
\hline Miscellaneous & 0.49 & 11.66 & 2.56 & 2.93 & 690 \\
\hline Paper and Printing & 0.00 & 0.10 & 0.19 & 0.83 & 2467 \\
\hline Plastics and Chemicals & 1.80 & 7.43 & 2.85 & 16.04 & 2205 \\
\hline Shipbuilding and Aerospace & 0.02 & 0.44 & 0.73 & 2.18 & 1111 \\
\hline Textiles & 0.00 & 0.05 & 0.24 & 0.88 & 1848 \\
\hline Wood and Furniture & 0.00 & 0.12 & 1.14 & 2.75 & 1048 \\
\hline \multicolumn{6}{|c|}{ Panel B: Non-manufacturing industries } \\
\hline Agriculture & 0.00 & 0.03 & 0.00 & 0.18 & 2552 \\
\hline Construction & 0.00 & 0.02 & 0.00 & 0.11 & 7108 \\
\hline Education and Research & 0.00 & 0.04 & 0.03 & 0.33 & 12636 \\
\hline Mining & 0.00 & 0.05 & 0.23 & 1.36 & 763 \\
\hline Services & 0.00 & 0.00 & 0.00 & 0.00 & 84776 \\
\hline Utilities & 0.00 & 0.02 & 0.00 & 0.25 & 745 \\
\hline
\end{tabular}

Note: This table presents the stock of robots adopted in the US and in seven European countries (Denmark, Finland, France, Italy, Spain, Sweden and the United Kingdom) by year and industry. Panel A reports information on 13 manufacturing industries, while Panel B reports information on six sectors outside of manufacturing. Columns 1 and 3 report industry values of the stock robots in 1993, and Columns 2 and 4 report the respective changes between 1993 and 2014. Finally, Column 5 reports the baseline industry employment in the US. 
Table A4: Robots and non-participation: Reduced form and OLS estimates

\begin{tabular}{lccccc}
\hline & {$[1]$} & {$[2]$} & {$[3]$} & {$[4]$} & {$[5]$} \\
\hline Panel A: Reduced form estimates & & & & & \\
EU7 robot exposure & $0.197^{* * *}$ & $0.221^{* * *}$ & $0.217^{* * *}$ & $0.189^{* * *}$ & $0.206^{* * *}$ \\
& $(0.035)$ & $(0.044)$ & $(0.033)$ & $(0.020)$ & $(0.055)$ \\
& 2166 & 2166 & 2166 & 2166 & 2166 \\
Observations & & & & & \\
Panel B: OLS estimates & & & & & \\
US robot exposure & $0.181^{* * *}$ & $0.181^{* * *}$ & $0.161^{* * *}$ & $0.126^{* * *}$ & $0.085^{*}$ \\
& $(0.038)$ & $(0.035)$ & $(0.020)$ & $(0.027)$ & $(0.045)$ \\
Observations & 2166 & 2166 & 2166 & 2166 & 2166 \\
\hline Covariates: & & & & & \\
Divisions & $\checkmark$ & $\checkmark$ & $\checkmark$ & $\checkmark$ & $\checkmark$ \\
Years & $\checkmark$ & $\checkmark$ & $\checkmark$ & $\checkmark$ & $\checkmark$ \\
Pre-trends & & $\checkmark$ & $\checkmark$ & $\checkmark$ & $\checkmark$ \\
Chinese imports & & & $\checkmark$ & $\checkmark$ & $\checkmark$ \\
Demographics & & & & $\checkmark$ & $\checkmark$ \\
Industries & & & & $\checkmark$ & $\checkmark$ \\
Occupations & & & & & $\checkmark$ \\
Unweighted & & & & & $\checkmark$ \\
\hline
\end{tabular}

Note: This table presents reduced form estimates of the effect of robot exposure (Panel A) and OLS estimates of the effect of US robot exposure (Panel B) on the change in the non-participation rate at the CZ level. Changes are expressed in percentage points of the working-age population and are multiplied by 100. Independent variables are standardized to have mean zero and standard deviation of one. There are three time periods and $722 \mathrm{CZs}$. Column 1 includes year dummies, nine census divisions and their interactions. Column 2 includes also changes in the non-participation rate and in the manufacturing employment rate between 1970 and 1990. Column 3 includes also exposure to Chinese imports. Columns 4 and 5 control also for demographic (share of individuals aged between 25 and 34 years, 35 and 44 years, 45 and 54 years, the share of Blacks, Hispanics, women and individuals with less than a college degree and logarithmic population), industry (shares of employment in the contruction, manufacturing, mining, research, service and utilities sector) and occupation (share of offshorable occupations, routine taskintensive occupations and occupations replaceable by robots) characteristics of CZ in 1990. Standard errors are robust against heteroskedasticity and allow for clustering at the state level. Regressions are weighted by CZ population in 1990 in Columns 1 to 4 and are unweighted in Column 5 . Coefficients with ${ }^{* * *},{ }^{* *}$ and ${ }^{*}$ are significant at the $1 \%, 5 \%$ and $10 \%$ confidence level. 
Table A5: Robots and non-participation between 1970-90

\begin{tabular}{lcccc}
\hline & {$[1]$} & {$[2]$} & {$[3]$} & {$[4]$} \\
\hline US robot exposure & 0.077 & 0.076 & -0.006 & 0.060 \\
& $(0.047)$ & $(0.049)$ & $(0.021)$ & $(0.106)$ \\
Observations & 1444 & 1444 & 1444 & 1444 \\
\hline Covariates: & & & & \\
Divisions & $\checkmark$ & $\checkmark$ & $\checkmark$ & $\checkmark$ \\
Years & $\checkmark$ & $\checkmark$ & $\checkmark$ & $\checkmark$ \\
Chinese imports & & $\checkmark$ & $\checkmark$ & $\checkmark$ \\
Demographics & & & $\checkmark$ & $\checkmark$ \\
Industries & & & $\checkmark$ & $\checkmark$ \\
Occupations & & & & $\checkmark$ \\
Unweighted & & & & $\checkmark$ \\
\hline
\end{tabular}

Note: This table presents IV estimates of the effect of US robot exposure on the change in the non-participation rate between 1970 and 1990 at the CZ level. Changes are expressed in percentage points of the working-age population and are multiplied by 100. Independent variables are standardized to have mean zero and standard deviation of one. There are two time periods (1970-80 and 1980-90 for non-participation and 1990-2000 and 2000-07 for robot exposure) and 722 CZs. Column 1 includes year dummies, nine census divisions and their interactions. Column 2 includes also changes in the non-participation rate and in the manufacturing employment rate between 1970 and 1990. Column 3 includes also exposure to Chinese imports. Columns 4 and 5 control also for demographic (share of individuals aged between 25 and 34 years, 35 and 44 years, 45 and 54 years, the share of Blacks, Hispanics, women and individuals with less than a college degree and logarithmic population), industry (shares of employment in the contruction, manufacturing, mining, research, service and utilities sector) and occupation (share of offshorable occupations, routine task-intensive occupations and occupations replaceable by robots) characteristics of $\mathrm{CZ}$ in 1990. Standard errors are robust against heteroskedasticity and allow for clustering at the state level. Regressions are weighted by CZ population in 1990 in Columns 1 to 4 and are unweighted in Column 5 . Coefficients with ${ }^{* * *},{ }^{* *}$ and ${ }^{*}$ are significant at the $1 \%, 5 \%$ and $10 \%$ confidence level. 
Table A6: Robots, imports and non-participation

\begin{tabular}{|c|c|c|c|c|c|}
\hline & [1] & {$[2]$} & {$[3]$} & [4] & {$[5]$} \\
\hline \multicolumn{6}{|l|}{ Panel A: IV estimates } \\
\hline US robot exposure & $\begin{array}{c}0.256^{* * *} \\
(0.059)\end{array}$ & $\begin{array}{c}0.279^{* * *} \\
(0.067)\end{array}$ & $\begin{array}{c}0.277^{* * *} \\
(0.060)\end{array}$ & $\begin{array}{c}0.257^{* * *} \\
(0.035)\end{array}$ & $\begin{array}{c}0.361^{* * *} \\
(0.121)\end{array}$ \\
\hline US import exposure & & & $\begin{array}{c}0.196^{* * *} \\
(0.067)\end{array}$ & $\begin{array}{c}0.148^{* * *} \\
(0.049)\end{array}$ & $\begin{array}{c}0.187^{* *} \\
(0.076)\end{array}$ \\
\hline Observations & 2166 & 2166 & 2166 & 2166 & 2166 \\
\hline \multicolumn{6}{|c|}{ Panel B: First-stage of US robot exposure } \\
\hline EU7 robot exposure & $\begin{array}{c}0.772^{* * *} \\
(0.052)\end{array}$ & $\begin{array}{c}0.793^{* * *} \\
(0.040)\end{array}$ & $\begin{array}{c}0.789^{* * *} \\
(0.051)\end{array}$ & $\begin{array}{c}0.740^{* * *} \\
(0.044)\end{array}$ & $\begin{array}{c}0.580^{* * *} \\
(0.059)\end{array}$ \\
\hline OT8 import exposure & & & $\begin{array}{c}0.273^{* * *} \\
(0.032)\end{array}$ & $\begin{array}{c}0.146^{* * *} \\
(0.039)\end{array}$ & $\begin{array}{c}0.070^{* *} \\
(0.032)\end{array}$ \\
\hline Observations & 2166 & 2166 & 2166 & 2166 & 2166 \\
\hline \multicolumn{6}{|c|}{ Panel C: First-stage of US import exposure } \\
\hline EU7 robot exposure & & & $\begin{array}{c}-0.006 \\
(0.011)\end{array}$ & $\begin{array}{c}-0.003 \\
(0.011)\end{array}$ & $\begin{array}{c}-0.020 \\
(0.014)\end{array}$ \\
\hline OT8 import exposure & & & $\begin{array}{c}1.003^{* * *} \\
(0.025)\end{array}$ & $\begin{array}{c}1.011^{* * *} \\
(0.023)\end{array}$ & $\begin{array}{c}0.922^{* * *} \\
(0.046)\end{array}$ \\
\hline Observations & 2166 & 2166 & 2166 & 2166 & 2166 \\
\hline \multicolumn{6}{|l|}{ Covariates: } \\
\hline Divisions & $\checkmark$ & $\checkmark$ & $\checkmark$ & $\checkmark$ & $\checkmark$ \\
\hline Years & $\checkmark$ & $\checkmark$ & $\checkmark$ & $\checkmark$ & $\checkmark$ \\
\hline Pre-trends & & $\checkmark$ & $\checkmark$ & $\checkmark$ & $\checkmark$ \\
\hline Chinese imports & & & $\checkmark$ & $\checkmark$ & $\checkmark$ \\
\hline Demographics & & & & $\checkmark$ & $\checkmark$ \\
\hline Industries & & & & $\checkmark$ & $\checkmark$ \\
\hline Occupations & & & & $\checkmark$ & $\checkmark$ \\
\hline Unweighted & & & & & $\checkmark$ \\
\hline
\end{tabular}

Note: This table presents IV estimates of the effect of robot exposure and import exposure on the change in the non-participation rate at the $\mathrm{CZ}$ level. Changes are expressed in percentage points of the working-age population and are multiplied by 100. Independent variables are standardized to have mean zero and standard deviation of one. There are three time periods and 722 CZs. Panels B and C report first stage estimates of robot exposure and import exposure. Column 1 includes year dummies, nine census divisions and their interactions. Column 2 includes also changes in the non-participation rate and in the manufacturing employment rate between 1970 and 1990. Column 3 includes also exposure to Chinese imports. Columns 4 and 5 control also for demographic (share of individuals aged between 25 and 34 years, 35 and 44 years, 45 and 54 years, the share of Blacks, Hispanics, women and individuals with less than a college degree and logarithmic population), industry (shares of employment in the contruction, manufacturing, mining, research, service and utilities sector) and occupation (share of offshorable occupations, routine task-intensive occupations and occupations replaceable by robots) characteristics of CZ in 1990. Standard errors are robust against heteroskedasticity and allow for clustering at the state level. Regressions are weighted by CZ population in 1990 in Columns 1 to 4 and are unweighted in Column 5. Coefficients with ${ }^{* * *},{ }^{* *}$ and ${ }^{*}$ are significant at the $1 \%, 5 \%$ and $10 \%$ confidence level. 
Table A7: Robots and non-participation: The role of the Great Recession

\begin{tabular}{|c|c|c|c|c|c|}
\hline & [1] & {$[2]$} & {$[3]$} & [4] & [5] \\
\hline \multicolumn{6}{|c|}{ Panel A: Exclude 2007-14 period (IV) } \\
\hline US robot exposure & $\begin{array}{c}0.242^{* * *} \\
(0.049)\end{array}$ & $\begin{array}{c}0.241^{* * *} \\
(0.045)\end{array}$ & $\begin{array}{c}0.232^{* * *} \\
(0.031)\end{array}$ & $\begin{array}{c}0.199^{* * *} \\
(0.025)\end{array}$ & $\begin{array}{c}0.257^{* * *} \\
(0.087)\end{array}$ \\
\hline Observations & 1444 & 1444 & 1444 & 1444 & 1444 \\
\hline \multicolumn{6}{|c|}{ Panel B: Effect prior and during 2007-14 period (reduced form) } \\
\hline EU7 robot exposure & $\begin{array}{c}0.190^{* * *} \\
(0.032)\end{array}$ & $\begin{array}{c}0.216^{* * *} \\
(0.041)\end{array}$ & $\begin{array}{c}0.208^{* * *} \\
(0.028)\end{array}$ & $\begin{array}{c}0.189^{* * *} \\
(0.020)\end{array}$ & $\begin{array}{c}0.210^{* * *} \\
(0.054)\end{array}$ \\
\hline EU7 robot exposure $\times 2007-14$ & $\begin{array}{c}0.342 \\
(0.349)\end{array}$ & $\begin{array}{c}0.229 \\
(0.327)\end{array}$ & $\begin{array}{c}0.388 \\
(0.336)\end{array}$ & $\begin{array}{c}0.042 \\
(0.311)\end{array}$ & $\begin{array}{l}-0.075 \\
(0.377)\end{array}$ \\
\hline Observations & 2166 & 2166 & 2166 & 2166 & 2166 \\
\hline \multicolumn{6}{|l|}{ Covariates: } \\
\hline Divisions & $\checkmark$ & $\checkmark$ & $\checkmark$ & $\checkmark$ & $\checkmark$ \\
\hline Years & $\checkmark$ & $\checkmark$ & $\checkmark$ & $\checkmark$ & $\checkmark$ \\
\hline Pre-trends & & $\checkmark$ & $\checkmark$ & $\checkmark$ & $\checkmark$ \\
\hline Chinese imports & & & $\checkmark$ & $\checkmark$ & $\checkmark$ \\
\hline Demographics & & & & $\checkmark$ & $\checkmark$ \\
\hline Industries & & & & $\checkmark$ & $\checkmark$ \\
\hline Occupations & & & & $\checkmark$ & $\checkmark$ \\
\hline Unweighted & & & & & $\checkmark$ \\
\hline
\end{tabular}

Note: This table presents estimates of the effect of US robot exposure on the change in the non-participation rate at the CZ level by examining the role of the Great Recession. Changes are expressed in percentage points of the working-age population and are multiplied by 100. Independent variables are standardized to have mean zero and standard deviation of one. There are 722 CZs. Panel A reports IV estimates and excludes the period of the Great Recession (2007-14) using only the first two periods in my sample. Panel B reports reduced form estimates and interacts robot exposure with a time dummy for the period of the Great Recession. This specification includes all three periods. Column 1 includes year dummies, nine census divisions and their interactions. Column 2 includes also changes in the non-participation rate and in the manufacturing employment rate between 1970 and 1990. Column 3 includes also exposure to Chinese imports. Columns 4 and 5 control also for demographic (share of individuals aged between 25 and 34 years, 35 and 44 years, 45 and 54 years, the share of Blacks, Hispanics, women and individuals with less than a college degree and logarithmic population), industry (shares of employment in the contruction, manufacturing, mining, research, service and utilities sector) and occupation (share of offshorable occupations, routine taskintensive occupations and occupations replaceable by robots) characteristics of CZ in 1990. Standard errors are robust against heteroskedasticity and allow for clustering at the state level. Regressions are weighted by CZ population in 1990 in Columns 1 to 4 and are unweighted in Column 5 . Coefficients with ${ }^{* * *},{ }^{* *}$ and ${ }^{*}$ are significant at the $1 \%, 5 \%$ and $10 \%$ confidence level. 
Table A8: Robot exposure across and within local labor markets

\begin{tabular}{lcc}
\hline & \multicolumn{2}{c}{ US robot exposure } \\
\cline { 2 - 3 } & Mean & Std. Dev. \\
\hline Panel A: Robots per thousand workers & \\
Overall & 0.526 & 0.491 \\
Between & & 0.452 \\
Within & & 0.192 \\
Panel B: Standardized & & \\
Overall & 0.000 & 1.000 \\
Between & & 0.921 \\
Within & & 0.391 \\
\hline & Estimates of US robot \\
& exposure between \\
& and within CZs \\
\cline { 2 - 3 } & {$[1]$} & {$[2]$} \\
\hline US robot exposure & $0.238^{* * *}$ & $0.708^{* * *}$ \\
& $(0.072)$ & $(0.187)$ \\
Observations & 722 & 2166 \\
\hline Covariates: & & \\
Divisions & $\checkmark$ & $\checkmark$ \\
Years & & $\checkmark$ \\
Pre-trends & & \\
Deminese imports & $\checkmark$ & $\checkmark$ \\
Industries & & \\
Occupations & & \\
CZ fixed effects & $\checkmark$ & $\checkmark$ \\
\hline
\end{tabular}

Note: The first part of this table presents unweighted averages and the between and within CZ standard deviation of US robot exposure. Panel A reports the mean and standard deviations in robots per thousand workers. Panel B reports standardized measures with mean zero and overall standard deviation of one. The second part of the table presents IV estimates of the effect of US robot exposure on the change in the non-participation rate and exploits between and within CZ variation in robot adoption separately. Changes are expressed in percentage points of the working-age population and are multiplied by 100 . Independent variables are standardized to have mean zero and standard deviation of one. Column 1 uses a long-difference specification between 1993 and 2014 and includes nine census divisions, changes in the non-participation rate and in the manufacturing employment rate between 1970 and 1990, exposure to Chinese imports and demographic (share of individuals aged between 25 and 34 years, 35 and 44 years, 45 and 54 years, the share of Blacks, Hispanics, women and individuals with less than a college degree and logarithmic population), industry (shares of employment in the contruction, manufacturing, mining, research, service and utilities sector) and occupation (share of offshorable occupations, routine task-intensive occupations and occupations replaceable by robots) characteristics of CZ in 1990. There is one period and there are 722 CZs. Column 2 uses a stacked first-difference specification and includes year dummies, nine census divisions, their interactions and CZ fixed effects. There are three time periods and $722 \mathrm{CZs}$. Standard errors are robust against heteroskedasticity and allow for clustering at the state level. Regressions are weighted by $\mathrm{CZ}$ population in 1990 . Coefficients with ${ }^{* * *},{ }^{* *}$ and ${ }^{*}$ are significant at the $1 \%, 5 \%$ and $10 \%$ confidence level. 
Table A9: Robots and migration across CZs using IRS data

\begin{tabular}{lccccc}
\hline & {$[1]$} & {$[2]$} & {$[3]$} & {$[4]$} & {$[5]$} \\
\hline Panel A: Outflows & & & & & \\
US robot exposure & -0.097 & -0.058 & -0.058 & 0.032 & 0.014 \\
& $(0.059)$ & $(0.040)$ & $(0.039)$ & $(0.021)$ & $(0.051)$ \\
Observations & 2166 & 2166 & 2166 & 2166 & 2166 \\
Panel B: Inflows & & & & & \\
US robot exposure & & & & & \\
& $-0.127^{* *}$ & $-0.079^{*}$ & $-0.078^{*}$ & 0.011 & -0.032 \\
Observations & $(0.060)$ & $(0.040)$ & $(0.040)$ & $(0.024)$ & $(0.075)$ \\
\hline Covariates: & 2166 & 2166 & 2166 & 2166 & 2166 \\
Divisions & & & & & \\
Years & $\checkmark$ & $\checkmark$ & $\checkmark$ & $\checkmark$ & $\checkmark$ \\
Pre-trends & $\checkmark$ & $\checkmark$ & $\checkmark$ & $\checkmark$ & $\checkmark$ \\
Chinese imports & & $\checkmark$ & $\checkmark$ & $\checkmark$ & $\checkmark$ \\
Demographics & & & $\checkmark$ & $\checkmark$ & $\checkmark$ \\
Industries & & & & $\checkmark$ & $\checkmark$ \\
Occupations & & & $\checkmark$ & $\checkmark$ \\
Unweighted & & & & $\checkmark$ \\
\hline
\end{tabular}

Note: This table presents IV estimates of the effect of US robot exposure on migration in- and outflows at the CZ level. Changes are expressed in percentage points of the population and are multiplied by 100. Independent variables are standardized to have mean zero and standard deviation of one. There are three time periods and $722 \mathrm{CZs}$. Column 1 includes year dummies, nine census divisions and their interactions. Column 2 includes also changes in the non-participation rate and in the manufacturing employment rate between 1970 and 1990. Column 3 includes also exposure to Chinese imports. Columns 4 and 5 control also for demographic (share of individuals aged between 25 and 34 years, 35 and 44 years, 45 and 54 years, the share of Blacks, Hispanics, women and individuals with less than a college degree and logarithmic population), industry (shares of employment in the contruction, manufacturing, mining, research, service and utilities sector) and occupation (share of offshorable occupations, routine task-intensive occupations and occupations replaceable by robots) characteristics of CZ in 1990. Standard errors are robust against heteroskedasticity and allow for clustering at the state level. Regressions are weighted by CZ population in 1990 in Columns 1 to 4 and are unweighted in Column 5. Coefficients with ${ }^{* * *},{ }^{* *}$ and ${ }^{*}$ are significant at the $1 \%, 5 \%$ and $10 \%$ confidence level. 
Table A10: Effect of robots on employment and non-participation of women

\begin{tabular}{lccccc}
\hline & {$[1]$} & {$[2]$} & {$[3]$} & {$[4]$} & {$[5]$} \\
\hline Panel A: Employment & & & & & \\
US robot exposure & $-0.156^{* * *}$ & $-0.155^{* * *}$ & $-0.161^{* * *}$ & $-0.171^{* * *}$ & -0.060 \\
& $(0.052)$ & $(0.052)$ & $(0.047)$ & $(0.051)$ & $(0.112)$ \\
Observations & 2166 & 2166 & 2166 & 2166 & 2166 \\
Panel B: Non-participation & & & & & \\
US robot exposure & & & & & \\
& $(0.045)$ & $(0.045)$ & $(0.042)$ & $(0.044)$ & $(0.127)$ \\
Observations & 2166 & 2166 & 2166 & 2166 & 2166 \\
\hline Covariates: & & & & & \\
Divisions & $\checkmark$ & $\checkmark$ & $\checkmark$ & $\checkmark$ & $\checkmark$ \\
Years & & $\checkmark$ & $\checkmark$ & $\checkmark$ & $\checkmark$ \\
Pre-trends & & $\checkmark$ & $\checkmark$ & $\checkmark$ & $\checkmark$ \\
Chinese imports & & & $\checkmark$ & $\checkmark$ & $\checkmark$ \\
$\begin{array}{l}\text { Demographics } \\
\text { Industries }\end{array}$ & & & & $\checkmark$ & $\checkmark$ \\
Occupations & & & & $\checkmark$ & $\checkmark$ \\
Unweighted & & & & & $\checkmark$ \\
\hline
\end{tabular}

Note: This table presents IV estimates of the effect of US robot exposure on the change in employment and non-participation of women at the CZ level. Changes are expressed in percentage points of the working-age population and are multiplied by 100. Independent variables are standardized to have mean zero and standard deviation of one. There are three time periods and 722 CZs. Column 1 includes year dummies, nine census divisions and their interactions. Column 2 includes also changes in the non-participation rate and in the manufacturing employment rate between 1970 and 1990. Column 3 includes also exposure to Chinese imports. Columns 4 and 5 control also for demographic (share of individuals aged between 25 and 34 years, 35 and 44 years, 45 and 54 years, the share of Blacks, Hispanics, women and individuals with less than a college degree and logarithmic population), industry (shares of employment in the contruction, manufacturing, mining, research, service and utilities sector) and occupation (share of offshorable occupations, routine task-intensive occupations and occupations replaceable by robots) characteristics of CZ in 1990. Standard errors are robust against heteroskedasticity and allow for clustering at the state level. Regressions are weighted by CZ population in 1990 in Columns 1 to 4 and are unweighted in Column 5. Coefficients with ***, ${ }^{* *}$ and ${ }^{*}$ are significant at the $1 \%, 5 \%$ and $10 \%$ confidence level. 
Table A11: Non-participation, school enrollment and robot exposure in the area of origin of students

\begin{tabular}{lccc}
\hline & $\begin{array}{c}\text { College degree } \\
\text { or more }\end{array}$ & $\begin{array}{c}\text { Less than } \\
\text { college }\end{array}$ \\
\cline { 2 - 2 } & {$[1]$} & & {$[2]$} \\
\hline Panel A: Local & $0.198^{* * *}$ & & $0.043^{* *}$ \\
US robot exposure & $(0.031)$ & & $(0.017)$ \\
$c_{d}$ & 2166 & & 2166 \\
Observations & & \\
Panel B: Weighted & $0.189^{* * *}$ & & $0.055^{* * *}$ \\
US robot exposure & $\left(c_{o}, c_{d}\right)$ & $(0.027)$ & \\
& 2166 & \\
Observations & $\checkmark$ & & 2166 \\
\hline Covariates: & & $\checkmark$ \\
\hline
\end{tabular}

Note: This table presents IV estimates of the effect of a weighted measure of robot exposure as in Di Giacomo and Lerch (2021) on the change in school enrollment of non-participants the CZ level. Changes are expressed in percentage points of the population subgroup and are multiplied by 100. Independent variables are standardized to have mean zero and standard deviation of one. There are three time periods and $722 \mathrm{CZs}$. Every regression includes year dummies, nine census divisions and their interactions, changes in the non-participation rate and the manufacturing employment rate between 1970 and 1990 , exposure to Chinese imports and demographic (share of individuals aged between 25 and 34 years, 35 and 44 years, 45 and 54 years, the share of Blacks, Hispanics, women and individuals with less than a college degree and logarithmic population), industry (shares of employment in the contruction, manufacturing, mining, research, service and utilities sector) and occupation (share of offshorable occupations, routine task-intensive occupations and occupations replaceable by robots) characteristics of $\mathrm{CZ}$ in 1990. Standard errors are robust against heteroskedasticity and allow for clustering at the state level. Regressions are weighted by $\mathrm{CZ}$ population in 1990 . Coefficients with ${ }^{* * *},{ }^{* *}$ and ${ }^{*}$ are significant at the $1 \%, 5 \%$ and $10 \%$ confidence level. 
Table A12: Robots, non-participation and school enrollment with institution controls

\begin{tabular}{lccc}
\hline \multicolumn{1}{l}{$[1]$} & {$[2]$} & {$[3]$} \\
\hline Panel A: College degree or more & & & \\
US robot exposure & $\begin{array}{c}0.198^{* * *} \\
(0.031)\end{array}$ & $\begin{array}{c}0.231^{* * *} \\
(0.061)\end{array}$ & $\begin{array}{c}0.192^{* * *} \\
(0.035)\end{array}$ \\
& 2166 & 2166 & 2166 \\
Observations & & & \\
Panel B: Less than college & & & \\
US robot exposure & $0.043^{* *}$ & $0.038^{*}$ & $0.044^{* *}$ \\
& $(0.017)$ & $(0.021)$ & $(0.022)$ \\
Observations & 2166 & 2166 & 2166 \\
\hline Covariates: & & & \\
Divisions & $\checkmark$ & $\checkmark$ & $\checkmark$ \\
Years & $\checkmark$ & $\checkmark$ & $\checkmark$ \\
Chinese imports & $\checkmark$ & $\checkmark$ & $\checkmark$ \\
Demographics & $\checkmark$ & $\checkmark$ & $\checkmark$ \\
Industries & $\checkmark$ & $\checkmark$ & $\checkmark$ \\
Occupations & & $\checkmark$ & $\checkmark$ \\
Institutions in 1990 & & $\checkmark$ & \\
Institutions in $t_{0}$ & & & $\checkmark$ \\
\hline
\end{tabular}

Note: This table presents IV estimates of the effect of robot exposure on the change in the non-participation rate of individuals who are enrolled in school by education at the CZ level. Changes are expressed in percentage points of the population subgroup and are multiplied by 100. Independent variables are standardized to have mean zero and standard deviation of one. There are three time periods and $722 \mathrm{CZs}$. Every regression includes year dummies, nine census divisions and their interactions, changes in the non-participation rate and the manufacturing employment rate between 1970 and 1990, exposure to Chinese imports and demographic (share of individuals aged between 25 and 34 years, 35 and 44 years, 45 and 54 years, the share of Blacks, Hispanics, women and individuals with less than a college degree and logarithmic population), industry (shares of employment in the contruction, manufacturing, mining, research, service and utilities sector) and occupation (share of offshorable occupations, routine task-intensive occupations and occupations replaceable by robots) characteristics of CZ in 1990. Columns 2 and 3 include also institutional controls in 1990 and in each subperiod respectively (number of public institutions, for-profit institutions, nonprofit institutions, community colleges and the number of top 20 schools in the university ranking). Standard errors are robust against heteroskedasticity and allow for clustering at the state level. Regressions are weighted by CZ population in 1990 . Coefficients with ${ }^{* * *},{ }^{* *}$ and ${ }^{*}$ are significant at the $1 \%, 5 \%$ and $10 \%$ confidence level. 
Table A13: Robots and self-reported physical and mental health of non-employed individuals

\begin{tabular}{|c|c|c|c|c|c|c|c|c|c|c|c|c|c|c|c|}
\hline & \multicolumn{14}{|c|}{ Days of health problems in the last 30 days } & \multirow{3}{*}{$\frac{21 \text { days }}{[15]}$} \\
\hline & 7 day & 8 days & 9 days & 10 days & 11 days & 12 days & 13 days & 14 days & 15 days & 16 days & 17 days & 18 days & 19 days & 20 days & \\
\hline & [1] & {$[2]$} & {$[3]$} & {$[4]$} & {$[5]$} & {$[6]$} & {$[7]$} & {$[8]$} & [9] & {$[10]$} & {$[11]$} & {$[12]$} & {$[13]$} & {$[14]$} & \\
\hline \multicolumn{16}{|c|}{ Panel A: Physical problems } \\
\hline US robot exposure & $\begin{array}{l}0.794^{* * *} \\
(0.344)\end{array}$ & $\begin{array}{c}0.934^{* * *} \\
(0.308)\end{array}$ & $\begin{array}{c}1.066^{* * *} \\
(0.314)\end{array}$ & $\begin{array}{c}0.951^{* * *} \\
(0.302)\end{array}$ & $\begin{array}{c}1.007^{* * *} \\
(0.200)\end{array}$ & $\begin{array}{c}0.989^{* * *} \\
(0.201)\end{array}$ & $\begin{array}{c}1.092^{* * *} \\
(0.243)\end{array}$ & $\begin{array}{c}1.078^{* * *} \\
(0.239)\end{array}$ & $\begin{array}{c}0.780^{* * *} \\
(0.238)\end{array}$ & $\begin{array}{l}0.483^{* *} \\
(0.194)\end{array}$ & $\begin{array}{l}0.479^{* *} \\
(0.195)\end{array}$ & $\begin{array}{l}0.524^{* *} \\
(0.201)\end{array}$ & $\begin{array}{l}0.509^{* *} \\
(0.212)\end{array}$ & $\begin{array}{l}0.530^{* *} \\
(0.212)\end{array}$ & $\begin{array}{l}0.611^{* *} \\
(0.249)\end{array}$ \\
\hline Observations & 1238 & 1238 & 1238 & 1238 & 1238 & 1238 & 1238 & 1238 & 1238 & 1238 & 1238 & 1238 & 1238 & 1238 & 1238 \\
\hline \multicolumn{16}{|c|}{ Panel B: Mental problems } \\
\hline US robot exposure & $\begin{array}{c}0.065 \\
(0.253)\end{array}$ & $\begin{array}{c}0.048 \\
(0.280)\end{array}$ & $\begin{array}{c}0.263 \\
(0.334)\end{array}$ & $\begin{array}{c}0.298 \\
(0.320)\end{array}$ & $\begin{array}{l}0.437^{*} \\
(0.249)\end{array}$ & $\begin{array}{l}0.450^{*} \\
(0.254)\end{array}$ & $\begin{array}{c}0.432 \\
(0.264)\end{array}$ & $\begin{array}{c}0.409 \\
(0.267)\end{array}$ & $\begin{array}{c}0.244 \\
(0.253)\end{array}$ & $\begin{array}{c}0.543^{* * *} \\
(0.176)\end{array}$ & $\begin{array}{c}0.553^{* * *} \\
(0.172)\end{array}$ & $\begin{array}{c}0.558^{* * *} \\
(0.166)\end{array}$ & $\begin{array}{c}0.580^{* * *} \\
(0.164)\end{array}$ & $\begin{array}{c}0.581^{* * *} \\
(0.164)\end{array}$ & $\begin{array}{c}0.641^{* * *} \\
(0.163)\end{array}$ \\
\hline Observations & 1238 & 1238 & 1238 & 1238 & 1238 & 1238 & 1238 & 1238 & 1238 & 1238 & 1238 & 1238 & 1238 & 1238 & 1238 \\
\hline Covariates: & $\checkmark$ & $\checkmark$ & $\checkmark$ & $\checkmark$ & $\checkmark$ & $\checkmark$ & $\checkmark$ & $\checkmark$ & $\checkmark$ & $\checkmark$ & $\checkmark$ & $\checkmark$ & $\checkmark$ & $\checkmark$ & $\checkmark$ \\
\hline
\end{tabular}

Note: This table presents IV estimates of the effect of US robot exposure on the change in self-reported health problems of non-employed individuals in the last 30 days. Panel A reports physical health problems and Panel B reports mental health problems. Changes are expressed in percentage points of non-employed working-age population multiplied by 100. All variables are standardized to have mean zero and standard deviation of one. All regressions include year dummies, nine census divisions and their interactions, as well as changes in the non-participation rate and the manufacturing employment rate between 1970 and 1990 , exposure to Chinese imports and demographic (share of individuals aged between 25 and 34 years, 35 and 44 years, 45 and 54 years, the share of Blacks, Hispanics, women and individuals with less than a college degree and logarithmic population), industry (shares of employment in the contruction, manufacturing, mining, research, service and utilities sector) and occupation (share of offshorable occupations, routine task-intensive occupations and occupations replaceable by robots) characteristics of CZ in 1990. Standard errors are robust against heteroskedasticity and allow for clustering at the state level. Regressions are weighted by CZ population in 1990 . Coefficients with ${ }^{* * *},{ }^{* *}$ and ${ }^{*}$ are significant at the $1 \%, 5 \%$ and $10 \%$ confidence level. 
Table A14: Robots and hospital admissions with disability-related diagnoses and mental disorders by length of stay

\begin{tabular}{|c|c|c|c|c|c|c|c|c|c|c|c|c|c|c|c|}
\hline & \multicolumn{14}{|c|}{ Minimum length of stay } & \multirow{3}{*}{$\frac{14 \text { days }}{[15]}$} \\
\hline & 0 days & 1 day & 2 days & 3 days & 4 days & 5 days & 6 days & 7 days & 8 days & 9 days & 10 days & 11 days & 12 days & 13 days & \\
\hline & [1] & [2] & {$[3]$} & [4] & [5] & [6] & [7] & [8] & [9] & [10] & [11] & [12] & [13] & [14] & \\
\hline \multicolumn{16}{|c|}{ Panel A: Disability-related diagnosis } \\
\hline US robot exposure & $\begin{array}{l}0.790^{* *} \\
(0.303)\end{array}$ & $\begin{array}{c}0.185 \\
(0.394)\end{array}$ & $\begin{array}{c}0.380 \\
(0.299)\end{array}$ & $\begin{array}{l}0.719^{* *} \\
(0.311)\end{array}$ & $\begin{array}{c}1.007^{* *} \\
(0.420)\end{array}$ & $\begin{array}{l}1.226^{* *} \\
(0.553)\end{array}$ & $\begin{array}{l}1.262^{* *} \\
(0.600)\end{array}$ & $\begin{array}{c}1.147^{* *} \\
(0.516)\end{array}$ & $\begin{array}{l}1.084^{* *} \\
(0.495)\end{array}$ & $\begin{array}{l}1.018^{* *} \\
(0.476)\end{array}$ & $\begin{array}{l}1.004^{* *} \\
(0.466)\end{array}$ & $\begin{array}{l}0.994^{* *} \\
(0.462)\end{array}$ & $\begin{array}{c}0.956^{* *} \\
(0.444)\end{array}$ & $\begin{array}{l}0.973^{* *} \\
(0.452)\end{array}$ & $\begin{array}{l}0.976^{\text {** }} \\
(0.449)\end{array}$ \\
\hline Observations & 469 & 469 & 469 & 469 & 469 & 469 & 469 & 469 & 469 & 469 & 469 & 469 & 469 & 469 & 469 \\
\hline \multicolumn{16}{|c|}{ Panel B: Mental disorders } \\
\hline US robot exposure & $\begin{array}{l}-0.243 \\
(0.857)\end{array}$ & $\begin{array}{l}-0.378 \\
(0.936)\end{array}$ & $\begin{array}{l}-0.113 \\
(0.825)\end{array}$ & $\begin{array}{c}0.341 \\
(0.591)\end{array}$ & $\begin{array}{c}0.834^{* *} \\
(0.398)\end{array}$ & $\begin{array}{c}1.276^{* * *} \\
(0.431)\end{array}$ & $\begin{array}{c}1.480^{* * *} \\
(0.517)\end{array}$ & $\begin{array}{c}1.458^{* * *} \\
(0.515)\end{array}$ & $\begin{array}{c}1.452^{* * *} \\
(0.522)\end{array}$ & $\begin{array}{l}1.459^{* *} \\
(0.543)\end{array}$ & $\begin{array}{l}1.576^{* *} \\
(0.607)\end{array}$ & $\begin{array}{l}1.618^{* *} \\
(0.628)\end{array}$ & $\begin{array}{l}1.581^{* *} \\
(0.615)\end{array}$ & $\begin{array}{l}1.608^{* *} \\
(0.645)\end{array}$ & $\begin{array}{l}1.658^{* *} \\
(0.649)\end{array}$ \\
\hline Observations & 469 & 469 & 469 & 469 & 469 & 469 & 469 & 469 & 469 & 469 & 469 & 469 & 469 & 469 & 469 \\
\hline Covariates: & $\checkmark$ & $\checkmark$ & $\checkmark$ & $\checkmark$ & $\checkmark$ & $\checkmark$ & $\checkmark$ & $\checkmark$ & $\checkmark$ & $\checkmark$ & $\checkmark$ & $\checkmark$ & $\checkmark$ & $\checkmark$ & $\checkmark$ \\
\hline
\end{tabular}

Note: This table presents IV estimates of the effect of US robot exposure on the change in the share of hospital admissions by minimum length of stay. Panel A reports hospital admissions with disability-related conditions (arthritis and rheumatism; back and spine problems; circulatory system diseases; respiratory system diseases; mental disorders; and diabetes). Panel B reports hospital admissions with mental disorders. Changes are expressed in percentage points of CZ hospital admissions multiplied by 100 . All variables diabetes). Panel B reports hospital admissions with mental disorders. Changes are expressed in percentage points of CZ hospital admissions multiplied by 100 . All variables
are standardized to have mean zero and standard deviation of one. All regressions include year dummies, nine census divisions and their interactions, as well as changes in the non-participation rate and the manufacturing employment rate between 1970 and 1990, exposure to Chinese imports and demographic (share of individuals aged between 25 and 34 years, 35 and 44 years, 45 and 54 years, the share of Blacks, Hispanics, women and individuals with less than a college degree and logarithmic population), industry (shares of employment in the contruction, manufacturing, mining, research, service and utilities sector) and occupation (share of offshorable occupations, routine task-intensive occupations and occupations replaceable by robots) characteristics of CZ in 1990. Standard errors are robust against heteroskedasticity and allow for clustering at the state level. Regressions are weighted by CZ hospital admissions. Coefficients with ${ }^{* * *},{ }^{* *}$ and ${ }^{*}$ are significant at the $1 \%, 5 \%$ and $10 \%$ confidence level. 
Table A15: Robots and hospital admissions with disability-related disorders (include also admissions with a stay of less than seven days)

\begin{tabular}{|c|c|c|c|c|c|c|}
\hline & $\begin{array}{l}\text { Arthritis } \\
\& \text { rheu- } \\
\text { matology }\end{array}$ & $\begin{array}{c}\text { Back or } \\
\text { spine } \\
\text { problems }\end{array}$ & $\begin{array}{l}\text { Ciculato- } \\
\text { ry system } \\
\text { diseases }\end{array}$ & $\begin{array}{l}\text { Respira- } \\
\text { tory system } \\
\text { diseases }\end{array}$ & $\begin{array}{c}\text { Mental } \\
\text { disorders }\end{array}$ & Diabetes \\
\hline & {$[1]$} & {$[2]$} & {$[3]$} & {$[4]$} & {$[5]$} & {$[6]$} \\
\hline US robot exposure & $\begin{array}{l}0.557^{*} \\
(0.292)\end{array}$ & $\begin{array}{c}0.238 \\
(0.149)\end{array}$ & $\begin{array}{c}0.448 \\
(0.444)\end{array}$ & $\begin{array}{l}0.347^{*} \\
(0.199)\end{array}$ & $\begin{array}{l}-0.290 \\
(0.864)\end{array}$ & $\begin{array}{l}0.363^{* *} \\
(0.173)\end{array}$ \\
\hline Observations & 469 & 469 & 469 & 469 & 469 & 469 \\
\hline Covariates: & $\checkmark$ & $\checkmark$ & $\checkmark$ & $\checkmark$ & $\checkmark$ & $\checkmark$ \\
\hline
\end{tabular}

Note: This table presents IV estimates of the effect of US robot exposure on the change in the share of hospital admissions with a diagnosis related to a cause of disability. Changes are expressed in percentage points of CZ hospital admissions multiplied by 100. Columns 1 to 6 report admissions diagnosed with arthritis or rheumatology, back or spine problems, circulatory system diseases, respiratory system diseases, mental disorders and diabetes. All variables are standardized to have mean zero and standard deviation of one. All regressions include year dummies, nine census divisions and their interactions, as well as changes in the non-participation rate and the manufacturing employment rate between 1970 and 1990, exposure to Chinese imports and demographic (share of individuals aged between 25 and 34 years, 35 and 44 years, 45 and 54 years, the share of Blacks, Hispanics, women and individuals with less than a college degree and logarithmic population), industry (shares of employment in the contruction, manufacturing, mining, research, service and utilities sector) and occupation (share of offshorable occupations, routine task-intensive occupations and occupations replaceable by robots) characteristics of CZ in 1990. Standard errors are robust against heteroskedasticity and allow for clustering at the state level. Regressions are weighted by CZ hospital admissions. Coefficients with ${ }^{* * *},{ }^{* *}$ and ${ }^{*}$ are significant at the $1 \%, 5 \%$ and $10 \%$ confidence level. 
Table A16: Robots and hospital admissions with disorders not directly related to a disability

\begin{tabular}{|c|c|c|c|c|c|c|c|}
\hline & \multicolumn{7}{|c|}{ Organic \& physical diseases } \\
\hline & $\begin{array}{c}\text { Infectious \& } \\
\text { parasitic } \\
\text { diseases }\end{array}$ & Cancer & $\begin{array}{c}\text { Endocr. } \\
\text { nutrition. } \\
\text { metabolic } \\
\text { diseases }\end{array}$ & $\begin{array}{l}\text { Nervous } \\
\text { system } \\
\text { diseases }\end{array}$ & $\begin{array}{l}\text { Digestive } \\
\text { system } \\
\text { diseases }\end{array}$ & $\begin{array}{c}\text { Skin \& } \\
\text { subcut. } \\
\text { tissue } \\
\text { diseases }\end{array}$ & $\begin{array}{c}\text { Unclassified } \\
\text { pain }\end{array}$ \\
\hline & [1] & [2] & {$[3]$} & [4] & [5] & {$[6]$} & [7] \\
\hline \multicolumn{8}{|c|}{ Panel A: Admissions by diagnosis } \\
\hline US robot exposure & $\begin{array}{c}0.140 \\
(0.139)\end{array}$ & $\begin{array}{c}0.271 \\
(1.491)\end{array}$ & $\begin{array}{c}1.166^{* * *} \\
(0.400)\end{array}$ & $\begin{array}{l}0.710^{*} \\
(0.379)\end{array}$ & $\begin{array}{c}0.471 \\
(0.386)\end{array}$ & $\begin{array}{c}0.298 \\
(0.266)\end{array}$ & $\begin{array}{c}0.283 \\
(0.372)\end{array}$ \\
\hline Observations & 469 & 469 & 469 & 469 & 469 & 469 & 469 \\
\hline \multicolumn{8}{|c|}{ Panel B: Admissions by diagnosis a with length of stay of more than seven days } \\
\hline US robot exposure & $\begin{array}{c}0.225 \\
(0.254)\end{array}$ & $\begin{array}{c}0.992 \\
(1.505)\end{array}$ & $\begin{array}{l}0.750^{*} \\
(0.372)\end{array}$ & $\begin{array}{c}0.423 \\
(0.261)\end{array}$ & $\begin{array}{c}0.585 \\
(0.415)\end{array}$ & $\begin{array}{l}0.471^{*} \\
(0.253)\end{array}$ & $\begin{array}{c}0.336 \\
(0.381)\end{array}$ \\
\hline Observations & 469 & 469 & 469 & 469 & 469 & 469 & 469 \\
\hline \multirow[t]{4}{*}{ Covariates: } & $\checkmark$ & $\checkmark$ & $\checkmark$ & $\checkmark$ & $\checkmark$ & $\checkmark$ & $\checkmark$ \\
\hline & \multicolumn{4}{|c|}{ Substance abuse } & \multicolumn{3}{|c|}{ External causes } \\
\hline & $\begin{array}{l}\text { Alcohol } \\
\text { abuse }\end{array}$ & $\begin{array}{c}\text { Tobacco } \\
\text { products } \\
\text { abuse }\end{array}$ & $\begin{array}{l}\text { Drug } \\
\text { abuse }\end{array}$ & $\begin{array}{l}\text { Opioid } \\
\text { abuse }\end{array}$ & Injuries & $\begin{array}{l}\text { Suicide } \\
\text { attempt }\end{array}$ & Accidents \\
\hline & [1] & {$[2]$} & {$[3]$} & {$[4]$} & [5] & [6] & [7] \\
\hline \multicolumn{8}{|c|}{ Panel C: Admissions by diagnosis } \\
\hline US robot exposure & $\begin{array}{l}-0.124 \\
(0.426)\end{array}$ & $\begin{array}{l}-1.025 \\
(1.042)\end{array}$ & $\begin{array}{c}-0.946 \\
(1.175)\end{array}$ & $\begin{array}{l}-1.436 \\
(1.343)\end{array}$ & $\begin{array}{l}-0.837 \\
(0.768)\end{array}$ & $\begin{array}{l}-0.380 \\
(0.480)\end{array}$ & $\begin{array}{l}-1.233 \\
(0.787)\end{array}$ \\
\hline Observations & 469 & 469 & 469 & 469 & 469 & 469 & 469 \\
\hline \multicolumn{8}{|c|}{ Panel D: Admissions by diagnosis with a length of stay of more than seven days } \\
\hline US robot exposure & $\begin{array}{l}0.353^{*} \\
(0.177)\end{array}$ & $\begin{array}{l}0.802^{* *} \\
(0.343)\end{array}$ & $\begin{array}{l}2.070^{* *} \\
(0.883)\end{array}$ & $\begin{array}{l}3.283^{*} \\
(1.781)\end{array}$ & $\begin{array}{c}0.045 \\
(0.319)\end{array}$ & $\begin{array}{c}0.608 \\
(0.532)\end{array}$ & $\begin{array}{l}-0.471 \\
(0.463)\end{array}$ \\
\hline Observations & 469 & 469 & 469 & 469 & 469 & 469 & 469 \\
\hline Covariates: & $\checkmark$ & $\checkmark$ & $\checkmark$ & $\checkmark$ & $\checkmark$ & $\checkmark$ & $\checkmark$ \\
\hline
\end{tabular}

Note: This table presents IV estimates of the effect of US robot exposure on the change in the share of hospital admissions with a diagnosis that is not directly related to a cause of disability. Panel A reports all hospital admissions by diagnosis type. Panel B reports hospital admissions with a length of stay of more than seven days by diagnosis type. Changes are expressed in percentage points of $\mathrm{CZ}$ hospital admissions multiplied by 100. All variables are standardized to have mean zero and standard deviation of one. All regressions include year dummies, nine census divisions and their interactions, as well as changes in the non-participation rate and the manufacturing employment rate between 1970 and 1990, exposure to Chinese imports and demographic (share of individuals aged between 25 and 34 years, 35 and 44 years, 45 and 54 years, the share of Blacks, Hispanics, women and individuals with less than a college degree and logarithmic population), industry (shares of employment in the contruction, manufacturing, mining, research, service and utilities sector) and occupation (share of offshorable occupations, routine task-intensive occupations and occupations replaceable by robots) characteristics of CZ in 1990. Standard errors are robust against heteroskedasticity and allow for clustering at the state level. Regressions are weighted by CZ hospital admissions. Coefficients with ${ }^{* * *},{ }^{* *}$ and ${ }^{*}$ are significant at the $1 \%, 5 \%$ and $10 \%$ confidence level. 
Table A17: Rotemberg weights

\begin{tabular}{|c|c|c|c|c|c|c|}
\hline & \multicolumn{5}{|c|}{$\begin{array}{c}\text { Rotemberg } \\
\text { weights }\end{array}$} & \multirow{2}{*}{$\begin{array}{c}\begin{array}{c}\text { Share of } \\
\text { robot change }\end{array} \\
{[6]}\end{array}$} \\
\hline & {$[1]$} & {$[2]$} & {$[3]$} & {$[4]$} & {$[5]$} & \\
\hline Automotive & .560 & .597 & .601 & .627 & .449 & .563 \\
\hline Plastics and Chemicals & .154 & .131 & .131 & .134 & .276 & .103 \\
\hline Basic Metals & .080 & .076 & .076 & .073 & .050 & .057 \\
\hline Electronics & .080 & .076 & .057 & .058 & .046 & .007 \\
\hline Food and Beverages & .076 & .075 & .081 & .083 & .136 & .068 \\
\hline Industrial Machinery & .017 & .018 & .022 & .019 & .020 & .035 \\
\hline Mining & .003 & .005 & .007 & .006 & .021 & .004 \\
\hline \multicolumn{7}{|l|}{ Covariates: } \\
\hline Divisions & $\checkmark$ & $\checkmark$ & $\checkmark$ & $\checkmark$ & $\checkmark$ & \\
\hline Pre-trends & & $\checkmark$ & $\checkmark$ & $\checkmark$ & $\checkmark$ & \\
\hline Chinese imports & & & $\checkmark$ & $\checkmark$ & $\checkmark$ & \\
\hline Demographics & & & & $\checkmark$ & $\checkmark$ & \\
\hline Industries & & & & $\checkmark$ & $\checkmark$ & \\
\hline Occupations & & & & $\checkmark$ & $\checkmark$ & \\
\hline Unweighted & & & & & $\checkmark$ & \\
\hline
\end{tabular}

Note: This table presents Rotemberg weights for the eight industries with the highest robot adoption between 1993 and 2014 - as explained in Goldsmith-Pinkham et al. (2020) - and the share of the overall change in robot stock between 1993 and 2014 that comes from these industries. Columns 1 to 5 report the average industry Rotemberg weights over the sample period for different model specifications. Column 1 includes nine census divisions. Column 2 includes also changes in the non-participation rate and in the manufacturing employment rate between 1970 and 1990. Column 3 includes also exposure to Chinese imports. Columns 4 and 5 control also for demographic (share of individuals aged between 25 and 34 years, 35 and 44 years, 45 and 54 years, the share of blacks, hispanics, women and individuals with less than a college degree and logarithmic population), industry (shares of employment in the contruction, manufacturing, mining, research, service and utilities sector) and occupation (share of offshorable occupations, routine task-intensive occupations and occupations replaceable by robots) characteristics of CZ in 1990. Regressions are weighted by CZ population in 1990 in Columns 1 to 4 and are unweighted in Column 5 . Column 6 reports the fraction of robot introduction over the sample period that comes from the eight industries with the highest average Rotemberg weights. 
Table A18: Robots and non-participation: Labor market specialization in the automotive industry

\begin{tabular}{lccccc}
\hline & {$[1]$} & {$[2]$} & {$[3]$} & {$[4]$} & {$[5]$} \\
\hline EU7 robot exposure: Low & $0.597^{* * *}$ & $0.727^{* * *}$ & $0.654^{* * *}$ & $0.483^{* * *}$ & $0.552^{* * *}$ \\
& $(0.144)$ & $(0.164)$ & $(0.145)$ & $(0.150)$ & $(0.139)$ \\
EU7 robot exposure: Middle & $0.312^{* * *}$ & $0.429^{* * *}$ & $0.403^{* * *}$ & $0.329^{* * *}$ & 0.305 \\
& $(0.088)$ & $(0.096)$ & $(0.097)$ & $(0.113)$ & $(0.202)$ \\
& $0.181^{* * *}$ & $0.208^{* * *}$ & $0.206^{* * *}$ & $0.187^{* * *}$ & $0.175^{* * *}$ \\
EU7 robot exposure: High & $(0.025)$ & $(0.031)$ & $(0.023)$ & $(0.018)$ & $(0.050)$ \\
& 2166 & 2166 & 2166 & 2166 & 2166 \\
Observations & & & & & \\
Covariates: & $\checkmark$ & $\checkmark$ & $\checkmark$ & $\checkmark$ & $\checkmark$ \\
Divisions & $\checkmark$ & $\checkmark$ & $\checkmark$ & $\checkmark$ & $\checkmark$ \\
Years & & $\checkmark$ & $\checkmark$ & $\checkmark$ & $\checkmark$ \\
Pre-trends & & & $\checkmark$ & $\checkmark$ & $\checkmark$ \\
Chinese imports & & & & $\checkmark$ & $\checkmark$ \\
Demographics & & & & $\checkmark$ & $\checkmark$ \\
Industries & & & & $\checkmark$ & $\checkmark$ \\
Occupations & & & & & $\checkmark$ \\
Unweighted & & & & \\
\hline
\end{tabular}

Note: This table presents reduced form estimates of the effect of robot exposure by specialization in the automotive industry on the change in the non-participation rate at the CZ level. Changes are expressed in percentage points of the working-age population and are multiplied by 100. Independent variables are standardized to have mean zero and standard deviation of one. There are three time periods and $722 \mathrm{CZs}$. The estimates report interactions of robot exposure with terciles of the CZ specialization in the auomotive industry (low, middle and high). Column 1 includes year dummies, nine census divisions and their interactions. Column 2 includes also changes in the non-participation rate and in the manufacturing employment rate between 1970 and 1990. Column 3 includes also exposure to Chinese imports. Columns 4 and 5 control also for demographic (share of individuals aged between 25 and 34 years, 35 and 44 years, 45 and 54 years, the share of Blacks, Hispanics, women and individuals with less than a college degree and logarithmic population), industry (shares of employment in the contruction, manufacturing, mining, research, service and utilities sector) and occupation (share of offshorable occupations, routine taskintensive occupations and occupations replaceable by robots) characteristics of CZ in 1990. Standard errors are robust against heteroskedasticity and allow for clustering at the state level. Regressions are weighted by CZ population in 1990 in Columns 1 to 4 and are unweighted in Column 5 . Coefficients with ${ }^{* * *},{ }^{* *}$ and ${ }^{*}$ are significant at the $1 \%, 5 \%$ and $10 \%$ confidence level. 
Table A19: Robots and non-participation: Alternative construction of the measures of robot exposure

\begin{tabular}{|c|c|c|c|c|c|}
\hline & {$[1]$} & {$[2]$} & [3] & [4] & [5] \\
\hline \multicolumn{6}{|c|}{ Panel A: EU5 countries (Acemoglu and Restrepo, 2020) } \\
\hline US robot exposure & $\begin{array}{c}0.285^{* * *} \\
(0.082)\end{array}$ & $\begin{array}{c}0.312^{* * *} \\
(0.091)\end{array}$ & $\begin{array}{c}0.309^{* * *} \\
(0.083)\end{array}$ & $\begin{array}{c}0.281^{* * *} \\
(0.051)\end{array}$ & $\begin{array}{c}0.457^{* *} \\
(0.172)\end{array}$ \\
\hline Observations & 2166 & 2166 & 2166 & 2166 & 2166 \\
\hline \multicolumn{6}{|c|}{ Panel B: EU7 countries and Germany } \\
\hline US robot exposure & $\begin{array}{c}0.216^{* * *} \\
(0.043)\end{array}$ & $\begin{array}{c}0.237^{* * *} \\
(0.049)\end{array}$ & $\begin{array}{c}0.235^{* * *} \\
(0.042)\end{array}$ & $\begin{array}{c}0.221^{* * *} \\
(0.024)\end{array}$ & $\begin{array}{c}0.270^{* * *} \\
(0.083)\end{array}$ \\
\hline Observations & 2166 & 2166 & 2166 & 2166 & 2166 \\
\hline \multicolumn{6}{|c|}{ Panel C: EU7 countries with $\ell_{c, j}^{1990}$} \\
\hline US robot exposure & $\begin{array}{c}0.291^{* * *} \\
(0.070)\end{array}$ & $\begin{array}{c}0.290^{* * *} \\
(0.069)\end{array}$ & $\begin{array}{c}0.278^{* * *} \\
(0.060)\end{array}$ & $\begin{array}{c}0.224^{* * *} \\
(0.036)\end{array}$ & $\begin{array}{c}0.327^{* * *} \\
(0.083)\end{array}$ \\
\hline Observations & 2166 & 2166 & 2166 & 2166 & 2166 \\
\hline \multicolumn{6}{|c|}{ Panel D: EU7 countries without $g_{j,\left(t_{0}, t_{1}\right)} \frac{R_{j, t_{0}}}{L_{j, 1990}}$} \\
\hline US robot exposure & $\begin{array}{c}0.202^{* * *} \\
(0.042)\end{array}$ & $\begin{array}{c}0.225^{* * *} \\
(0.050)\end{array}$ & $\begin{array}{c}0.220^{* * *} \\
(0.041)\end{array}$ & $\begin{array}{c}0.205^{* * *} \\
(0.027)\end{array}$ & $\begin{array}{c}0.226^{* * *} \\
(0.078)\end{array}$ \\
\hline Observations & 2166 & 2166 & 2166 & 2166 & 2166 \\
\hline \multicolumn{6}{|l|}{ Covariates: } \\
\hline Divisions & $\checkmark$ & $\checkmark$ & $\checkmark$ & $\checkmark$ & $\checkmark$ \\
\hline Years & $\checkmark$ & $\checkmark$ & $\checkmark$ & $\checkmark$ & $\checkmark$ \\
\hline Pre-trends & & $\checkmark$ & $\checkmark$ & $\checkmark$ & $\checkmark$ \\
\hline Chinese imports & & & $\checkmark$ & $\checkmark$ & $\checkmark$ \\
\hline Demographics & & & & $\checkmark$ & $\checkmark$ \\
\hline Industries & & & & $\checkmark$ & $\checkmark$ \\
\hline Occupations & & & & $\checkmark$ & $\checkmark$ \\
\hline Unweighted & & & & & $\checkmark$ \\
\hline
\end{tabular}

Note: This table presents IV estimates of the effect of US robot exposure on the change in the non-participation rate at the CZ level using different instrument measures. Changes are expressed in percentage points of the working-age population and are multiplied by 100. Independent variables are standardized to have mean zero and standard deviation of one. There are three time periods and 722 CZs. Panel A reports estimates using an instrument that includes only five European countries. I exclude Spain and the United Kingdom as in the measure in Acemoglu and Restrepo (2020). Panel B reports estimates using an instrument which includes seven European countries and Germany. Panel C reports estimates using an instrument with seven European countries, but US employment shares of 1990 instead of 1970. Panel D reports estimates using an endogenous variable and an instrument of robot density without the adjustment term of industry growth. Column 1 includes year dummies, nine census divisions and their interactions. Column 2 includes also changes in the non-participation rate and in the manufacturing employment rate between 1970 and 1990. Column 3 includes also exposure to Chinese imports. Columns 4 and 5 control also for demographic (share of individuals aged between 25 and 34 years, 35 and 44 years, 45 and 54 years, the share of Blacks, Hispanics, women and individuals with less than a college degree and logarithmic population), industry (shares of employment in the contruction, manufacturing, mining, research, service and utilities sector) and occupation (share of offshorable occupations, routine task-intensive occupations and occupations replaceable by robots) characteristics of CZ in 1990. Standard errors are robust against heteroskedasticity and allow for clustering at the state level. Regressions are weighted by CZ population in 1990 in Columns 1 to 4 and are unweighted in Column 5. Coefficients with ${ }^{* * *},{ }^{* *}$ and ${ }^{*}$ are significant at the $1 \%, 5 \%$ and $10 \%$ confidence level. 
Table A20: Effect of robots on employment and non-participation in logarithmic changes

\begin{tabular}{lccccc}
\hline & {$[1]$} & {$[2]$} & {$[3]$} & {$[4]$} & {$[5]$} \\
\hline Panel A: Employment & & & & & \\
US robot exposure & $-0.529^{* * *}$ & $-0.566^{* * *}$ & $-0.564^{* * *}$ & $-0.557^{* * *}$ & $-0.856^{* * *}$ \\
& $(0.082)$ & $(0.094)$ & $(0.085)$ & $(0.045)$ & $(0.168)$ \\
Observations & 2166 & 2166 & 2166 & 2166 & 2166 \\
& & & & & \\
Panel B: Non-participation & & & & & \\
US robot exposure & $1.702^{* * *}$ & $1.840^{* * *}$ & $1.827^{* * *}$ & $1.659^{* * *}$ & $2.780^{* * *}$ \\
& $(0.408)$ & $(0.443)$ & $(0.388)$ & $(0.230)$ & $(1.031)$ \\
Observations & 2166 & 2166 & 2166 & 2166 & 2166 \\
\hline Covariates: & & & & & \\
Divisions & $\checkmark$ & $\checkmark$ & $\checkmark$ & $\checkmark$ & $\checkmark$ \\
Log-population & $\checkmark$ & $\checkmark$ & $\checkmark$ & $\checkmark$ & $\checkmark$ \\
Years & $\checkmark$ & $\checkmark$ & $\checkmark$ & $\checkmark$ & $\checkmark$ \\
$\begin{array}{l}\text { Pre-trends } \\
\text { Chinese imports }\end{array}$ & & $\checkmark$ & $\checkmark$ & $\checkmark$ & $\checkmark$ \\
Demographics & & & $\checkmark$ & $\checkmark$ & $\checkmark$ \\
Industries & & & & $\checkmark$ & $\checkmark$ \\
Occupations & & & & $\checkmark$ & $\checkmark$ \\
Unweighted & & & & & $\checkmark$ \\
\hline
\end{tabular}

Note: This table presents IV estimates of the effect of US robot exposure on the change in employment and non-participation at the CZ level. Changes are expressed in logarithms and are multiplied by 100. Independent variables are standardized to have mean zero and standard deviation of one. There are three time periods and $722 \mathrm{CZs}$. Column 1 includes changes in the logarithmic working-age population, year dummies, nine census divisions and their interactions. Column 2 includes also changes in the non-participation rate and in the manufacturing employment rate between 1970 and 1990 . Column 3 includes also exposure to Chinese imports. Columns 4 and 5 control also for demographic (share of individuals aged between 25 and 34 years, 35 and 44 years, 45 and 54 years, the share of Blacks, Hispanics, women and individuals with less than a college degree and logarithmic population), industry (shares of employment in the contruction, manufacturing, mining, research, service and utilities sector) and occupation (share of offshorable occupations, routine task-intensive occupations and occupations replaceable by robots) characteristics of CZ in 1990. Standard errors are robust against heteroskedasticity and allow for clustering at the state level. Regressions are weighted by CZ population in 1990 in Columns 1 to 4 and are unweighted in Column 5. Coefficients with $^{* * *},{ }^{* *}$ and ${ }^{*}$ are significant at the $1 \%, 5 \%$ and $10 \%$ confidence level. 
Table A21: Effect of robots on employment with standard errors clustered at the IFR industry level

\begin{tabular}{lcccc}
\hline & {$[1]$} & {$[2]$} & {$[3]$} & {$[4]$} \\
\hline US robot density & -3.459 & $-4.476^{* *}$ & $-4.768^{* *}$ & $-8.400^{* * *}$ \\
& $(1.996)$ & $(2.055)$ & $(2.074)$ & $(2.606)$ \\
Observations & 57 & 57 & 57 & 57 \\
\hline Covariates: & & & & \\
Years & $\checkmark$ & $\checkmark$ & $\checkmark$ & $\checkmark$ \\
Pre-trends & & $\checkmark$ & & \\
Demographics & & $\checkmark$ & & \\
Occupations & & $\checkmark$ & $\checkmark$ & $\checkmark$ \\
Industry FE & & & & $\checkmark$ \\
Unweighted & & & & \\
\hline
\end{tabular}

Note: This table presents IV estimates of the effect of US robot density on the change in employment at the industry level. Changes are expressed in logarithmic changes and are multiplied by 100. Robot density is equal to the shift component of Equations 3 and 4 and is standardized to have mean zero and standard deviation of one. There are three time periods and 19 IFR industries. Column 1 includes year dummies. Column 2 includes also changes in IFR log-employment between 1970 and 1990, as well as demographic (share of individuals aged between 25 and 34 years, 35 and 44 years, 45 and 54 years, the share of Blacks, Hispanics, women and individuals with less than a college degree) and occupational (share of offshorable occupations, routine task-intensive occupations and occupations replaceable by robots) controls at the industry level in 1990 . Columns 3 and 4 include IFR industry FE. Standard errors are robust against heteroskedasticity and allow for clustering at the industry level. Regressions are weighted by industry employment in 1990 in Columns 1 to 3 and are unweighted in Column 4 . Coefficients with ${ }^{* * *},{ }^{* *}$ and ${ }^{*}$ are significant at the $1 \%, 5 \%$ and $10 \%$ confidence level. 
Table A22: Effect of robots on employment and non-participation with standard errors clustered at division level

\begin{tabular}{lccccc}
\hline & {$[1]$} & {$[2]$} & {$[3]$} & {$[4]$} & {$[5]$} \\
\hline Panel A: Employment & & & & & \\
US robot exposure & $-0.439^{* * *}$ & $-0.463^{* * *}$ & $-0.461^{* * *}$ & $-0.461^{* * *}$ & $-0.734^{* * *}$ \\
& $(0.082)$ & $(0.090)$ & $(0.082)$ & $(0.046)$ & $(0.189)$ \\
& 2166 & 2166 & 2166 & 2166 & 2166 \\
Observations & & & & & \\
Panel B: Non-participation & & & & & \\
US robot exposure & $0.256^{* *}$ & $0.279^{* *}$ & $0.277^{* * *}$ & $0.257^{* * *}$ & $0.361^{*}$ \\
& $(0.077)$ & $(0.089)$ & $(0.081)$ & $(0.049)$ & $(0.177)$ \\
Observations & 2166 & 2166 & 2166 & 2166 & 2166 \\
\hline Covariates: & & & & & \\
Divisions & $\checkmark$ & $\checkmark$ & $\checkmark$ & $\checkmark$ & $\checkmark$ \\
Years & $\checkmark$ & $\checkmark$ & $\checkmark$ & $\checkmark$ & $\checkmark$ \\
$\begin{array}{l}\text { Pre-trends } \\
\text { Chinese imports }\end{array}$ & & $\checkmark$ & $\checkmark$ & $\checkmark$ & $\checkmark$ \\
$\begin{array}{l}\text { Demographics } \\
\text { Industries } \\
\text { Occupations } \\
\text { Unweighted }\end{array}$ & & & $\checkmark$ & $\checkmark$ & $\checkmark$ \\
\hline
\end{tabular}

Note: This table presents IV estimates of the effect of US robot exposure on the change in employment and non-participation at the CZ level. Changes are expressed in percentage points of the working-age population and are multiplied by 100 . Independent variables are standardized to have mean zero and standard deviation of one. There are three time periods and $722 \mathrm{CZs}$. Column 1 includes year dummies, nine census divisions and their interactions. Column 2 includes also changes in the non-participation rate and in the manufacturing employment rate between 1970 and 1990. Column 3 includes also exposure to Chinese imports. Columns 4 and 5 control also for demographic (share of individuals aged between 25 and 34 years, 35 and 44 years, 45 and 54 years, the share of Blacks, Hispanics, women and individuals with less than a college degree and logarithmic population), industry (shares of employment in the contruction, manufacturing, mining, research, service and utilities sector) and occupation (share of offshorable occupations, routine task-intensive occupations and occupations replaceable by robots) characteristics of $\mathrm{CZ}$ in 1990. Standard errors are robust against heteroskedasticity and allow for clustering at the division level. Regressions are weighted by $\mathrm{CZ}$ population in 1990 in Columns 1 to 4 and are unweighted in Column 5 . Coefficients with ${ }^{* * *},^{* *}$ and ${ }^{*}$ are significant at the $1 \%, 5 \%$ and $10 \%$ confidence level. 
Table A23: Robots and non-participation: Alternative covariates

\begin{tabular}{|c|c|c|c|c|c|c|}
\hline & [1] & [2] & [3] & [4] & [5] & [6] \\
\hline \multicolumn{7}{|c|}{ Panel A: Inclusion of state fixed effects } \\
\hline US robot exposure & $\begin{array}{c}0.313^{* * *} \\
(0.093)\end{array}$ & $\begin{array}{c}0.360^{* * *} \\
(0.101)\end{array}$ & $\begin{array}{c}0.353^{* * *} \\
(0.095)\end{array}$ & $\begin{array}{c}0.337^{* * *} \\
(0.071)\end{array}$ & $\begin{array}{c}0.363^{* *} \\
(0.167)\end{array}$ & \\
\hline Observations & 2166 & 2166 & 2166 & 2166 & 2166 & \\
\hline \multicolumn{7}{|c|}{ Panel B: Inclusion of non-robot automation technologies } \\
\hline US robot exposure & $\begin{array}{c}0.248^{* * *} \\
(0.061)\end{array}$ & $\begin{array}{c}0.255^{* * *} \\
(0.060)\end{array}$ & $\begin{array}{c}0.254^{* * *} \\
(0.057)\end{array}$ & $\begin{array}{c}0.258^{* * *} \\
(0.036)\end{array}$ & $\begin{array}{c}0.373^{* * *} \\
(0.131)\end{array}$ & \\
\hline Observations & 2166 & 2166 & 2166 & 2166 & 2166 & \\
\hline \multicolumn{7}{|c|}{ Panel C: Period covariates } \\
\hline US robot exposure & $\begin{array}{c}0.256^{* * *} \\
(0.059)\end{array}$ & $\begin{array}{c}0.279^{* * *} \\
(0.067)\end{array}$ & $\begin{array}{c}0.277^{* * *} \\
(0.060)\end{array}$ & $\begin{array}{c}0.202^{* * *} \\
(0.027)\end{array}$ & $\begin{array}{c}0.271^{* * *} \\
(0.084)\end{array}$ & \\
\hline Observations & 2166 & 2166 & 2166 & 2166 & 2166 & \\
\hline \multicolumn{7}{|c|}{ Panel D: Selection of covariates using a two-step lasso } \\
\hline US robot exposure & & & & & & $\begin{array}{c}0.386^{* * *} \\
(0.130)\end{array}$ \\
\hline Observations & & & & & & 2166 \\
\hline \multicolumn{7}{|l|}{ Covariates: } \\
\hline Divisions & $\checkmark$ & $\checkmark$ & $\checkmark$ & $\checkmark$ & $\checkmark$ & \\
\hline Years & $\checkmark$ & $\checkmark$ & $\checkmark$ & $\checkmark$ & $\checkmark$ & \\
\hline State & $\checkmark$ & $\checkmark$ & $\checkmark$ & $\checkmark$ & $\checkmark$ & \\
\hline Pre-trends & & $\checkmark$ & $\checkmark$ & $\checkmark$ & $\checkmark$ & \\
\hline Chinese imports & & & $\checkmark$ & $\checkmark$ & $\checkmark$ & \\
\hline Demographics & & & & $\checkmark$ & $\checkmark$ & \\
\hline Industries & & & & $\checkmark$ & $\checkmark$ & \\
\hline Occupations & & & & $\checkmark$ & $\checkmark$ & \\
\hline Unweighted & & & & & $\checkmark$ & \\
\hline LASSO covariates & & & & & & $\checkmark$ \\
\hline
\end{tabular}

Note: This table presents IV estimates of the effect of US robot exposure on the change in the non-participation rate at the CZ level including state fixed effects and a selection of covariates using a two-step LASSO. Changes are expressed in percentage points of the working-age population and are multiplied by 100 . Independent variables are standardized to have mean zero and standard deviation of one. There are three time periods and $722 \mathrm{CZs}$. Panel A reports estimates including state FE, Panel B includes beginning of subperiod (1990, 2000 and 2007) covariates and Panel C reports estimates selecting a set of covariates using a LASSO approach. Column 1 includes year dummies, nine census divisions and their interactions. Column 2 includes also changes in the non-participation rate and in the manufacturing employment rate between 1970 and 1990. Column 3 includes also exposure to Chinese imports. Columns 4 and 5 control also for demographic (share of individuals aged between 25 and 34 years, 35 and 44 years, 45 and 54 years, the share of Blacks, Hispanics, women and individuals with less than a college degree and logarithmic population), industry (shares of employment in the contruction, manufacturing, mining, research, service and utilities sector) and occupation (share of offshorable occupations, routine task-intensive occupations and occupations replaceable by robots) characteristics of CZ in 1990 in Panel A and in 1990, 2000 and 2007 in Panel B. Column 6 includes the nine census divisions, the share of individuals with less than a college degree, the logarithmic population, the share of employment in the above mentioned sectors, the share of routine task-intensive occupations and occupations that are replaceable by robots in 1990, all interacted with time dummies. In addition, it includes the employment share in the automotive industry, male manufacturing and heavy manufacturing in 1990 and exposure to US imports from China. Standard errors are robust against heteroskedasticity and allow for clustering at the state level. Regressions are weighted by CZ population in 1990 in Columns 1 to 4 and 6 and are unweighted in Column 5 . Coefficients with ${ }^{* * *},{ }^{* *}$ and ${ }^{*}$ are significant at the $1 \%, 5 \%$ and $10 \%$ confidence level. 
Table A24: Robots, non-participation and other shocks

\begin{tabular}{lc}
\hline & {$[1]$} \\
\hline US robot exposure & $0.258^{* * *}$ \\
& $(0.036)$ \\
PC adoption & -0.069 \\
& $(0.051)$ \\
IT intensity & 0.011 \\
& $(0.066)$ \\
Routine occupations & -0.061 \\
& $(0.071)$ \\
Offshorable occupations & -0.086 \\
& $(0.065)$ \\
Observations & 2166 \\
\hline Covariates: & $\checkmark$ \\
\hline
\end{tabular}

Note: This table presents IV estimates of the effect of US robot exposure, personal computer adoption, IT capital intensity, the share of routine task-intensive occupations and the share of offshorable occupations on the change in non-participation at the CZ level. There are three time periods and $722 \mathrm{CZs}$. The regression includes year dummies, nine census divisions and their interactions, as well as changes in the non-participation rate and in the manufacturing employment rate between 1970 and 1990 , exposure to Chinese imports and demographic (share of individuals aged between 25 and 34 years, 35 and 44 years, 45 and 54 years, the share of Blacks, Hispanics, women and individuals with less than a college degree and logarithmic population), industry (shares of employment in the contruction, manufacturing, mining, research, service and utilities sector) and occupation (share of offshorable occupations, routine task-intensive occupations and occupations replaceable by robots) characteristics of CZ in 1990. Standard errors are robust against heteroskedasticity and allow for clustering at the state level. Regressions are weighted by $\mathrm{CZ}$ hospital admissions. Coefficients with ${ }^{* * *},{ }^{* *}$ and ${ }^{*}$ are significant at the $1 \%, 5 \%$ and $10 \%$ confidence level. 
Table A25: Robots and non-participation using the perpetual inventory method

\begin{tabular}{lccccc}
\hline & {$[1]$} & {$[2]$} & {$[3]$} & {$[4]$} & {$[5]$} \\
\hline Panel A: 5\% depreciation rate & & & & & \\
US robot exposure & $0.210^{* * *}$ & $0.233^{* * *}$ & $0.226^{* * *}$ & $0.204^{* * *}$ & $0.292^{* * *}$ \\
& $(0.059)$ & $(0.065)$ & $(0.053)$ & $(0.028)$ & $(0.100)$ \\
Observations & 2166 & 2166 & 2166 & 2166 & 2166 \\
& & & & & \\
Panel B: 10\% depreciation rate & & & & & \\
US robot exposure & $0.279^{* * *}$ & $0.297^{* * *}$ & $0.296^{* * *}$ & $0.264^{* * *}$ & $0.459^{* * *}$ \\
& $(0.079)$ & $(0.083)$ & $(0.075)$ & $(0.044)$ & $(0.162)$ \\
Observations & 2166 & 2166 & 2166 & 2166 & 2166 \\
Panel C: 15\% depreciation rate & & & & & \\
US robot exposure & $0.346^{* * *}$ & $0.350^{* * *}$ & $0.357^{* * *}$ & $0.300^{* * *}$ & $0.622^{* * *}$ \\
& $(0.108)$ & $(0.108)$ & $(0.104)$ & $(0.069)$ & $(0.222)$ \\
Observations & 2166 & 2166 & 2166 & 2166 & 2166 \\
\hline Covariates: & & & & & \\
Divisions & $\checkmark$ & $\checkmark$ & $\checkmark$ & $\checkmark$ & $\checkmark$ \\
Years & $\checkmark$ & $\checkmark$ & $\checkmark$ & $\checkmark$ & $\checkmark$ \\
Pre-trends & & $\checkmark$ & $\checkmark$ & $\checkmark$ & $\checkmark$ \\
Chinese imports & & & $\checkmark$ & $\checkmark$ & $\checkmark$ \\
Demographics & & & & $\checkmark$ & $\checkmark$ \\
Industries & & & & $\checkmark$ & $\checkmark$ \\
Occupations & & & & & $\checkmark$ \\
Unweighted & & & & & $\checkmark$ \\
\hline
\end{tabular}

Note: This table presents IV estimates of the effect of US robot exposure on the change in non-participation at the CZ level. The operational stock of robots is constructed based on yearly shipments using the perpetual inventory method, assuming a depreciation rate of $5 \%, 10 \%$ and $15 \%$. Changes are expressed in percentage points of the working-age population and are multiplied by 100. Independent variables are standardized to have mean zero and standard deviation of one. There are three time periods and $722 \mathrm{CZs}$. Column 1 includes year dummies, nine census divisions and their interactions. Column 2 includes also changes in the non-participation rate and in the manufacturing employment rate between 1970 and 1990 . Column 3 includes also exposure to Chinese imports. Columns 4 and 5 control also for demographic (share of individuals aged between 25 and 34 years, 35 and 44 years, 45 and 54 years, the share of Blacks, Hispanics, women and individuals with less than a college degree and logarithmic population), industry (shares of employment in the contruction, manufacturing, mining, research, service and utilities sector) and occupation (share of offshorable occupations, routine task-intensive occupations and occupations replaceable by robots) characteristics of CZ in 1990. Standard errors are robust against heteroskedasticity and allow for clustering at the division level. Regressions are weighted by CZ population in 1990 in Columns 1 to 4 and are unweighted in Column 5 . Coefficients with ${ }^{* * *},{ }^{* *}$ and ${ }^{*}$ are significant at the $1 \%, 5 \%$ and $10 \%$ confidence level. 


\section{IdEP Economic Papers}

The series IdEP Economic Papers, ideally continues the work of the "Quaderni della Facoltà" the publication of which began in 1998 and ended in 2013.

For a complete list of the Quaderni see: http://econpapers.repec.org/paper/lugwpaper/

IdEP Economic Papers also gathers the legacy of the CEPRA Working Papers, published from 2012 to 2013.

The full list at: http://econpapers.repec.org/paper/lugwcepra/

2014:

No. 01

F. Mazzonna, F. Peracchi, Unhealthy retirement? Evidence of occupation heterogeneity

No. 02

L. Di Giorgio, M. Filippini, G. Masiero, The relationship between costs and quality in nonprofit nursing homes

No. 03

F.C. Billari, V. Galasso, Fertility decisions and pension reforms : evidence from natural experiments in Italy

No. 04

M. Jametti, M. Joanis, Elections and de facto expenditure decentralization in Canada

No. 05

M. Jametti, Weathering the global financial crisis : is direct democracy of any help?

No. 06

U. Pagano, M. Vatiero, Costly institutions as substitutes : novelty and limits of the Coasian approach

No. 07

R. Parchet, Are local tax rates strategic complements or strategic substitutes?

No. 08

R. Ippoliti, M. Vatiero, An analysis of how 2002 judicial reorganization has impacted on the performance of the First Instance Courts (Preture) in Ticino

No. 09

F. Mazzonna, P. Salari, Short term effects of public smoking bans on health 
2015:

No. 01

S. Galletta, Direct democracy, partial decentralization and voter information : evidence from Swiss municipalities

No. 02

I. Sarman, Second homeowners' intention to move : an integrated ordered logit model with latent variable

No. 03

M.J. Roe, M. Vatiero, Corporate governance and its political economy

No. 04

M. Filippini, M. Koller, G. Masiero, Competitive tendering versus performance-based negotiation in Swiss public transport

No. 05

O. Giuntella, F. Mazzonna, If you don't snooze you lose health and gain weight : evidence from a regression discontinuity design

No. 06

M. Filippini, B. Hirl, G. Masiero, Rational habits in residential electricity demand

2016:

No. 01

S. Galletta, Law enforcement, municipal budgets and spillover effects : evidence from a quasiexperiment in Italy

No. 02

S. Galletta, A. Redonda, Corporate flat tax reforms and businesses'location choices. Evidence from Switzerland

No. 03

M. Filippini, W. Greene, G. Masiero, Persistent and transient productive inefficiency in a regulated industry: electricity distribution in New Zealand 
No. 04

M. Vatiero, On the (political) origin of "corporate governance" species

No. 05

E. Gentili, G. Masiero, F. Mazzonna, The role of culture in long-term care

No. 06

M. Vatiero, Learning from the Swiss corporate governance exception

No. 07

F. Cavalcanti, G. Daniele, S. Galletta, Popularity shocks and political selection : the effects of anti-corruption audits on candidates' quality

2017:

No. 01

P. Bello, Exchange rate fluctuations and border crossings : evidence from the Swiss-Italian border

No. 02

E. Gentili, F. Mazzonna, What drives the substitutability between native and foreign workers? Evidence about the role of language

No. 03

G. Daniele, S. Galletta, B. Geys, Abandon ship? Party brands and politicians' responses to a political scandal

2018:

No. 01

G. Masiero, F. Mazzonna, O. Verbeek, What drives the rise of antidepressant consumption? Evidence from Switzerland

No. 02

U. Pagano, M. Vatiero, Positional goods and legal orderings 
2019:

No. 01

G. Masiero, M. Santarossa, Earthquakes, grants and public expenditure : how municipalities respond to natural disasters

No. 02

G. Masiero, F. Mazzonna, S. Steinbach, O. Verbeek, The effect of local growth in antidepressant consumption on mental health outcomes

No. 03

T. Ly, Taxes, traffic jam and spillover in the metropolis

2020:

No. 01

P. Bello, The environmental cost and the accident externality of driving: evidence from the Swiss franc's appreciation

No. 02

P. Bello, Gender-based price discrimination in the annuity market: evidence from Chile

No. 03

B. Lerch, Robots and nonparticipation in the US: where have all the workers gone? 